\title{
Immunological properties of parthenogenetic stem cell derived cardiomyocytes and their application in cardiac tissue engineering
}

\author{
Doctoral Thesis \\ In partial fulfillment of the requirements for the degree \\ "Doctor rerum naturalium (Dr. rer. nat.)" \\ in the Molecular Medicine Study Program \\ at the Georg-August University Göttingen.
}

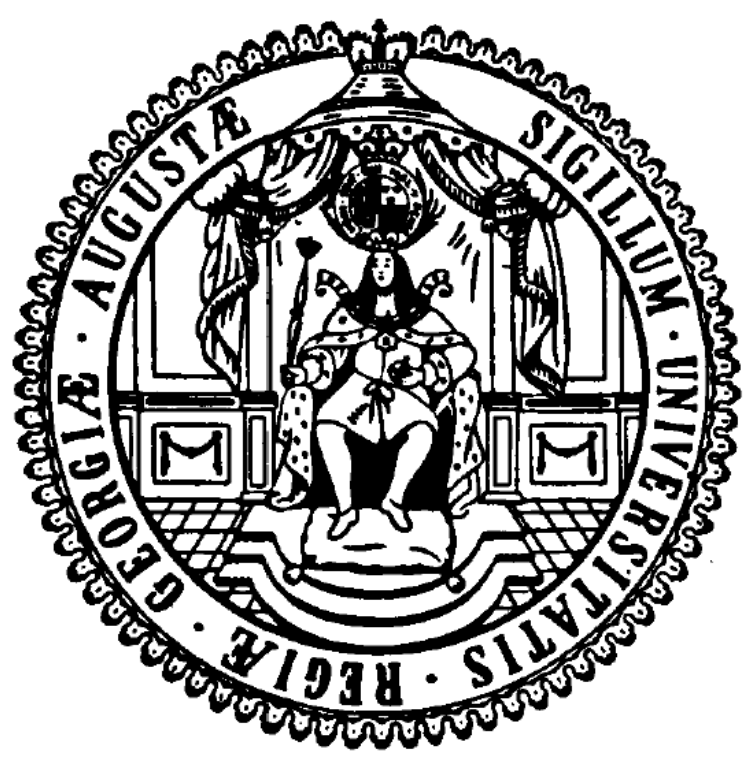

Submitted by

Satish Galla

Born in Rayapudi, India

Göttingen, 2016. 


\section{Members of the Thesis Committee:}

\section{Supervisor}

Name, Institute: Prof. Dr. med. Wolfram-Hubertus Zimmermann

Department of Pharmacology and Toxicology, University Medical Center, Georg-August University, Göttingen.

Second member of the thesis committee

Name, Institute: Prof. Dr. med. Ralf Dressel

Department of Cellular and Molecular Immunology, University Medical Center, GeorgAugust University, Göttingen.

Third member of the thesis committee

Name, Institute: Prof. Dr. med. Michael P.Schön

Department of Dermatology, University Medical Center, Georg-August University, Göttingen.

Date of Disputation: 14.06.2016 


\section{Affidavit}

Here I declare that my doctoral thesis entitled "Immunological properties of parthenogenetic stem cell derived cardiomyocytes and their application in cardiac tissue engineering." has been written independently with no other sources and aids than quoted.

Furthermore, I confirm that this thesis has not yet been submitted as part of another examination process neither in identical nor in similar form.

\section{Satish Galla}

Göttingen, April 2016 


\section{Table of Contents}

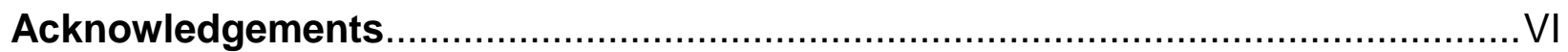

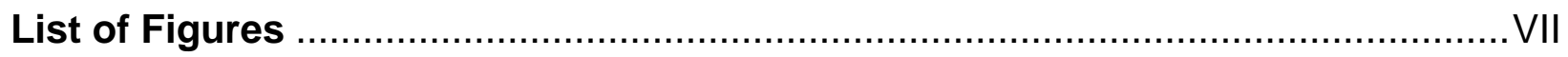

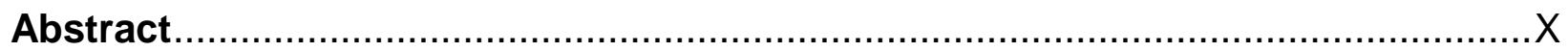

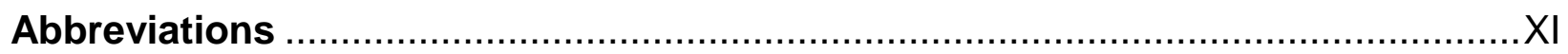

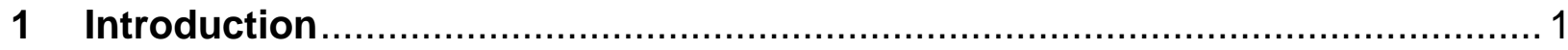

1.1 Cardiovascular diseases and cardiac tissue engineering ............................ 1

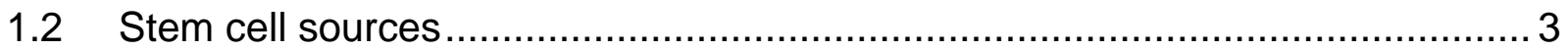

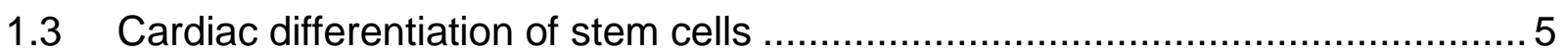

1.4 Major histocompatibility complex and transplantation immunology ................... 7

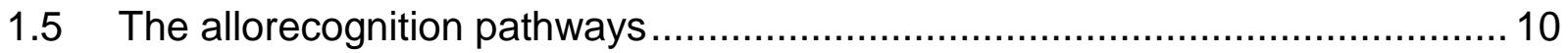

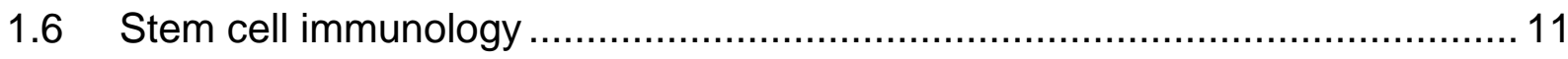

1.7 Interferon gamma and regulation of major histocompatibility complex............ 14

1.8 Immune regulatory properties of pluripotent stem cells ............................... 15

1.9 Major histocompatibility complex homozygosity ...................................... 17

1.10 Major histocompatibility complex-haploidentical parthenogenetic stem cells ... 18

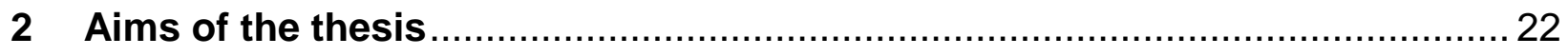

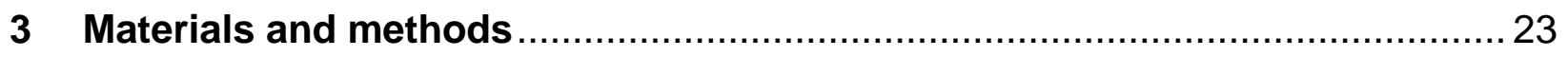

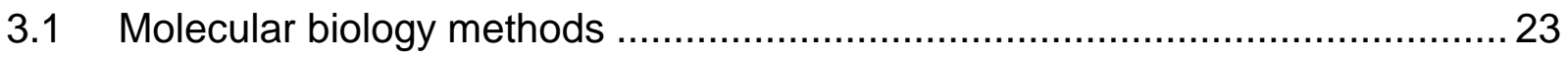




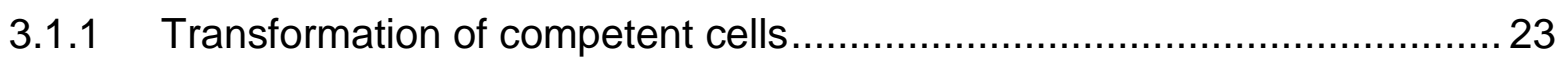

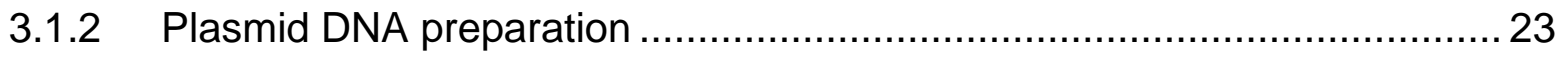

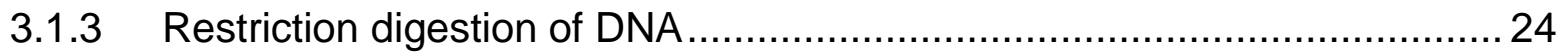

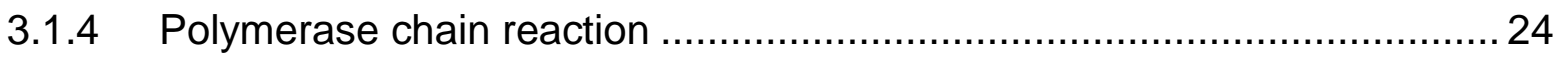

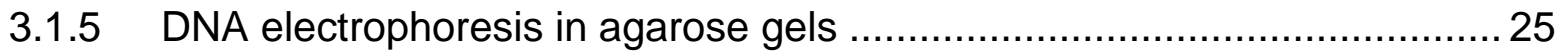

3.1.6 Isolation of DNA fragments from agarose gels ....................................26

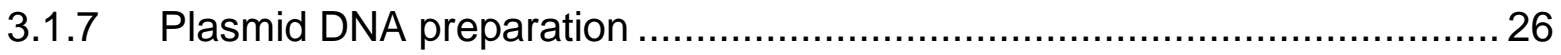

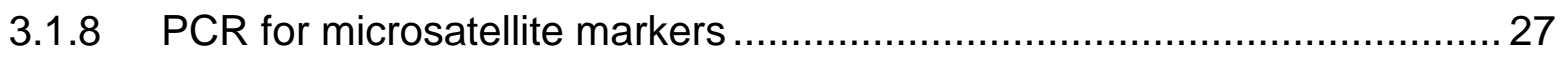

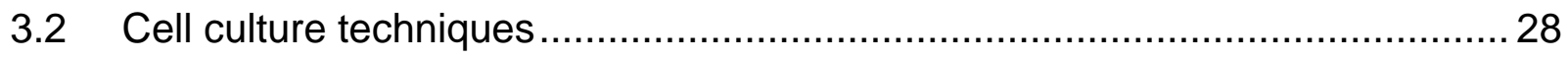

3.2.1 Preparation of murine embryonic fibroblasts feeder cultures ................... 28

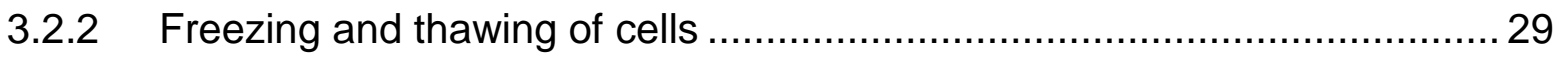

3.2.3 Neomycin selectable parthenogenetic stem cell lines ...........................29

3.2.4 Characterization of parthenogenetic stem cell clones ............................ 30

3.2.5 Culture of parthenogenetic stem cells .................................................. 31

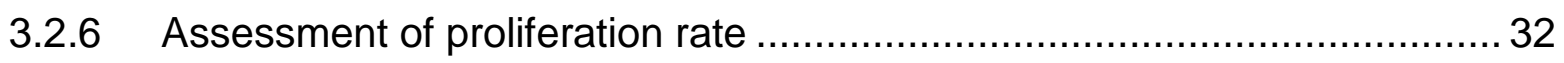

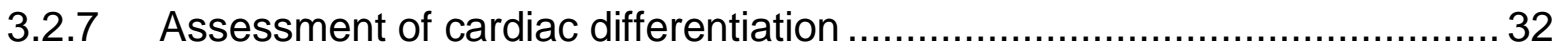

3.2.8 Differentiation in spinner flask cultures ............................................... 33

3.2.9 Assessment of contractility in embryoid bodies ...................................... 34

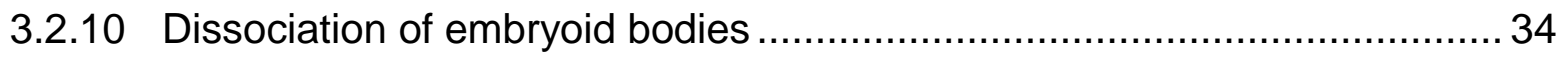


3.2.11 Preparation of engineered heart muscle

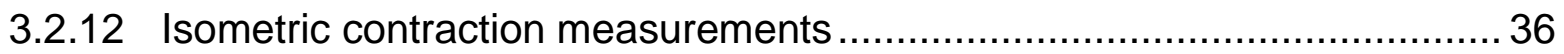

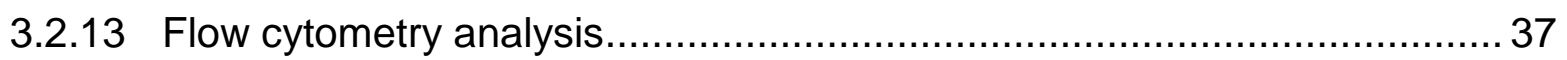

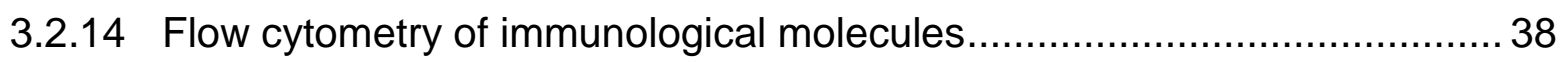

3.2.15 Isolation of neonatal mouse cardiomyocytes ......................................... 38

3.2.16 Isolation of cardiomyocytes by the Langendorff method.......................... 39

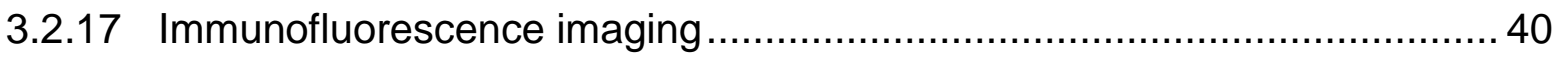

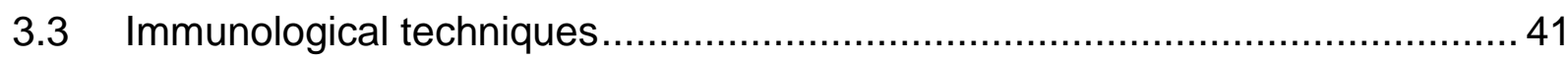

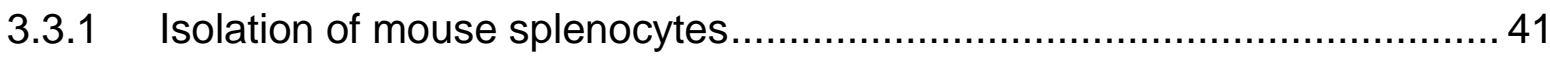

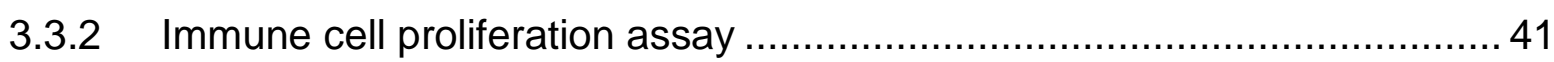

3.3.3 Isolation of T-lymphocytes from spleen .............................................. 43

3.3.4 In vitro cytotoxicity assay .............................................................. 43

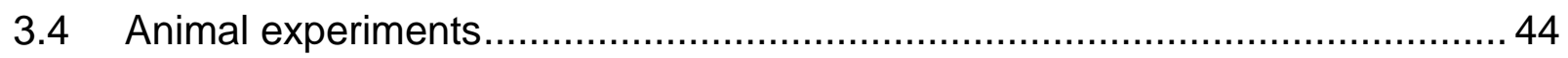

3.4.1 Cell implantation under the kidney capsule ......................................... 44

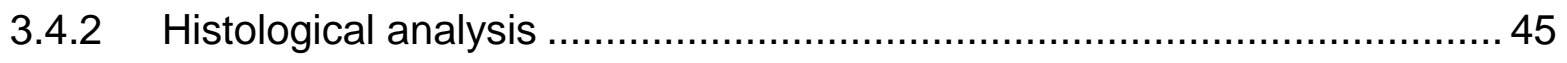

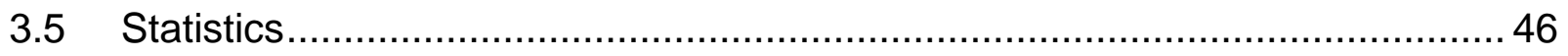

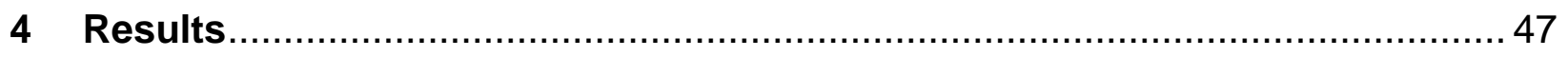

4.1 Genetic modification of a parthenogenetic stem cell line …........................... 47 
4.1.1 Determination of growth rate of non-transgenic parthenogenetic stem cell lines.

4.1.2 Confirmation of transgene identity .................................................... 48

4.1.3 aMHC-Neo parthenogenetic stem cell line ......................................... 49

4.1.4 Morphological and molecular evidence for pluripotency .........................50

4.1.5 Cardiomyocyte differentiation and purification in spinner flasks ...............51

4.1.6 High cardiomyocyte purity after selection .......................................... 53

4.1.7 Morphological properties of PSC-derived cardiomyocytes ......................54

4.2 Immunological properties of PSC-derived cells ........................................... 54

4.2.1 PSC-derivatives express immunologically relevant surface markers.........55

4.2.2 Sustained expression of MHC-I on PSC-derivatives ….......................... 57

4.3 Functional and immunological properties of engineered heart muscle.............58

4.3.1 Contractile parameters of engineered heart muscle .............................. 59

4.3.2 Morphological analysis of engineered heart muscle ............................... 60

4.3.3 Immunologically relevant proteins in engineered heart muscle .................60

4.4 Immunological properties of native cardiomyocytes ..................................... 63

4.4.1 Expression of MHC-I on cardiomyocytes from neonatal mice ..................63

4.4.2 Expression of MHC-I on cardiomyocytes from adult mice ....................... 64

4.5 In vitro immunogenicity analysis of PSC-cardiomyocytes .............................65 


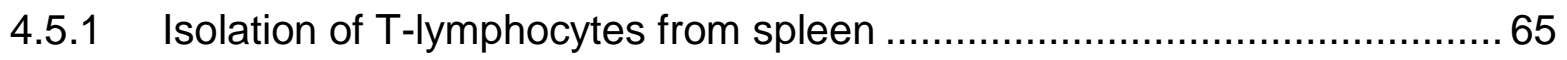

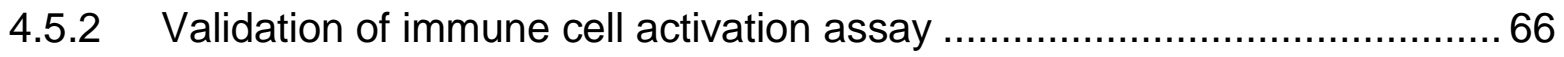

4.5.3 Activation of cytotoxic T-Lymphocytes ............................................. 71

4.6 In vivo immunogenicity analysis of PSC-derivatives ................................... 72

4.6.1 Retention of PSC-derived cardiac body implants .................................. 73

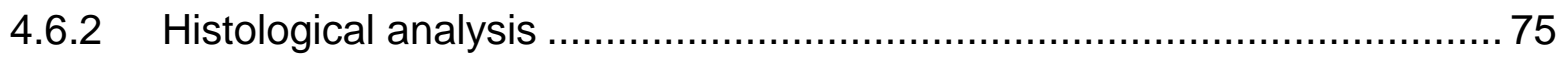

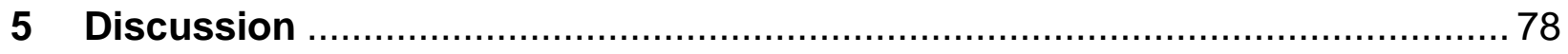

5.1 Generation and differentiation of a neomycin selectable PSC line .................. 79

5.2 Immunologically relevant proteins on PSC-derived cardiomyocytes and non-

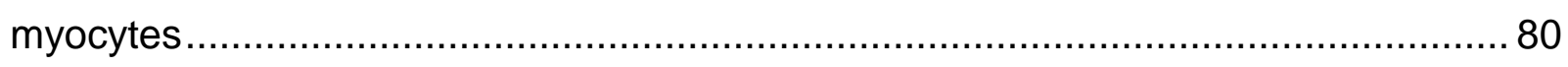

5.3 Expression of immunologically relevant molecules in EHM ......................... 82

5.4 MHC-I expression on neonatal and adult heart cardiomyocytes ...................... 83

5.5 In vitro immunogenicity of PSC-derived cardiomyocytes and non-myocytes ... 84

5.6 In vivo immunogenicity of PSC-derived cardiomyocytes and non-myocytes.... 86

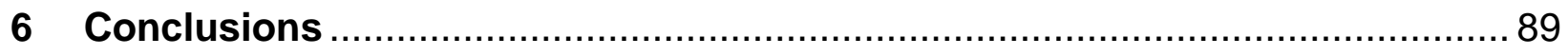

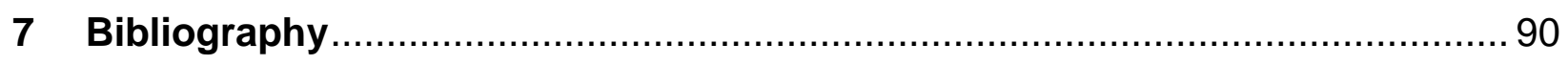

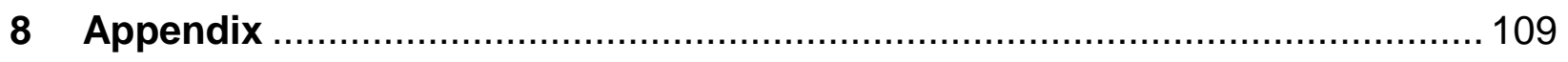

8.1 Appendix 1 (Supporting Information) ……............................................... 109

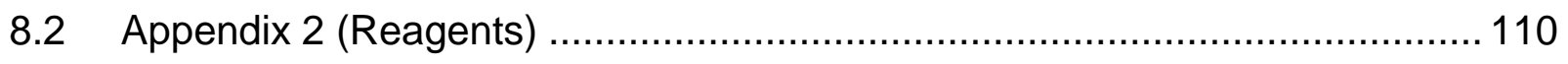




\section{Acknowledgements}

First of all, I would like to thank Prof. Dr. Wolfram-Hubertus Zimmermann for giving me the opportunity to come to Göttingen and pursue $\mathrm{PhD}$ in the Department of Pharmacology and Toxicology. I would like to thank him for his immense scientific advice, excellent guidance, continuous support and freedom given to work throughout my project. I have learned many things under his guidance and I honestly could not have imagined having a better supervisor.

I am grateful to my thesis committee members Prof. Dr. Michael Schön and Prof. Dr. Ralf Dressel for constructive comments, inspiring discussions and for making my thesis committee meetings more enlightening.

I would like to thank Dr. med. Michael Didié and Dr. rer. nat. Vijayakumar Muppala who helped me with critical and valuable advices during the course of my thesis and for their tremendous patience, constant support, encouragement and their commitment to help tackle tough issues in this project. I have learned many things in their mentorship.

I would like to thank Prof. Dr. Loren J. Field for kindly providing the MHC-Neo plasmid. Big thanks to my workmates Dr. med. Malte Tiburcy, Sumor Sur, Elif Levent, Eriona Heta, Farah Raad, Dr. rer. nat. Mei Ling Chang Liao, Brian Golat and Dr. rer. nat. PL Soong for their help with many things in the office and lab work. Special thanks to Elena Chebbok for helping me with all the official German translations. Also I would like to thank the bachelor students Laura Wolbeck and Ivan Silbern for working with me. I would like to thank all the people, especially technical staff from the Department of Pharmacology and Toxicology. Many thanks to my Indian friends in Göttingen for spending good times and making me feel like home.

I would like to thank my parents, in-laws and also my extended family for their continuous support. All their encouragements through video chats from India gave lots of motivation. I would like to thank my dearest friend Madhupriya Mahankali for her support and joyful moments.

Last but not least, many thanks to my wife, Padmasree Galla and my son Niketh Galla for all their love, support, and patience, also for making all the things move smoothly during my Ph.D. 


\section{List of Figures}

Figure 1: Generation of stem cells for cardiac tissue engineering ............................. 4

Figure 2: MHC polymorphism on mouse chromosome $17 . . \ldots \ldots \ldots \ldots \ldots \ldots \ldots \ldots \ldots \ldots \ldots \ldots . . . . . . . \ldots$

Figure 3: Direct and indirect T-cell allorecognition pathways... ................................... 11

Figure 4: Interferon-gamma signal transduction pathway ....................................... 15

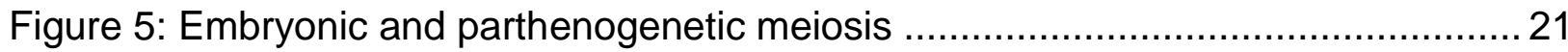

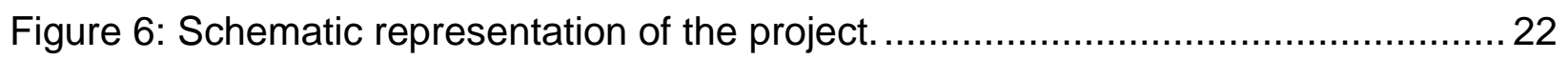

Figure 7: Schematic overview of PSC differentiation in spinner flasks........................ 33

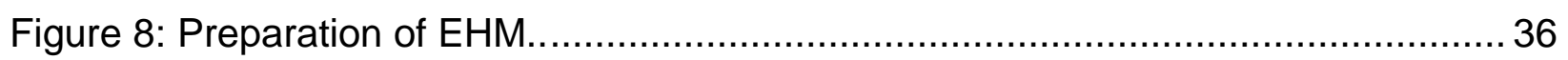

Figure 9: Experimental setup for in vitro proliferation assay..................................... 42

Figure 10: Schematic overview of implantation experiments....................................... 45

Figure 11: MHC genotyping and assessment of PSC growth................................... 48

Figure 12: Confirmation aMHC-Neo plasmid identity.............................................. 49

Figure 13: Identification of transgenic PSC clones by PCR........................................ 50

Figure 14: Morphological and molecular evidence for pluripotency............................5 51

Figure 15: Morphology and beating in PSC-derived EBs and cardiac bodies............... 52

Figure 16: Cardiomyocyte purity after selection in spinner flask cultures.....................53

Figure 17: Morphology of PSC-derived cardiomyocytes..........................................54 
Figure 18: Flow cytometry analysis of cell surface markers associated with immune responses.

Figure 19: Flow cytometry analysis of PD-L1 and PD-1 associated with immune escape. 57

Figure 20: Sustained MHC-I expression after transient IFNy stimulation. 58

Figure 21: Contractile properties of PSC-EHM. 59

Figure 22: Morphological characterization of engineered heart muscle. 60

Figure 23: Cardiomyocyte content in EHM. 61

Figure 24: Immunological properties of PSC-EHM derived cells................................. 62

Figure 25: MHC-I expression on neonatal mouse cardiomyocytes.. 63

Figure 26: MHC-I expression on adult mouse cardiomyocytes. 64

Figure 27: Assessment of splenocyte identity by flow cytometry. 66

Figure 28: T-lymphocyte proliferation assay. 67

Figure 29: In vitro immunogenicity induction by MHC-matched PSC-derivatives. 68

Figure 30: In vitro immunogenicity induction by MHC-mismatched PSC-derivatives.. .. 69

Figure 31: In vitro immunogenicity induction by MHC-matched PSC-EHM.................. 70

Figure 32: In vitro immunogenicity induction by MHC-mismatched PSC-EHM.. ...........71

Figure 33: Activation of cytotoxic T-lymphocytes by PSC-CM..................................... 72

Figure 34: Morphological analysis of PSC-derived cardiac bodies and EBs................ 73

Figure 35: Retention of PSC-derived cardiac body implants................................... 74 
Figure 36: H\&E staining of kidney sections implanted with cardiac bodies..

Figure 37: H\&E staining of kidney sections implanted with embryoid bodies............... 77 


\section{Abstract}

Cardiovascular diseases and their long term consequences constitute serious health and economic burdens. Although promising new therapeutic approaches to ameliorate the detrimental consequences have been introduced, there is still no therapy that would lead to a therapeutically efficient replacement of lost cardiomyocytes (CMs), e.g. after a myocardial infarction. CMs can be reliably generated from pluripotent stem cells, including embryonic and induced pluripotent stem cells. Parthenogenetic stem cells (PSCs) have recently been introduced as an alternative, attractive pluripotent stem cell entity. PSCs generated from pharmacologically activated unfertilized oocytes contain only maternal chromosomes, and show a growth and differentiation behavior similar to embryonic stem cells (ESCs). The unique chromosomal constitution of PSCs makes them largely haploidentical, creating the possibility for immunological matching.

In this study we demonstrated that transgenic major histocompatibility complex (MHC)haploidentical PSCs $\left(\mathrm{H}-2^{\mathrm{d} / \mathrm{d}}\right)$ can be generated carrying a neomycin resistance gene (NeoR) transcribed under the control of the CM-restricted alpha myosin heavy chain (MYH6) promoter for antibiotic selection of PSC-CMs. Differentiation and cardiomyocytes purification could be achieved at a large scale in suspension culture spinner flasks. PSC-derived non-myocytes (NM) express MHC-I which was significantly upregulated after interferon gamma (IFNy) stimulation. PSC-derived CM did not express MHC-I and MHC-II under basal conditions, but were up-regulated after IFNy treatment. Expression of co-stimulatory molecules (CD40, CD80 and CD86) was not evident in PSC-derivatives under baseline or IFNy stimulated conditions. PD-L1 expression was upregulated after IFNy stimulation. In vitro immune cell proliferation assays showed that PSC-CM and PSC-NM had strong effect on lymphocyte activation, while PSC-EHM had negligible effect on lymphocyte stimulation. Implantation of PSC-CM under the kidney capsule suggested enhanced survival under MHC-matching. In conclusion, this study provides insight into the immunological properties of PSC-derived cardiomyocytes and their derivatives. 


\section{Abbreviations}

\begin{tabular}{|c|c|}
\hline PSC & parthenogenetic stem cells \\
\hline ESC & embryonic stem cells \\
\hline iPSC & induced pluripotent stem cells \\
\hline maGSC & male germline stem sells \\
\hline LIF & leukemia inhibitory factor \\
\hline EB & embryoid body \\
\hline EGFP & enhanced green fluorescence protein \\
\hline $\mathrm{MHC}$ & major histocomptability complex \\
\hline $\mathrm{mHC}$ & minor histocompatibility complex \\
\hline HLA & human leukocyte antigen \\
\hline CD & cluster of differentiation \\
\hline ICAM & intracellular adhesion molecule \\
\hline GvHD & graft vs host disease \\
\hline APC & antigen presenting cells \\
\hline MSC & mesenchymal stem cells \\
\hline CTL & cytotoxic T-lymphocyte \\
\hline TCR & T-cell receptor \\
\hline IL & interleukins \\
\hline IFN & interferons \\
\hline IFNy & interferon gamma \\
\hline IFNGR & interferon gamma receptor \\
\hline GAS & interferon gamma activation site \\
\hline iNOS & induced nitric oxide synthase \\
\hline
\end{tabular}




\begin{tabular}{ll} 
IRF & interferon response factor \\
MIG & monokine induced interferon gamma \\
ISRE & interferon stimulated response element \\
TGF $\beta$ & transforming growth factor beta \\
IDO & indoleamine 2, 3-dioxygenase \\
TAP & transporter associated antigen processing \\
NK cells & natural killer cells \\
DMAP & 6-dimethylaminopurine \\
SSEA-1 & stage specific embryonic antigen 1 \\
MI & metaphase I \\
PB & polar body \\
EHM & engineered heart muscle \\
CM & cardiomyocytes \\
NM & non myocytes \\
OD & optical density \\
PCR & polymerase chain reaction \\
MEFs & mouse embryonic fibroblasts \\
PBS & phosphate buffered saline \\
DMEM & Dulbecco's modified eagle's medium \\
FCS & fetal calf serum \\
NEAA & non essential aminoacids \\
DMSO & dimethyl sulphoxide \\
NeoR & neomycin resistance \\
EDTA & ethylenediaminetetraacetic acid \\
FOC & force of contraction \\
\hline
\end{tabular}




$\begin{array}{ll}\text { BSA } & \text { bovine serum albumin } \\ \text { PD-1 } & \text { programmed death 1 } \\ \text { PD-L1 } & \text { programmed death ligand-1 } \\ \text { MACS } & \text { magnetic activated cell sorting } \\ \text { MEM } & \text { minimal essential medium } \\ \text { GAPDH } & \text { glyceraldehyde 3-phosphate-dehydrogenase } \\ \text { G-418 } & \text { geneticin } \\ \text { BDM } & \text { 2, 3-butanedione 2-monoxime } \\ \text { DAPI } & \text { 4', 6'-diamidino-2-phenylindole } \\ \text { aMyHC } & \text { alpha myosin heavy chain (MyH6) } \\ \text { B2M } & \text { beta 2-microglobulin } \\ \text { IgG } & \text { immunoglobulin G } \\ \text { CDCs } & \text { cardiosphere derived cells } \\ \text { CFSE } & \text { carboxyfluorescein succinimidyl ester } \\ \text { NKT cells } & \text { natural killer T cells } \\ \text { CVB3 } & \text { coxsakievirus B3 }\end{array}$




\section{Introduction}

\subsection{Cardiovascular diseases and cardiac tissue engineering}

Patients commonly lose approximately 50 grams, i.e. $10 \%$ of the total heart muscle mass upon myocardial infarction (Vunjak-Novakovic et al., 2010). This loss in contractile cells is for the most part irreversible and thus leads to contractile failure of the heart. Heart failure is a leading cause of death throughout the world (Doppler et al., 2013; Sanchez et al., 2006). In light of an increasing life expectancy and incidence of cardiovascular insults with age and the increasing effectiveness of acute medical interventions leading to the stabilization of hemodynamics without any palpable remuscularization, there is a pressing need to develop novel therapeutics to regenerate or biologically repair the failing heart.

Drug and device therapies (e.g. cardiac resynchronization, left ventricular assist devices) have improved the prognosis of heart failure patients (Katz, 2008). However, in end stage heart failure, heart transplantation remains the only causal therapy (Agnetti et al., 2015). Due to the shortage of organ donors ( 300 heart transplants are performed annually in Germany), heart transplantation will remain an option only for a few selected heart failure patients and cannot be considered as a therapeutic solution for the anticipated heart failure epidemic. In vitro engineered heart muscle is thus developed to overcome this limitation and provide ideally functional and immunologically matched allografts.

Tissue engineering combines cells, biomaterials and growth factors to generate functional three-dimensional (3D) tissue outside of the body. Cardiac regeneration using engineered tissue requires the seamless integration of bioengineered structure into the myocardium. Structural, functional and immunological properties of the engineered grafts have to be matched with the recipient to achieve this (Karikkineth and Zimmermann, 2013; Soler-Botija et al., 2012; Ye et al., 2013).

The heart is a highly complex organ with contractile, conductive and vascular systems working together to provide its dynamic function. The heart is one of the first fully 
functional organs formed in the human body and mechanically the most dynamic one (Buckingham et al., 2005). Cardiomyocytes form a three-dimensional network that propagates electrical signals across cellular junctions to trigger mechanical contractions and pump the blood (Severs, 2000). However cardiomyocytes make up for only $25-35 \%$ of the cells in an adult heart while endothelial cells, fibroblasts and smooth muscle cells represent the majority of the cardiac cell population (Bergmann et al., 2015; Pinto et al., 2016).

Several groups have reported promising results with various methods for constructing cardiomyocytes seeded patches (Ye et al., 2013). The first engineered cardiac muscle with palpable contractile performance was generated from chick embryo cardiomyocytes in collagen hydrogels (Eschenhagen et al., 1997) by an adaptation of a three-dimensional culture format for biophysical studies of chick embryo fibroblasts (Kolodney and Elson, 1993). This protocol could be successfully adopted to the rat model and further optimized by the introduction of Matrigel ${ }^{\mathrm{TM}}$ to enhance cardiomyocytes spreading and mechanical loading and to improve force development (Zimmermann et al., 2000). Function and geometry could subsequently be optimized by adding non-myocytes (Naito et al., 2006b) and fusion of individual tissue units (Zimmermann et al., 2006). Most recently combined electromechanical stimulation was introduced to further advance tissue maturation (Godier-Furnemont et al., 2015). This engineered heart muscle (EHM) technology was also demonstrated to be applicable to mouse and human pluripotent stem cell derived cardiomyocytes (Didie et al., 2013; Soong et al., 2012; Tiburcy et al., 2014). Alternative tissue engineering technologies include cell sheet engineering in which three dimensional tissues are formed by layering cell sheets without any additional scaffold materials (Shimizu et al., 2002).

Implantation of EHM on chronically scarred (Zimmermann et al., 2006) or acutely injured (Didie et al., 2013) myocardium was feasible and demonstrated therapeutic efficacy, i.e., enhance systolic thickening of the infarct region. The therapeutic effect was most pronounced in rats with overt heart failure (Zimmermann et al., 2006). In a recent xenograft study of human EHM in immune compromised rats (RNU-rats) longterm survival of engrafted cardiomyocytes and a delayed disease progression after 
ischemia/reperfusion injury could be demonstrated (Riegler et al., 2015). A concurrent finding was strong vascularization of the primarily avascular grafts upon implantation. A surprising observation already in an earlier syngeneic implantation model was strong immune rejection (Zimmermann et al., 2002). Hence, immune suppression had to be applied and was used successfully in the follow-up allograft study (Zimmermann et al., 2006). To address the immunological complication also in an allograft setting, parthenogenetic stem cells were developed and tested in mice with matching and mismatching H-2 composition (Didie et al., 2013). The results of this study were in line with the hypothesis that haploidentical parthenogenetic stem cells would represent more generic donor lines for cell based tissue repair because of their less complex variation in the MHC locus (Doulatov and Daley, 2013).

\subsection{Stem cell sources}

A human left ventricle consists of $6 \pm 1.8 \times 10^{9}$ myocyte nuclei which varies depending on the age of the individual (Olivetti et al., 1991). After a myocardial infarction approximately one billion cardiomyocytes (Murry and Keller, 2008) are lost, that have to be replaced in a successful tissue engineering cardiac repair approach. Several animal studies showed a successful engraftment of immature cardiomyocytes into the adult heart (Delcarpio and Claycomb, 1995; Koh et al., 1993; Koh et al., 1995; Muller-Ehmsen et al., 2002; Rubart et al., 2003). Limiting factors for such a therapeutic approach are low cell retention and the availability of cardiomyocytes at clinical scale and quality. Pluripotent stem cells could overcome the limited provision of cardiomyocytes if their differentiation into functionally competent cardiomyocytes can be ensured. Large efforts have been made to develop strategies for the differentiation of different pluripotent stem cell types into cardiomyocytes. Embryonic stem cells constitute the prototypic pluripotent stem cell type. Mouse embryonic stem cells (ESCs) appear to be derived preferentially from the early inner cell mass (Evans and Kaufman, 1981). At this stage, murine ESCs rely on the presence of leukemia inhibitory factor (LIF) to maintain pluripotency. In contrast, human embryonic stem cells appear to be largely derived from the epiblast and thus dependent on basic fibroblast growth factor (bFGF) signaling to maintain pluripotency in culture (Thomson et al., 1998). In spite of these differences, 
human and murine ESCs exhibit comparable differentiation potential. Here it is important to note that differences in the extent of cardiac differentiation are often reported for different ESC lines (Hannes et al., 2015; Sepac et al., 2012).

Mainly owing to ethical concerns related to the inevitable destruction of a potentially viable embryo during ESC generations, alternative pluripotent cell sources have been sought for. These include parthenogenetic stem cells (PSC) (Didie et al., 2013), male germline stem cells (maGSCs) (Guan et al., 2006) and induced pluripotent stem cells (iPSC) (Takahashi and Yamanaka, 2006) (Figure 1).

Embryonic stem cells (ESCs) are highly susceptible to directed differentiation towards the cardiomyocyte lineage (Burridge et al., 2015; Kattman et al., 2011; Lian et al., 2013; Zhu et al., 2011) Induced pluripotent stem cells have similar properties, but appear more variable in outcome (Wright et al., 2014). Although less studied than ESC and iPSC, there is clear evidence for similar cardiomyogenic potential in ESC and PSC (Didie et al., 2013).

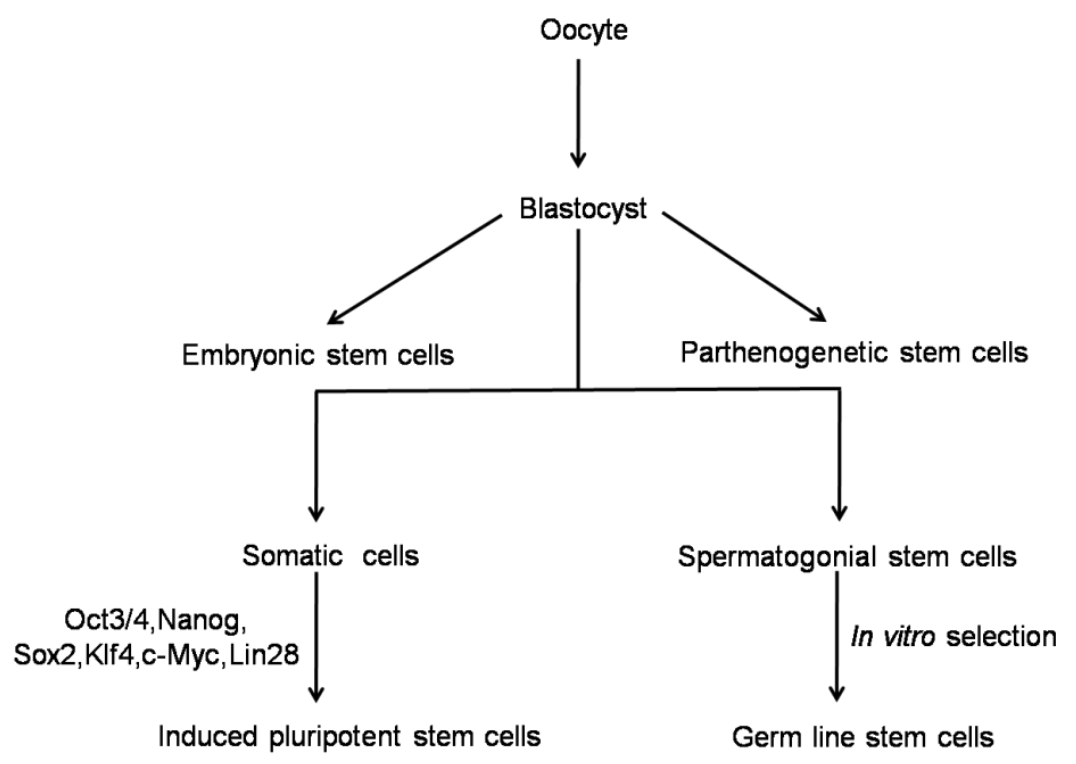

Figure 1: Generation of stem cells for cardiac tissue engineering. The inner cell mass of embryonic and parthenogenetic blastocysts can be harvested to establish pluripotent stem cells from its outgrowths. Male germ line stem cells and induced pluripotent stem cells require selection in culture or reprogramming of somatic cells. Figure adapted from Zimmermann (2011). 


\subsection{Cardiac differentiation of stem cells}

It has been demonstrated that the formation of ESC aggregates induces multicellular interactions and thus promotes their differentiation into the derivatives of all three germ layers (Wobus and Boheler, 2005). This property is exploited commonly for the induction of cardiac differentiation in mouse ESCs. ESC aggregates are generally prepared via the formation of suspended spherical aggregates called embryoid bodies (EB).

There are two major conventional methods for the preparation of EBs. One is a hanging drop method and the other is a suspension culture method. In case of the hanging drop method, the droplets of ESC suspension are hanged from the lid of culture dishes for several days and then an EB is formed in each droplet. In this method, the size of EBs can be controlled by the cell concentration in the suspension. It has been shown that the direction and efficiency of ESC differentiation significantly depend on the size of EBs ( $\mathrm{Ng}$ et al., 2005; Wobus et al., 1991). Therefore, the hanging drop method is advantageous to prepare size-controlled EBs for the efficient and reproducible ESC differentiation into a specific lineage. On the other hand, the hanging drop method is time consuming and labor-intensive and thus disadvantageous in the mass preparation of cardiomyocytes.

In case of the suspension culture method, ESCs are cultured in non-adhesive culture dishes for several days and then EBs are forming randomly and spontaneously. In this method, a large number of EBs can be easily prepared. In contrast, however, the size of EBs is not controlled and thus the differentiation efficiency and reproducibility becomes much lower than the case of hanging drop method (Kurosawa, 2007). For the generation of large number of cardiomyocytes, more cost-effective culture methods are needed. Several research groups started to develop scalable culture methods for the mass preparation of size-controlled EBs, such as multiwell plates (Kim et al., 2007), microwell substrates (Khademhosseini et al., 2006; Mohr et al., 2006), patterned culture plates (Bauwens et al., 2008; Sasaki et al., 2009) and rotary suspension culture in bioreactors (Carpenedo et al., 2007). 
Selecting bioreactors for stem cell expansion and differentiation mainly depends on whether the cells are adherent, suspension grown as single cells or aggregates for EB formation (King and Miller, 2007). In addition, bioreactors have significant advantages over static suspension culture which are as follows: scale up of expansion and differentiation of ES cells, less labor-intensive, less space requirement and the ability to monitor and control critical culture parameters (i.e. $\mathrm{pH}$, dissolved oxygen, glucose consumption and lactic acid production) (Kempf et al., 2014). In this study we have chosen spinner flask type bioreactors for the differentiation of PSC into cardiomyocytes in large scale.

Spinner flasks have been developed, as promising in vitro systems for stem cell expansion, EB cultivation and differentiation of ES/iPS cells into specific cell types (Serra et al., 2009). Spinner flasks provide attractive benefits due to their simple design, scalable configuration, the possibility for culture of cells in aggregates or microcarriers (Abranches et al., 2007) and ease of continuous monitoring for tight regulation of the culture environment (e.g. $\mathrm{O}_{2}$ tension, $\mathrm{pH}$, shear forces, medium exchange rate) (Zandstra et al., 2003). The rotation of hanging pendulum in spinner flasks results in the formation of large ES cells aggregates within a few days (Schroeder et al., 2005). The scaling-up is generally simple because of improved homogenous mixing of cell suspension achieved by stirring. Numerous culture parameters for this system have been optimized including the agitation rate, cell concentration and medium compositions. Consequently, an optimal medium velocity promoting the suitable shear stress for the cell type being cultured is also important (Fok and Zandstra, 2005).

For clinical uses, pluripotent stem cells must be propagated and efficiently differentiated into cardiomyocytes which should be highly purified before transplantation to prevent the development of tumors derived from contaminating pluripotent stem cells (Lin et al., 2010). Several biochemical substances, such as retinoic acid (Wobus et al., 1997), ascorbic acid (Takahashi et al., 2003), nitric oxide (Kanno et al., 2004), Bone morphogenetic protein (BMP) inhibitors (Yuasa et al., 2005), Wnt inhibitors (Naito et al., 
2006a) and activin A (Laflamme et al., 2007), were found to promote cardiac differentiation of ESCs.

With respect to the purification of ESC-derived cardiomyocytes, Klug et al. developed a transgenic purification method using antibiotic-resistant gene, which was designed to be expressed in differentiated cardiomyocytes; cardiomyocytes purities of $99 \%$ can be achieved with this approach (Klug et al., 1996). Similar genetic purification methods were developed later by the use of reporter genes such as enhanced green fluorescence protein (EGFP) which yields around 98\% pure cardiomyocytes (Anderson et al., 2007; Hidaka et al., 2003). Cardiomyocytes up to $99 \%$ purity was also obtained by transgene-free metabolic selection after differentiation of stem cells (Tohyama et al., 2013). Enriched populations of functional cardiomyocytes with up to $88 \%$ purity can also be obtained by discontinuous percoll gradient centrifugation ( $E$ et al., 2006).

\subsection{Major histocompatibility complex and transplantation immunology}

Transplantation of cells, tissues and organs between genetically non-identical individuals results in most cases in the development of an immune response towards the graft and consequently to graft destruction which poses a pivotal challenge for translating cell based therapeutics into a clinical application. Organ rejection is primarily targeted at proteins, so called alloantigens presented by donor cells at the cell membrane (Bradley et al., 2002). There are three distinct classes of alloantigens: (1) the major histocompatibility complex antigens (MHC), (2) the minor histocompatibility complex $(\mathrm{mHC}$ ) antigens and (3) the $\mathrm{ABO}$ blood group antigens. The most rapid and acute rejection occurs due to failure to properly match donor and recipient MHC alleles (Drukker, 2004).

Human MHC molecules are known as human leukocyte antigen (HLA) and mouse as $\mathrm{H}$ 2 , for histocompatibility 2. The HLA genes are located on human chromosome 6 . The mouse $\mathrm{H}-2$ genes are located on mouse chromosome 17 (Figure 2). The MHC genes are traditionally divided into three classes: the MHC class I and class II genes, which encode the antigen-presenting MHC molecules and the class III genes, a miscellaneous 
group of genes encoding molecules with important immune functions and others with no known immune function. Another immunologically highly relevant gene, the gene encoding b2-microglobulin lies outside the MHC coding region, on mouse chromosome 2. All the other genes encoding chains of the class I and class II MHC molecules are present in several different copies within the MHC genomic region and each cell expressing them displays several different MHC molecules (Moussa et al., 2012). The peptide antigen-presenting MHC molecules are known as classical MHC molecules. There are also structurally related molecules of both classes that do not function in the presentation of peptide antigens to T-cells: these are known as non-classical MHC molecules. The classical MHC molecules are present in more than 500 different variants.

Mouse chromosome 17

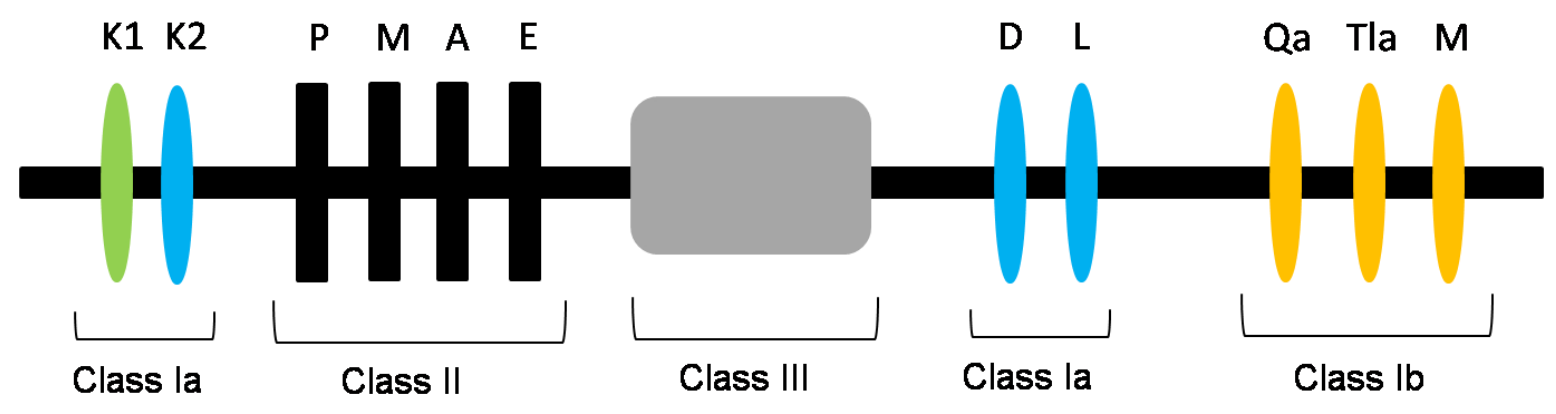

Class la: classical class I molecules Class II molecules

Class Ib: non-classical class I molecules Class III molecules

Figure 2: MHC polymorphism on mouse chromosome 17. Distribution of MHC- molecules on mouse chromosome 17. Figure adapted from Moussa et al. (2012).

The MHC antigens were originally recognized for their role in initiating T-cell responses that lead to the rejection of transplanted tissue. The MHC class I antigens are traditionally associated with the activation of CD8+ cytotoxic T-lymphocytes (CTLs), whereas MHC class II antigens are recognized by CD4+ helper T-lymphocytes $\left(T_{H}\right)$ (Bradley et al., 2002). 
It is well established that HLA compatibility determines kidney and bone marrow allograft survival (Picascia et al., 2014). Cardiac rejection can be either hyper acute, acute or chronic which attack two different compartments of the heart. (1) Hyper acute rejection is mediated by preformed antibodies in the recipient directed against donor cell antigen's (Dronavalli et al., 2015). (2) Acute rejection is defined by interstitial mononuclear cell infiltrates with myocyte damage. (3) Chronic rejection is mediated by constant low grade inflammation of the vasculature with similarities to classical arteriosclerosis and subsequent organ failure (Kaul et al., 2015).

The behavior of alloantigen specific T-cells in response to heart, skin and islet allografts, showed marked differences in the susceptibility of different organs to rejection and resistance to the induction of tolerance. It could be demonstrated that CD8+ T-cells are dependent on CD4+ T-cells during cardiac allograft rejection in contrast to skin and islet allografts (Jones et al., 2001). It has also been demonstrated that increasing the mass of transplanted organs prolonged graft survival (Sun et al., 1995).

The expression of MHC antigens in various organs and tissues was determined intensively in animals and humans. Several groups show that expression of class II antigens is increased in rejected organs and in tissues undergoing autoimmune injury, in viral disease and in inflammatory conditions (Isobe et al., 1992). High expression of MHC-I on the myocardium was observed in $75 \%$ of cardiac biopsies from patients who had received cardiac transplantation (Rose et al., 1986). However, in most studies MHC-expression was analyzed in histological samples of whole hearts including noncardiomyocytes. Cardiac interstitial cells such as endothelial and dendritic cells can serve as non-professional and professional antigen presenting cells respectively. Within the myocardium they express high levels of MHC I, MHC II and Intracellular adhesion molecule 1 (ICAM-1) (Karabekian et al., 2011). Native adult cardiomyocytes express low levels of MHC I antigens (MHC K and D in mice) and do not express detectable levels of MHC II antigens (MHC IA and IE in mice) (Isobe et al., 1992).

Theoretically HLA-A, B, C antigen expression should be on the membranes of nucleated cells. Under normal conditions without activation of immune system there is 
no expression of $\mathrm{MHC}$ class I antigen on the cardiomyocyte sarcolemma. Whether the absence of $\mathrm{MHC}$ antigen expression is a methodological problem because the antigen density is below the sensitivity of staining or is a true absence of these proteins is unclear (Hufnagel and Maisch, 1991). Interestingly allogeneic cardiosphere derived cells appear less immunogenic in vivo and can survive in the infarcted myocardium for 3 weeks in order to stimulate endogenous reparative and regenerative pathways (Malliaras et al., 2012).

Cardiac cells are able to upregulate MHC-antigens after viral infection. Huber et.al showed that two types of CD8+ T-cells infiltrate the myocardium during coxsackievirus B3-induced myocarditis. One type expresses $\alpha \beta$ T-cell receptors and represents the classical antigen specific T-cells which are MHC antigen restricted and abundant in peripheral lymphoid tissues. The second type expresses $\gamma \delta$ T-cell receptors, these cells are usually a minor component of peripheral lymphoid tissues, but tend to accumulate in inflammatory lesions. These lymphocytes recognize antigen independently of $\mathrm{MHC}$ molecules through Fas dependent apoptosis (Huber, 2000).

Apart from $\mathrm{MHC}$ antigens, minor histocompatibility antigens can also trigger graft versus host disease (GvHD) (Goulmy, 1997; Korngold and Sprent, 1983). A number of minor antigens have now been described and characterized (Simpson et al., 2002). Even if the stem cells are from an autologous source, it is possible that so called autoantigens are presented followed by an immune response (Boyd et al., 2005).

\subsection{The allorecognition pathways}

The allorecognition pathways are mainly mediated by professional antigen presenting cells (APCs) and T-cells which can be divided into the direct and the indirect allorecognition pathways. In the direct allorecognition pathway donor derived APCs, contained within the graft, move to near lymph nodes where they interact with host CD4+ and CD8+ T-cells. Due to the expression of foreign MHC class II molecules resident $\mathrm{CD} 4+$ and $\mathrm{CD} 8+\mathrm{T}$-cells become activated and elicit an immune response leading to acute graft rejection (Figure 3). 
In the indirect allorecognition pathway professional APCs of the host engulf antigens derived from transplanted cells which became necrotic or apoptotic. These MHC antigens are subsequently presented to host CD4+ and CD8+ T-cells in draining lymph nodes inducing immune rejection against somatic cells which display these antigens. In the context of stem cell derived cardiac cell replacement therapies mainly the indirect pathway would be involved since preferably pure cell population without the presence of APCs would be transplanted.
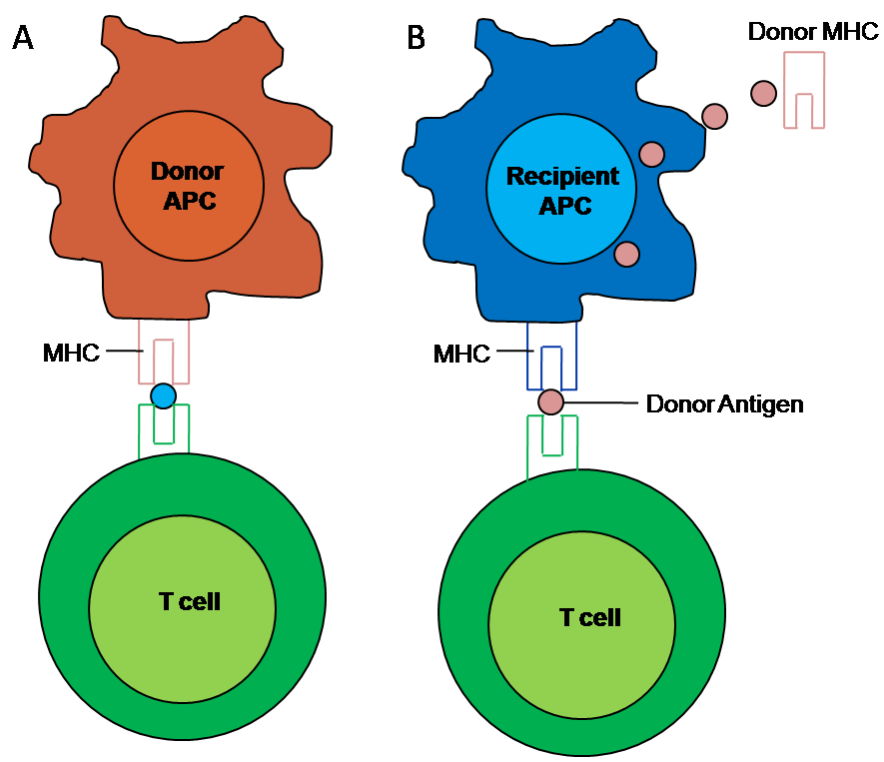

Figure 3: Direct and indirect T-cell allorecognition pathways. A. In direct allorecognition, T-cells recognize intact allogeneic MHC molecules together with the bound antigen on the surface of donor APCs in the graft. B. In indirect allorecognition, alloantigens are recognized as linear peptides in the milieu of recipient MHC class II molecules after they have been processed and presented by recipient APCs. Figure adapted from Bradley et al. (2002).

\subsection{Stem cell immunology}

Many stem cells express no or only low levels of MHC antigens and have been considered to be immune privileged or lacking the ability to induce an immune response. In fact, ESCs and mesenchymal stem cells (MSCs) have been considered as prototypes for immune privileged cells for cell transplantation studies (Menendez et al., 2005; Yang, 2007) 
Using standard flow cytometry, neither MHC class I nor MHC class II complexes were detected on the cell surface of mESCs (Magliocca et al., 2006; Tian et al., 1997). However, even very few MHC class I complexes on target cells are sufficient to induce transient calcium signaling and killing activity in CTLs (Brower et al., 1994) and the ability of CTLs to kill mESCs was shown in vitro (Dressel et al., 2009).

The presence of MHC class I molecules on mESCs was also demonstrated utilizing lacZ-inducible, antigen/MHC class I specific T-cell hybridomas (Abdullah et al., 2007). These T-cell hybridomas had a lacZ reporter gene under control of the IL-2 promoter. Following T-cell receptor (TCR)-dependent activation upon co-culture with aPIG ESCs, the T-cell hybridomas expressed $\beta$-galactosidase. In addition, T-cell mediated responses against mESCs were demonstrated in vivo (Boyd and Wood, 2009; Dressel et al., 2009; Robertson et al., 2007; Wu et al., 2008).

Contradictory data was published regarding the ability of mESCs to respond to IFNY signaling. One group reported that the expression of MHC class I molecules was not enhanced after IFNy treatment, neither on transcript nor on protein level (Abdullah et al., 2007; Nussbaum et al., 2007; Tian et al., 1997). Another group reported that MHC class I molecule expression increased after IFNy treatment in mESCs (Bonde and Zavazava, 2006). Likewise, it remains uncertain how the expression of MHC class I molecules changes upon differentiation of mESCs.

Lampton et al. have examined levels of mRNA and protein expression of MHC class I proteins, as well as several MHC class I antigen processing and presentation chaperones in mESCs and PSC (Lampton et al., 2008). They found that $\mathrm{H}-2^{\mathrm{K}}, \mathrm{Qa}-2$, TAP1, TAP2 and tapasin mRNAs were all expressed at low levels in undifferentiated and differentiated ESCs which were significantly upregulated in response to IFNY treatment after 14 days of differentiation. Likewise, expression of $\mathrm{H}-2^{\mathrm{Kb}}$ and $\mathrm{H}-2^{\mathrm{Kk}}$ proteins were upregulated to measurable levels by IFNy after differentiation, but Qa-2 protein expression remained low or absent. They also found that MHC class I, TAP1, TAP2 and tapasin mRNAs were all expressed at very low levels in ESCs compared to 
T-cells, suggesting transcriptional regulation of these genes in ESCs (Lampton et al., 2008).

It was reported that MHC class I molecules were generally up-regulated when mESC differentiate into teratomas in vivo (Nussbaum et al., 2007). Another study suggested that mESCs only transiently, between day 4 and day 6 of differentiation, slightly upregulate MHC class I protein expression (Abdullah et al., 2007). Also regarding the susceptibility of mESCs to the cytotoxic activity of natural killer (NK) cells several groups were able to show that mESCs are efficiently killed. This was most likely due to low MHC class I molecule expression, which serve as ligand for inhibitory NK cell receptors, combined with expression of ligands for activating NK cell receptors (Dressel et al., 2010; Dressel et al., 2008; Frenzel et al., 2009). In summary, the findings published so far suggest that ESCs are probably more immunogenic than initially proposed in many early studies, in which a general immune privilege of ESCs was suggested (Bonde and Zavazava, 2006; Koch et al., 2008; Li et al., 2004; Magliocca et al., 2006).

Allogeneic immune response was detected in mice after implantation of labeled embryonic stem cells in ischemic myocardium (Kofidis et al., 2005). It was also found that mESC transplanted into injured myocardium provoke infiltration of T-cells, B cells and macrophages. The transplanted cells and their progeny disappear over a period of weeks, most likely because of this response (Swijnenburg et al., 2005). In contrast to this, Fandrich et al. showed that allogeneic rat ESC-like cells injected into the portal vein induce a state of tolerance that allows survival of cardiac allografts of the same major histocompatibility complex (MHC) types as the ESC (Fandrich et al., 2002).

Transplantation of differentiated ESC in an animal model could enhance MHC-I levels and the myocardium could be particularly inductive for an immune response (Drukker and Benvenisty, 2004). After myocardial injury, inflammation occurs which leads to recruitment of active immune cells (van Laake et al., 2006). It has been demonstrated that hESC derived cardiomyocytes can survive and mature after intramyocardial injection in immunodeficient mice up to 12 weeks (van Laake et al., 2007). In one of the studies with mESC, cyclosporin was used as a immunosuppressive agent to avoid 
immune rejections in rats (Naito et al., 2004). In contrast transplantation of PSC into ischemic myocardium of immune competent animals significantly enhanced neovascularization and improved heart function (Liu et al., 2013a). Taken together, most of the in vivo experiments with stem cell-derived cardiomyocyte implantations were done under immunosuppression or in immune deficient animal models.

\subsection{Interferon gamma and regulation of major histocompatibility complex}

Interferons (IFNs) are proteins released by host cells in response to the presence of pathogens or tumor cells. They are typically divided into type I (alpha and beta) and type II (gamma) classes. Besides antiviral function, IFNs have broader range of antiproliferation and pro-inflammatory activities (Schroder et al., 2004). IFNy exposure to cells can up regulate MHC class I expression on their cell surface and enhance CTLs recognition (Rosa and Fellous, 1988). In this way, CTLs kill bacteria and virus infected cells via CTL epitope/MHC class I complexes on the surface of target cells (Boehm et al., 1997). The components of MHC class I antigen processing machinery are upregulated by IFNy through the JAK/STAT signal transduction pathway (Kohlhuber et al., 1997; Wu et al., 1997) (Figure 4). IFNy performs its biological functions through binding to IFNy-receptor (IFNGR). IFNGR is present on all nucleated cells.

Initially, it was understood that CD4+ T helper cell type 1 (Th1) lymphocytes, CD8+ cytotoxic lymphocytes and NK cells exclusively produce IFNy (Bach et al., 1997; Young, 1996). However, now it is known that other cells, such as B cells, natural killer T-cells (NKT) and professional antigen-presenting cells (APCs) secrete IFNY (Carnaud et al., 1999). IFNY production by professional APCs (monocyte/macrophage, dendritic cells (DCs)) acting locally may be important in cell self-activation and activation of nearby cells (Frucht et al., 2001). IFNy secretion by NK cells and possibly professional APCs is likely to be important in early host defense against infection, whereas T-lymphocytes become the major source of IFNy in the adaptive immune response (Sen, 2001). 


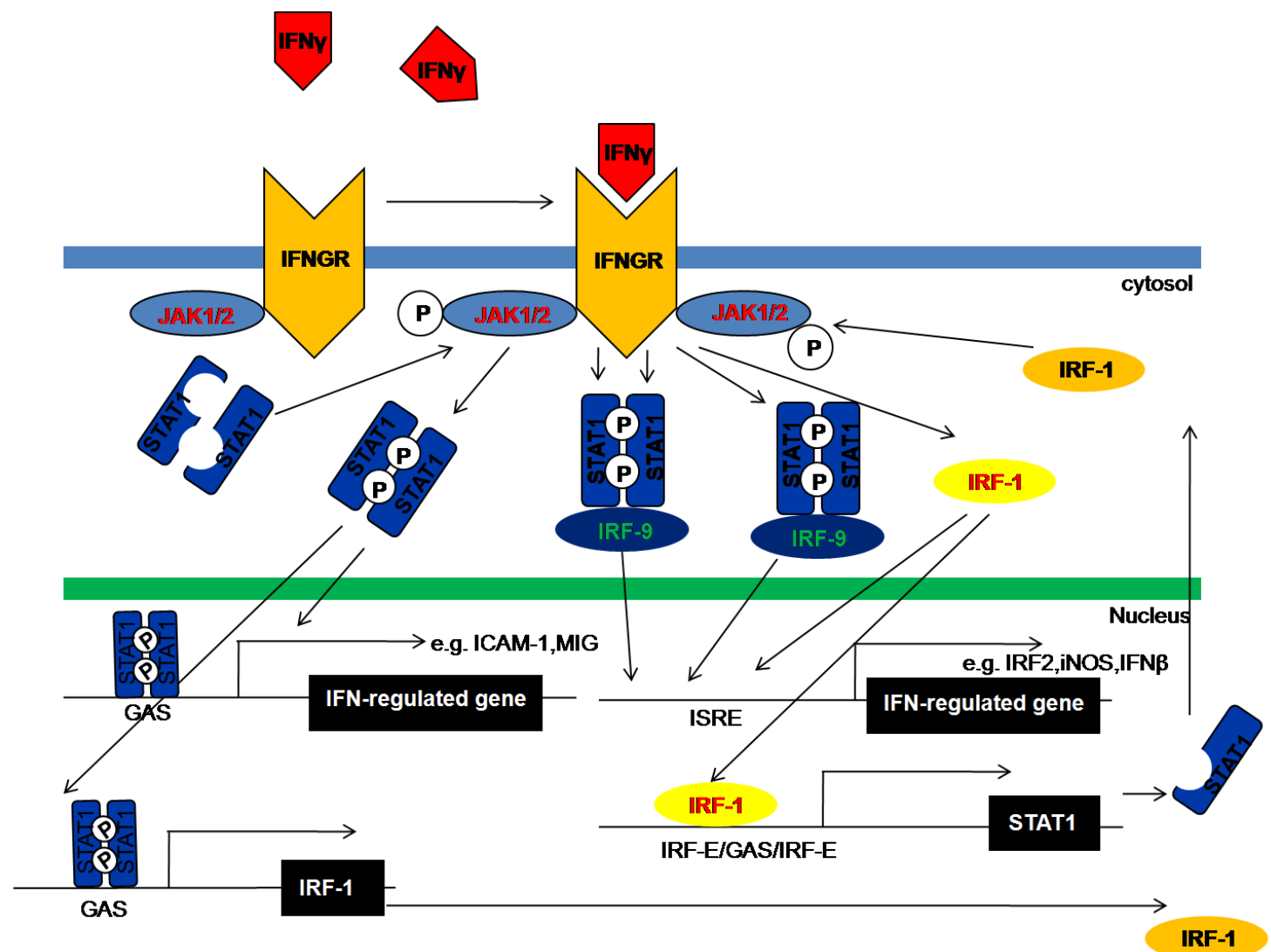

Figure 4: Interferon-gamma signal transduction pathway. Ligand (IFNY) binding causes a conformational change IFNGR, such that the inactive JAK kinases are activated by phosphorylations. The activated JAK phosphorylates STAT1. STAT1 homodimers move to the nucleus and bind to promoter IFNY activation site (GAS) elements to initiate/suppress transcription of IFNy regulated genes. IRF-1 is also able to promote transcription of STAT1 through an unusual ISRE site (IRF-E/GAS/IRF-E). ICAM-1, Intercellular adhesion molecule-1; MIG, monokine induced by IFNY; iNOS, inducible nitric oxide synthase; IRF, Interferon response factor; ISRE, Interferon stimulated response element. Figure adapted from Schroder et al. (2004).

\subsection{Immune regulatory properties of pluripotent stem cells}

In addition to the proposed immune privilege of ESCs due to undetectable MHC class I expression, further mechanisms of ESCs to evade immune responses were reported. Such mechanisms appear evolutionary plausible for ESCs since these cells, derived from the early blastocyst, need immune escape mechanisms to avoid the maternal immune response (Trowsdale and Betz, 2006). Abdullah et al. reported that murine ESCs are protected against immune responses, due to high expression of serpin 6 
(Abdullah et al., 2007). This protein is an endogenous inhibitor of granzyme $B$, the serine protease that enables NK cells and CTLs to lyse target cells via the granule exocytosis pathway (Medema et al., 2001). Another known protective protein against cellular cytotoxicity is cathepsin B. Cathepsin B is a protease that inactivates the poreforming activity of perforin, thereby inhibiting the transport of granzyme $B$ into target cells. It was shown that CTLs protect themselves against perforin of their own cytotoxic granules by expression of cathepsin B (Balaji et al., 2002).

Furthermore, it was reported that expression of Fas ligand (FasL) on murine ESCs play a crucial role for their immune escape (Bonde and Zavazava, 2006). FasL is a transmembrane protein on cytotoxic cells that induces apoptosis in Fas receptor expressing cells. In addition to the granzyme B pathway, the expression of FasL is a mechanism of CTLs to induce apoptosis in target cells (Nagata, 1996). Cells of immune privileged areas such as testis or cornea express FasL, thereby avoiding the cytotoxic activity of infiltrating CTLs by a counter attack (Ferguson and Griffith, 1997; Griffith and Ferguson, 1997). Accordingly, Bonde et al. reported that $75 \%$ of pre-activated T-cells became apoptotic following exposure to murine ESCs and apoptosis was inhibited by addition of a FasL neutralizing antibody in a concentration dependent manner (Bonde and Zavazava, 2006). However, in other studies no FasL expression on several murine ESCs was detected (Brunlid et al., 2007; Frenzel et al., 2009). In addition, no FasL expression was detected on human ESCs (Drukker et al., 2006; Grinnemo et al., 2006).

It was also reported that ESCs evade the immune response by secretion of TGF $\beta$. It is well established that TGF $\beta$, released by regulatory T-cells, inhibits the activation of naive T-cells. The release of TGF $\beta$ by mESCs was demonstrated using ELISA and ESC-conditioned medium was able to suppress proliferation of CD4 positive T-cells. Proliferation was largely restored after addition of a TGF $\beta$ sRII/Fc fusion protein or addition of a TGF $\beta$ neutralizing antibody (Koch et al., 2008). Indoleamine 2,3dioxygenase (IDO), a tryptophan-catabolizing enzyme, suppresses immune reactions which is mainly observed in mesenchymal stem cells (MSC). T-cell proliferation is inhibited by tryptophan depletion from the cellular microenvironment and further studies demonstrated that the tryptophan catabolite kynurenine induces apoptosis in T-cells by 
activation of caspase-8 (Fallarino et al., 2002; Munn and Mellor, 2007; Munn et al., 1999)

\subsection{Major histocompatibility complex homozygosity}

The issue of immune mediated rejection of an allotransplant remains a major challenge. Immunogenicity of a stem cell derivative depends on the expression of the highly polymorphic MHC genes. This polymorphism is further increased by genetic heterozygosity. The risk of transplant rejection is proportional to the degree of cellsurface antigen differences between the donor cells and the recipient. In an autologous transplant, donor tissue is identical to the recipient. However, autologous transplants are not usually practical because of site availability and morbidity. Donor tissues are typically screened for cell-surface antigens in order to determine the degree of $\mathrm{MHC}$ compatibility with the recipient. Matching donor and recipient tissue for HLA antigens reduces the chance of a cytotoxic T-cell response in the recipient and thus greatly increases the likelihood of transplant survival. In heart transplantation with limited donor organ availability only ABO matching is performed (Sjogren et al., 2010).

A transplant can be much less immunogenic when its two MHC haplotypes are identical resulting in a much higher probability for tissue matching. Grafts derived from such homozygous stem cells, presenting as few as three or four antigens, would match a much wider range of hosts than a heterozygous graft (Lin et al., 2003). Because some HLA haplotypes have a higher distribution in the population, the use of homozygous stem cells holds the possibility of creating a bank of stem cells covering most phenotypes in the general population (Nakajima et al., 2007).

Normal ESC derived from fertilized embryos are genetically divergent from any patient requiring tissue transplantation (Drukker, 2004). It was estimated that a stem cell bank containing 10 stem cell lines from selected homozygous HLA-typed volunteers could match $93 \%$ of the UK population with a minimal requirement for immune suppression (Taylor et al., 2011). Similarly as few as 50 such homozygous lines could potentially match $90 \%$ of the Japanese population (Nakatsuji et al., 2008). But the chances of 
obtaining homozygous iPSC or ESC on a more global scale are extremely rare or nearly impossible. There are several ways to develop MHC homozygous grafts including the knockout of one MHC haplotype in a heterozygous stem cell line or the fertilization of an oocyte with a sperm that has an MHC identical to the oocyte or generating iPS from MHC homozygous donors.

Even though iPSC seems to provide a perfect match for autologous condition, many reports have shown that iPSC derivatives are immunogenic either because of reprogramming factors or reprogramming induced DNA damage (Araki et al., 2013; Cao et al., 2013; Kruse et al., 2015; Zhao et al., 2011). Because of these limitations with HLA homozygosity from hESC and hiPSC as mentioned above one possible alternative is to generate HLA homozygous cell lines is by parthenogenesis. PSCs are by nature largely haploidentical (75\% of the cell lines appear haploidentical for HLA), with only crossing over events during meiosis I causing some heteroyogosity (Revazova et al., 2008)

\subsection{Major histocompatibility complex-haploidentical parthenogenetic stem cells}

The term parthenogenesis is derived from the greek word for "virgin birth". It is a form of reproduction in which an unfertilized egg can develop into a blastocyst and in some non-mammalian species even fertile offspring. Several insect species including aphids, bees and ants, but also lower vertebrates such as some fish and chicken under developmental pressure can reproduce by parthenogenesis (Sarvella, 1973). Recently parthenogenesis has received considerable attention as a tool for the production of largely haploidentical diploid plutipotent stem cells (Didie et al., 2013; Doulatov and Daley, 2013). The possibility of deriving stem cells from parthenogenetic blastocysts without destruction of an embryo makes parthenotes also ethically widely acceptable and because of their typical haploidentical HLA gene loci an advantage as to HLA matching in an allograft setting (Wininger, 2004). A potential concern of haploidentity is that autosomal recessive mutations may present a potentially harmful phenotype. 
The phenomenon of parthenogenesis was discovered in the $18^{\text {th }}$ century by Charles Bonnet. The molecular events that lead to oocyte activation have been studied in detail in invertebrates, amphibians and mice. Mouse parthenotes are capable of developing beyond the post implantation stage (day 10 of gestation) in vivo (Kaufman et al., 1977; Kono et al., 2004; Surani et al., 1984); porcine parthenotes have developed up to postactivation day 29 (limb bud stage, past the early heart beating stage); rabbit parthenotes until day 10-11 (Ozil, 1990); primates (Callithrix jacchus) have only been shown to implant (Marshall et al., 1998); in humans, parthenogenesis can occur and lead to ovarian teratomas (Oliveira et al., 2004), but not to full embryonic development. The reason for the arrested development in parthenotes is believed to be due to genomic imprinting. In normal zygotes maternal and paternal haploid genomes are epigenetically distinct and both sets are required for successful development of the organism (Sasaki et al., 1992; Surani et al., 1990). Since all genetic material in parthenotes is of maternal origin, there is no paternal imprinting component and this prevents proper development of extra embryonic tissues whose expression is regulated by the male genome (Surani and Barton, 1983).

There is no confirmed example of unassisted mammalian parthenogenetic reproduction, but mammalian oocytes can be artificially activated to undergo parthenogenesis in vitro by a two-step protocol involving the treatment with a chemical agent (ionomycin, ethanol, or inositol 1,4,5-triphosphate) to elevate $\mathrm{Ca} 2+$ levels transiently, followed by application of an inhibitor of protein synthesis (cycloheximide) or protein phosphorylation (6-dimethylaminopurine(DMAP)) (Hipp and Atala, 2004). Success rates and viability appear to be species dependent.

Mouse oocytes can be activated to undergo parthenogenesis by exposure to $\mathrm{Ca}^{2+}$ and $\mathrm{Mg}^{2+}$ free medium; medium containing hyaluronidase; exposure to ethanol, $\mathrm{Ca}^{2+}$ ionophores, or chelators; inhibitors of protein synthesis and electrical stimulation (Surani et al., 1984). Pronuclear formation and cleavage occurs following incubation with calcium ionophore and puromycin or DMAP (Nakagawa et al., 2001). Broad differentiation capability of primate (Macaca fascicularis) pluripotent stem cells derived by parthenogenesis was demonstrated. The in vitro differentiation of these cells to well 
characterized dopaminergic neurons (Cibelli et al., 2002) and hepatocytes (Espejel et al., 2014) was established. Parthenogenetic stem cells (PSCs) showed self-renewal capacity and indefinite proliferation in vitro, but with impaired embryonic and extra embryonic development as a consequence of altered genomic imprinting in vivo (Allen et al., 1994; Nagy et al., 1989; Spindle et al., 1996). Specification to ectodermal differentiation is not effected in vitro (Vrana et al., 2003) and in vivo (Sturm et al., 1994), while endodermal and mesodermal cell lineage specifications are compromised developmentally in parthenotes (Allen, Barton et al. 1994). The first human PSC line was unintentionally created in a failed nuclear transfer experiment (Mai et al., 2007). Revazova et.al created intentionally, six pluripotent HLA heterozygous human PSC lines by chemical activation of unfertilized oocytes harvested directly from explanted ovaries of patients undergoing super ovulation treatment (Revazova et al., 2007). Since then several human parthenogenetic stem cell lines have been reported (de Fried et al., 2008; Hao et al., 2009; Mai et al., 2007).

Using various activation protocols, it is possible to create PSCs with different HLA status. Parthenogenetic activation of immature oocytes (MI) and inhibiting the extrusion of first polar body prevents segregation of homologous chromosome pairs (Daughtry and Mitalipov, 2014). This result in the generation of haploid PSC, however the acquisition of $\mathrm{Ml}$ oocytes is not trivial. Parthenogentic activation of meiosis II (MII) oocytes with a combination of the activating agent's ionomycin and 6dimethylaminopurine (6-DMAP) blocks the extrusion of the second polar body; therefore, activated oocytes retain all of their genetic material (Figure 5). The HLA genotypes of hPSCs derived from these oocytes can be heterozygous or homozygous due to crossing over events and thus can be genetically HLA-matched to the donors (Didie et al., 2013; Doulatov and Daley, 2013). 


\section{A}

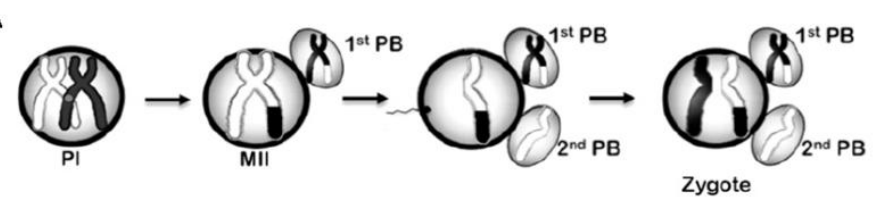

B

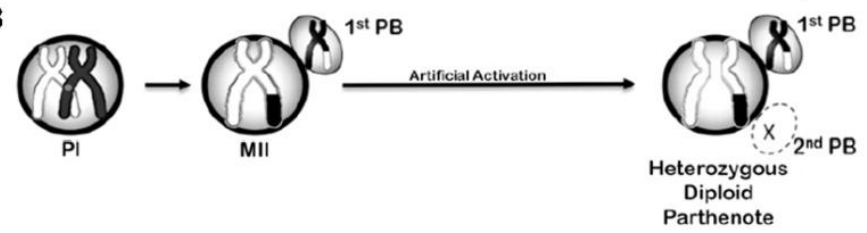

C

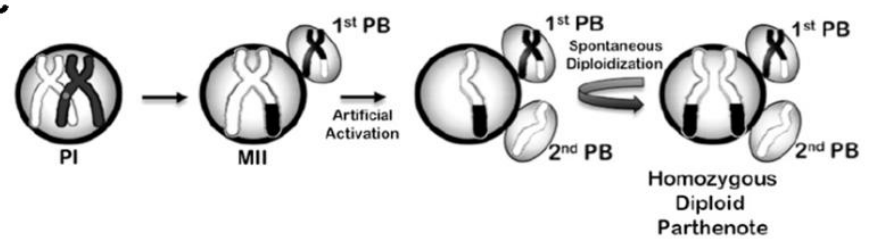

D

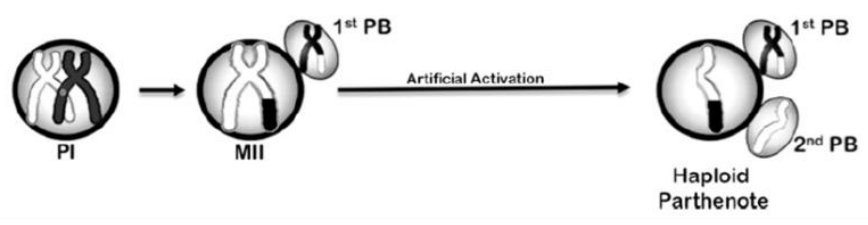

Figure 5: Embryonic and parthenogenetic meiosis. A. During normal fertilization the maternal or paternal chromosomes segregate into the first polar body $\left(1^{\text {st }} \mathrm{PB}\right)$ in meiosis I (MI). In meiosis II (MII) a further reduction of the chromosomal DNA occurs by the separation of sister chromatids and the extrusion of one set of chromatids as the second polar body $\left(2^{\text {nd }} P B\right)$. Fusion of two haploid gametes (oocyte and sperm) results in a diploid zygote B. In heterozygous parthenogenesis, meiosis II (MII) arrested oocytes are activated artificially by blocking extrusion of the second polar body. Diploidy is maintained and the resulting blastocysts yield hetrozygous diploid parthenote. C. In homozygous parthenogenesis autodiploidization of haploid genome occurs leading to the formation of homozygous diploid parthnotes. D. In haploid parthenogenesis haploid genome is maintained through following mitotic divisions resulting in the formation of haploid parthnote. Pl: prophase I. Figure adapted from Daughtry and Mitalipov (2014). 


\section{Aims of the thesis}

The main aim of the thesis was to study the immunological properties of MHChomozygous PSC-derived cardiomyocytes in vitro and in vivo, with the long-term objective to apply engineered heart muscle derived from PSC-derived cardiomyocytes in human heart repair.

The following specific aims were addressed:

1) Set-up of a bioreactor differentiation protocol for cardiomyocytes derivation from PSC.

2) Generation of engineered heart muscle (EHM) from PSC-derived cardiomyocytes.

3) Characterization of the immunological properties of PSC-derivatives and PSC$\mathrm{EHM}$ in vitro and in vivo.

4) Characterization of immunogenicity of MHC-homozygous PSC-derived nonmyocytes and cardiomyocytes in vivo.

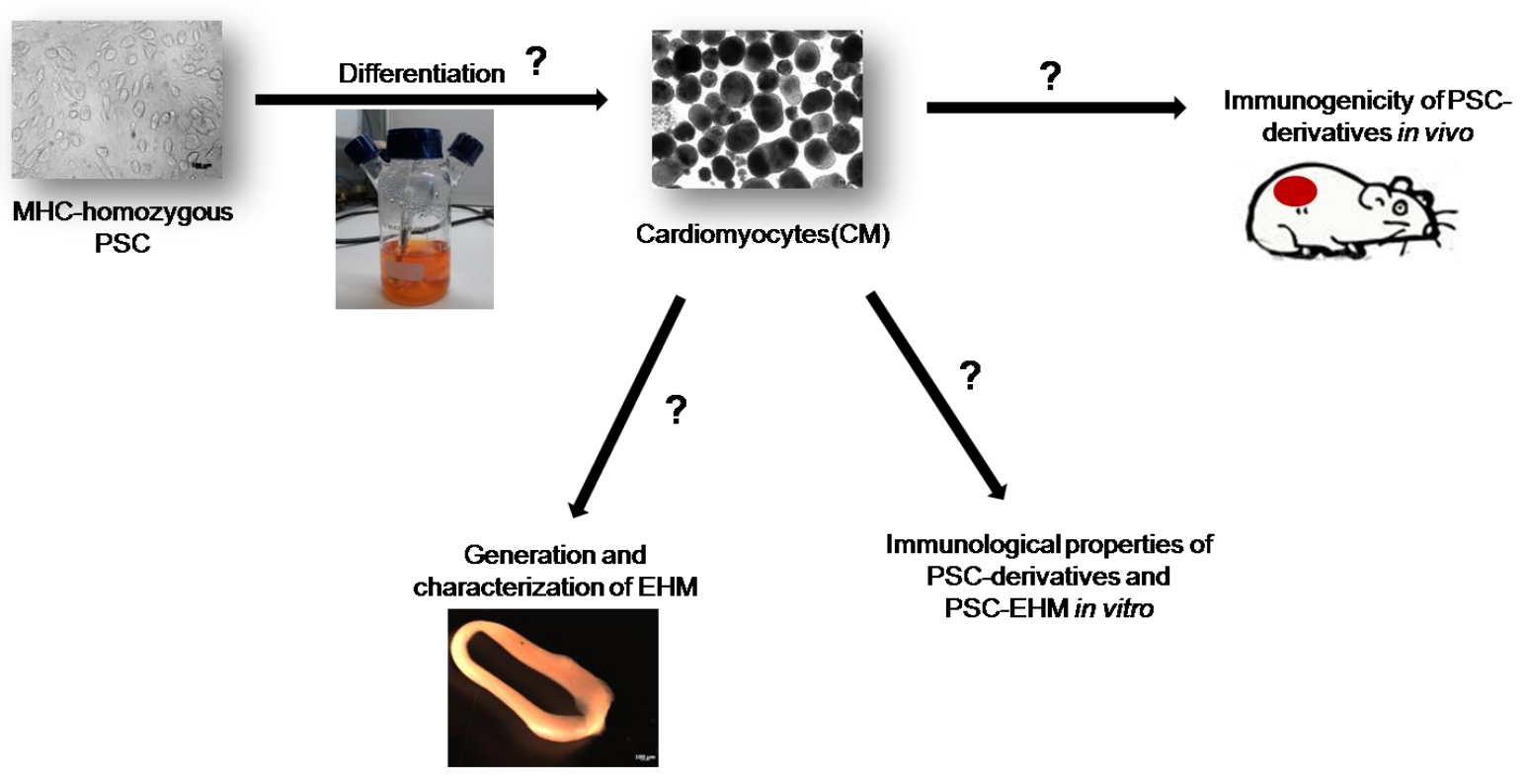

Figure 6: Schematic representation of the project. 


\section{Materials and methods}

\subsection{Molecular biology methods}

\subsubsection{Transformation of competent cells}

$50 \mu \mathrm{l}$ of competent E.coli cells (DH5a) were thawed on ice and incubated with $1 \mu \mathrm{l}$ of plasmid (10-100 $\mathrm{ng}$ ) and kept on ice for $30 \mathrm{~min}$. The transformation reaction mixture was then subjected to heat shock at $42^{\circ} \mathrm{C}$ for $1 \mathrm{~min}$ and then immediately kept on ice for 2-3 min. In order to accelerate the bacterial growth, $250 \mu \mathrm{l}$ of SOC medium (Invitrogen) was added to the mixture and incubated at $37^{\circ} \mathrm{C}$, with shaking for $1 \mathrm{hr}$. The SOC medium with bacteria $(50-100 \mu \mathrm{l})$ was then plated on LB agar plates containing ampicillin $(100 \mu \mathrm{g} / \mathrm{ml})$ and incubated at $37^{\circ} \mathrm{C}$ for less than $16 \mathrm{hrs}$.

\subsubsection{Plasmid DNA preparation}

Colonies were picked from the LB-agar plates and cultured in $50 \mathrm{ml}$ polypropylene tubes (Falcon) containing $5 \mathrm{ml}$ of LB medium (Appendix) and $100 \mu \mathrm{g} / \mathrm{ml}$ ampicillin. The liquid culture was incubated at $37^{\circ} \mathrm{C}$ with shaking at $450 \mathrm{rpm}$ for 8 to $12 \mathrm{hrs}$ till an optical density (OD) of 0.6 was reached. Plasmid DNA was extracted and purified from DH5a cells as follows: $2 \mathrm{ml}$ of the liquid culture was transferred to $2 \mathrm{ml}$ reaction tubes (Eppendorf). Cells were pelleted by centrifugation at $14,000 \times \mathrm{g}$ for 30 seconds. The supernatant was decanted and the pellet was resuspended in $250 \mu \mathrm{l}$ buffer P1 (QIAGEN, Cat\#19051) by vortexing. $250 \mu \mathrm{l}$ of buffer P2 (QIAGEN, Cat\#19052) was added to the homogenous cell suspension to initiate cell lysis. The tubes were mixed well by gentle inversion for several times (without vortexing) and allowed to stand at room temperature for 5 minutes (or until the cell suspensions were clear). Lysis reaction was neutralized by the addition of $300 \mu \mathrm{l}$ buffer P3 (QIAGEN, Cat\#19053) followed by gentle inversion of the tubes. The tubes were kept on ice for 5 minutes and centrifuged at maximum speed $(20,000 \mathrm{xg})$ for 10 minutes. Supernatants containing plasmid DNA were then transferred to $1.5 \mathrm{ml}$ tubes. $600 \mu \mathrm{l}$ of isopropanol was added to each tube, mixed vigorously and kept at room temperature for 2 minutes to precipitate the plasmid DNA. The plasmid DNA was pelleted by centrifugation at maximum speed $(20,000 \times \mathrm{g})$ 
and $4^{\circ} \mathrm{C}$ for 20 minutes and supernatants were carefully aspirated. $400 \mu \mathrm{l}$ of $70 \%$ ethanol was added to each tube followed by gentle inversion to wash the DNA pellets. The DNA was pelleted by centrifugation at maximum speed $(20,000 \times \mathrm{g})$ and $4^{\circ} \mathrm{C}$ for 5 minutes and the supernatants were carefully removed.

\subsubsection{Restriction digestion of DNA}

The restriction analysis was performed with $1 \mu \mathrm{g}$ DNA in a total volume of $10 \mu \mathrm{l}$. The DNA sample was digested with restriction enzymes (AfllI/HindIII) in the prescribed buffer (NEB buffers) at the recommended temperature for 1-2 hrs. At the end of incubation, the single and/or double digested DNA samples and undigested controls were analyzed by agarose gel electrophoresis (100 ng/lane) and purified if necessary.

Reaction Mixture:

DNA

NEB buffer

BSA

Aflll enzyme $(20,000 \mathrm{U} / \mathrm{ml})$

Hindlll enzyme $(20,000 \mathrm{U} / \mathrm{ml})$

Sterile $\mathrm{H}_{2} \mathrm{O}$
$1 \mu \mathrm{l}$

$1 \mu \mathrm{l}$

$1 \mu l$

$0.3 \mu l$

$0.3 \mu \mathrm{l}$

$6.4 \mu \mathrm{l}$

\subsubsection{Polymerase chain reaction}

In order to amplify the genomic DNA or single stranded cDNA, polymerase chain reaction (PCR) was performed. For PCR amplification, Takara Ex Taq ${ }^{\circledR}$ DNA polymerase (Clonetech) was used. All amplifications were performed using a PCR cycler (Veriti® 96-well Thermal cycler; Applied Biosystems) under optimized conditions for each target sequence. PCR reactions were performed in sterile $0.2 \mathrm{ml}$ thin wall tubes as described below.

Sequences encoding for the pluripotency markers Oct3/4, Nanog, Sox-2 and Rex-1 as well as GAPDH as a house keeping gene were amplified. Primer sequences are given in the appendix 2.1 
4x Reaction-Master Mix:

10x ExTaq Buffer $\quad 5 \mu \mathrm{l}$

dNTP mix (2.5 mmol/L each) $\quad 4 \mu \mathrm{l}$

ExTaq polymerase $(5 \mathrm{U} / \mu \mathrm{l}) \quad 0.25 \mu \mathrm{l}$

Forward Primer $(10 \mu \mathrm{mol} / \mathrm{L}) \quad 1 \mu \mathrm{l}$

Reverse Primer $(10 \mu \mathrm{mol} / \mathrm{L}) \quad 1 \mu \mathrm{l}$

$\mathrm{dH}_{2} \mathrm{O}(36.75 \mu \mathrm{l})$ added up to $48 \mu \mathrm{l}$.

PCR conditions

1. Denaturation $1 \mathrm{~min} \quad 95^{\circ} \mathrm{C}$

2. Denaturation $15 \mathrm{sec} \quad 95^{\circ} \mathrm{C}$

3. Annealing $15 \mathrm{sec} \quad 60^{\circ} \mathrm{C}$

4. Elongation $30 \mathrm{sec} \quad 72^{\circ} \mathrm{C}$

5. Repeat step 2- 4 for 29-35 cycles

7. Hold at $4^{\circ} \mathrm{C}$ until further use

\subsubsection{DNA electrophoresis in agarose gels}

To analyze the PCR products, samples were electrophoretically separated according to their molecular size in $2 \%$ agarose gels. The agarose was boiled in a microwave for 2-3 min in $1 \times$ TAE buffer and after cooling to $\left(\sim 60^{\circ} \mathrm{C}\right) 2-3 \mu$ of ethidium bromide solution $(10 \mathrm{mg} / \mathrm{ml})$ per $100 \mathrm{ml}$ gel was added and poured in a gel casting plate. The amount of DNA loaded was as follows on a gel: $10 \mu \mathrm{l}$ of PCR reaction /lane, for plasmid after purification $100 \mathrm{ng} /$ lane, for the restriction digest $100 \mathrm{ng} /$ /ane. Migration of the DNA in the gel can be judged by visually monitoring the migration of the tracking dyes, that is bromophenol blue and xylene cyanol present in the DNA loading buffer. After adequate migration, DNA fragments were visualized on an ultraviolet transilluminator (due to the intercalation of the fluorescent dye ethidium bromide into the double strand of DNA, DNA becomes fluorescent) and photographed by a camera attached to a gel documentation system (GelDoc ${ }^{\mathrm{TM}} \mathrm{XR}$ imaging system, Biorad). In order to define the size of the DNA fragments, DNA size marker was also loaded on the gel. 


\subsubsection{Isolation of DNA fragments from agarose gels}

The linearized DNA fragments were eluted from the agarose gel using QIAquick gel extraction kit (QIAGEN) based on the manufacturer's protocol. After gel electrophoresis, the appropriate DNA fragment with proper size was carefully excised from the agarose gel with a clean, sharp blade. The excised gel was weighed in a $2 \mathrm{ml}$ reaction tube (Eppendorf) and $300 \mu \mathrm{l}$ of Buffer QG was added per $100 \mathrm{mg}$ of gel. The tubes were incubated at $50^{\circ} \mathrm{C}$ for 10 minutes. After the gel slice was completely dissolved, $100 \mu \mathrm{l}$ of isopropanol was added to the tube and mixed well by vortexing. The mixture was then transferred to a QIAquick spin column with a $2 \mathrm{ml}$ collection tube and spun at 13,000 $\mathrm{xg}$ for 1 minute. The flow-through was discarded. The column was washed with $0.5 \mathrm{ml}$ Buffer $Q G$ and centrifuged at 13,000 $\times \mathrm{g}$ for 1 minute. The flow-through was discarded and the column was washed with $0.75 \mathrm{ml} \mathrm{PE} \mathrm{Buffer.} \mathrm{After} \mathrm{centrifugation} \mathrm{at} 13,000 \times \mathrm{g}$ for 1 minute, the flow-through was discarded, and the centrifugation was repeated once to remove residual wash buffer. The column was placed into a clean $1.5 \mathrm{ml}$ tube and 50 $\mu \mathrm{l}$ Buffer EB was added to the center of the column. The tube was allowed to stand at room temperature for up to $4 \mathrm{~min}$ and the DNA was eluted from the column by centrifugation at $13,000 \times \mathrm{g}$ for 1 minute. The concentration of DNA was quantified using a spectrophotometer (Nanodrop, ND-1000, Thermo Scientific).

\subsubsection{Plasmid DNA preparation}

After the confirmation of purified plasmid DNAs, a large scale preparation (maxi prep) was carried out using the NucleoBond Xtra Maxi kit (Macherey-Nagel). $1 \mathrm{ml}$ of starter bacterial culture was mixed with $250 \mathrm{ml}$ LB medium (Appendix) containing $100 \mu \mathrm{g} / \mathrm{ml}$ ampicillin in a $1 \mathrm{~L}$ conical flask. The mixture was incubated on a shaker at $37^{\circ} \mathrm{C}$ overnight. The following steps were performed based on manufacturer's protocol for low-copy plasmid purification. $250 \mathrm{ml}$ of bacterial liquid culture was transferred into an ultracentrifuge tube and spun at $6,000 \times \mathrm{g}$ for 15 minutes at $4^{\circ} \mathrm{C}$. After discarding the supernatant, the cell pellet was completely resuspended in $24 \mathrm{ml}$ of Buffer RES+RNase A by pipetting the cells up and down. $24 \mathrm{ml}$ of Buffer LYS was added to the suspension and mixed thoroughly by gentle inversion until a homogeneous cell lysate was obtained. 
The cell lysate was then incubated at room temperature for 5 minutes. During the incubation period, a NucleoBond ${ }^{\circledR}$ Xtra Column together with the inserted column filter was equilibrated with $25 \mathrm{ml}$ of Buffer EQU. $24 \mathrm{ml}$ of Buffer NEU was added to the suspension and the cell lysate was mixed by gentle inversion. The cell lysate was then loaded into the equilibrated NucleoBond $\AA$ Xtra Column Filter. The column filter containing cell lysate was washed with $15 \mathrm{ml}$ of Buffer EQU. The column filter was discarded and $25 \mathrm{ml}$ of Buffer WASH was applied to the center of NucleoBond® Xtra Column. The plasmid DNA was eluted by the addition of $15 \mathrm{ml}$ of Buffer ELU and the eluate was collected in a $50 \mathrm{ml}$ centrifuge tube. The eluted plasmid DNA was then precipitated by adding $10.5 \mathrm{ml}$ of isopropanol at room temperature and mixed thoroughly using a vortex. The tube was centrifuged at $15,000 \mathrm{xg}$ for 30 minutes at $4^{\circ} \mathrm{C}$. After discarding the supernatant, the DNA pellet was washed with $70 \%$ ethanol at room temperature and centrifuged again at $15,000 \times \mathrm{g}$ for 30 minutes at $4^{\circ} \mathrm{C}$. The DNA pellet was allowed to air-dry at room temperature and reconstituted with appropriate volume of buffer TE. The resulting purified plasmid DNA was quantified by a spectrophotometer (Nanodrop, ND-1000, Thermo Scientific).

\subsubsection{PCR for microsatellite markers}

In order to analyze microsatellite marker D17Mit178 located on the chromosome 17 the double stranded genomic DNA from different non transgenic PSC-lines was isolated. PCR was performed to amplify the D17Mit178 locus (refer to appendix 2.1 for primer sequence information). For PCR amplification, Takara Ex Taq ${ }^{\circledR}$ DNA polymerase (Clonetech) was used. All amplifications were performed using PCR cycler (Veriti®96 well thermocycler, Applied Biosystems) under optimized conditions for each target sequence. PCR conditions are summarized below 
PCR conditions

1. Denaturation $15 \sec 95^{\circ} \mathrm{C}$

2. Annealing $15 \mathrm{sec} 60-56^{\circ} \mathrm{C}$

3. Elongation $20 \mathrm{sec} 72^{\circ} \mathrm{C}$

Repeat steps 1, 2 and 3 for 20 cylces

4. Denaturation $15 \mathrm{sec} 95^{\circ} \mathrm{C}$

5. Annealing $15 \sec 56^{\circ} \mathrm{C}$

6. Elongation $15 \mathrm{sec} 72^{\circ} \mathrm{C}$

Repeat steps 4 for 15 cycles

7. Hold at $4{ }^{\circ} \mathrm{C}$

After amplification the products were separated by electrophoresis and visualized after incubation with ethidium bromide.

\subsection{Cell culture techniques}

\subsubsection{Preparation of murine embryonic fibroblasts feeder cultures}

PSCs are usually grown on a layer of mitotically inactivated primary MEFs in the presence of leukemia inhibitory factor (LIF) to promote growth and prevent differentiation. Mouse embryos (NMRI strain) were harvested at day 13 post coitum (p.c., assuming day one is the first day the plug is observed) following timed pregnancies after euthanasia of the pregnant mouse by cervical dislocation. The heads and internal organs (liver, heart) were dissected prior to enzymatic dissociation in $0.25 \%$ trypsin to produce single cell suspensions. MEFs were expanded in MEF medium (Appendix 2) on $15 \mathrm{~cm}$ culture plates. After enzymatic dispersion (0.25\% trypsin) MEFs were suspended in cryopreservation medium $(1 \mathrm{ml})$, frozen and stored in liquid nitrogen. MEFs were mitotically inactivated prior to use as a feeder layer either by $\mathrm{y}$-irradiation (30 Gy) or mitomycin C treatment $(50 \mu \mathrm{g} / \mathrm{ml})$. We routinely used irradiated MEFs for PSC- maintenance.

A frozen vial of PO MEFs was thawed and plated in a $15 \mathrm{~cm}$ tissue culture plate with MEF medium. The cells were allowed to grow until confluent ( 3 to 5 days). Medium was 
changed after the first day and every other day thereafter. The cells were then passaged by trypsinization and resuspended in $10 \mathrm{ml}$ MEF medium followed by plating at a 1:10 dilution. Medium was added to a final volume of $25 \mathrm{ml}$ in $15 \mathrm{~cm}$ plate. The cells were allowed to grow until confluent ( 3 to 5 days) and passage at a 1:5 to 1:10 dilution, using twenty-five to fifty $150 \mathrm{~cm}$ cell culture plates. Medium from confluent plates was removed and the cells were rinsed with $15 \mathrm{ml} \mathrm{Ca}^{2+}$ and $\mathrm{Mg}^{2+}$ free PBS and overlayed with $0.25 \%$ trypsin. MEFs from ten to fifteen $15 \mathrm{~cm}$ cell culture plates were typically processed in parallel. The pellet was resuspended in $10 \mathrm{ml}$ MEF medium and transferred in suspension to a $50 \mathrm{ml}$ falcon tube at a concentration of 2 million cells per $\mathrm{ml}$. The cells were then exposed 2 times to 30Gy of $\mathrm{y}$-radiation (Biobeam 8000) for 15 min each. The number of cells was counted and either used freshly for PSC-culture by plating $\left(1 \times 10^{6} \mathrm{cell} / 10 \mathrm{~cm}\right.$ dish $)$ or frozen $\left(8 \times 10^{6}\right.$ cells $/$ vial $)$ for later use.

\subsubsection{Freezing and thawing of cells}

PSCs and MEFs were trypsinized, washed, centrifuged and resuspended in medium. The cell concentration was adjusted to $1-2 \times 10^{6}$ cells per $\mathrm{ml}$ and $0.5 \mathrm{ml}$ of this suspension was mixed with $0.5 \mathrm{ml}$ of cell freezing medium (Appendix 2 ) containing $80 \%$ FBS and $20 \%$ DMSO. Aliquots of cells $\left(1-2 \times 10^{6}\right.$ cells $\left./ 1 \mathrm{ml}\right)$ were frozen at $-80^{\circ} \mathrm{C}$ overnight and for long-term storage transferred to liquid nitrogen. For thawing, frozen cells were quickly transferred from liquid nitrogen into a $37^{\circ} \mathrm{C}$ water bath, thawed, washed with $10 \mathrm{ml}$ of pre-warmed medium and seeded on a dish coated with $0.1 \%$ gelatin or seeded with irradiated MEFs (see above) depending on the requirements of the experiment.

\subsubsection{Neomycin selectable parthenogenetic stem cell lines}

Approximately $5 \times 10^{6}$ PSC were resuspended in $800 \mu \mathrm{l}$ PBS. $20 \mu \mathrm{g}$ of a linearized plasmid encoding for a neomycin-resistance (NeoR) under control of a cardiomyocytesspecific $5.5 \mathrm{~kb}$ aMHC promoter fragment and a hygromycin resistance (Hygro R) under the control of ubiquitously active phosphoglycerate kinase (PGK) promoter (kindly provided by Prof. Loren J. Field, Indianapolis, USA) was diluted in $100 \mu \mathrm{l}$ of PBS and 
mixed with the cell suspension. The mixture was transferred into a GenePulser cuvette (0.4 cm electrode, gap 50). The cell and plasmid mix was incubated on ice for 20 minutes. Electroporation was then performed using GenePulser Electroporator (BioRad) at $300 \mathrm{~V}$ and $1200 \mu \mathrm{F}$, pulse $2 \mathrm{~ms}$. Immediately after electroporation the cell suspension was transferred to a $10 \mathrm{~cm}$ dish containing $10 \mathrm{ml}$ of stem cell medium with LIF and layered with irradiated MEFs prepared one day earlier. Selection of resistant colonies was started $48 \mathrm{hrs}$ later by addition of hygromycin at a concentration of $200 \mu \mathrm{g} / \mathrm{ml}$. Approximately 10 days later resistant colonies were obtained. 11 colonies were picked and sub cultured as separate clones. All clones were expanded and frozen in multiple vials. At least four positive clones (by PCR for NeoR gene) were chosen for the initial round of screening for cardiac differentiation. Clone-10 was randomly chosen and all the data shown in this study is from aMHC-Neo PSC clone 10.

\subsubsection{Characterization of parthenogenetic stem cell clones}

DNA was extracted from cultured cells using DNeasy Blood \& Tissue Kit (QIAGEN) following the manufacture's protocol. In brief, 1-2 × $10^{6}$ cells were collected and pelleted at $300 \mathrm{x} \mathrm{g}$ for 5 minutes. The cell pellet was resuspended with DPBS and cells were lysed with Buffer $\mathrm{AL}$ containing proteinase K. After incubating at $56^{\circ} \mathrm{C}$ for 10 minutes, DNA was precipitated by adding $96-100 \%$ ethanol and mixing thoroughly. Samples were transferred into DNeasy Mini spin columns and spun at $7000 \times \mathrm{g}$ for 1 minute to allow DNA to bind to the membrane of the columns. The columns were washed with Buffer AW1 and AW2 in sequence. Finally, DNA was eluted from the columns by adding Buffer AE. PCR reactions were carried out using GeneAmp ${ }^{\circledR}$ PCR System 9700 (Applied biosystems) and Takara Ex Taq ${ }^{\circledR}$ DNA polymerase (Clonetech). The primer sequences for detecting the transgene neoR are listed in appendix 2.1. PCR conditions are described below. PCR products were separated by electrophoresis in $1 \%$ agarose gels as described above 
Reaction Mixture:

dNTP $(2.5 \mathrm{mmol} / \mathrm{L}$ each $) \quad 1.6 \mu \mathrm{l}$

10x buffer

$2 \mu \mathrm{l}$

Forward primer $(10 \mathrm{mmol} / \mathrm{L}) \quad 0.2 \mu \mathrm{l}$

Reverse primer $(10 \mathrm{mmol} / \mathrm{L}) \quad 0.2 \mu \mathrm{l}$

Extaq polymerase $(5 \mathrm{U} / \mu \mathrm{l}) \quad 0.1 \mu \mathrm{l}$

DNA $(500 \mathrm{ng} / \mu \mathrm{l}) \quad 2 \mu \mathrm{l}$

Distilled water $\quad 13.9 \mu \mathrm{l}$

PCR Conditions:

1. Denaturation $30 \mathrm{sec} 94^{\circ} \mathrm{C}$

2. Denaturation $10 \mathrm{sec} 98^{\circ} \mathrm{C}$

3. Annealing $30 \mathrm{sec} 61^{\circ} \mathrm{C}$

4. Elongation $30 \mathrm{sec} 72^{\circ} \mathrm{C}$

5. Repeat steps 1-4 for 35 cycles

6. Elongation $5 \mathrm{~min} 72^{\circ} \mathrm{C}$ Hold at $4^{\circ} \mathrm{C}$

\subsubsection{Culture of parthenogenetic stem cells}

PSC-colonies were cultured on feeder layer cells (MEFs). At least one day before plating the PSC-colonies, $10 \mathrm{~cm}$ culture dishes (Nunclon ${ }^{\mathrm{TM}} \Delta$ ) were coated with $0.1 \%$ gelatin and incubated at $37^{\circ} \mathrm{C}$ in a humidified incubator with $5 \% \mathrm{CO}_{2}$ for 10 minutes. One million inactive MEFs were plated and cultured with MEF medium. Medium was changed after $24 \mathrm{hrs}$. The MEFs plates were kept at $37^{\circ} \mathrm{C}$ in a humidified incubator with $5 \% \mathrm{CO}_{2}$ one week before use. PSCs were suspended in stem cell medium (SC medium). $1 \times 10^{6}$ cells were plated on the MEFs dishes and cells were evenly distributed by swirling the dishes gently. Medium was changed daily. When the cell density reached $80 \%$ confluence, cells were split into fresh MEFs dishes at 1:3 or 1:6 ratio. Medium was aspirated and cells were washed with DPBS (without $\mathrm{Ca} / \mathrm{Mg}$ ) once. 3 $\mathrm{ml}$ of Trypsin/EDTA (0.25\%; Invitrogen) was added to a $10 \mathrm{~cm}$ dish and incubated at $37^{\circ} \mathrm{C}$ in a humidified incubator with $5 \% \mathrm{CO}_{2}$ for 3 minutes. Trypsin/EDTA was 
inactivated by adding $5 \mathrm{ml}$ of SC medium (Appendix 2). Single cell suspension was obtained by trituration. The single cell suspension was then transferred to a $15 \mathrm{ml}$ tube and pelleted at $300 \mathrm{xg}$ for 5 minutes. Supernatant was removed and the pellet was resuspended with $5 \mathrm{ml}$ fresh ES medium. Cell number was counted by CASY cell counter (Model TT, Roche Innovatis AG) and required number of cells (approx.1 million) was plated onto $10 \mathrm{~cm}$ fresh MEF dishes.

\subsubsection{Assessment of proliferation rate}

$5 \times 10^{4}$ undifferentiated PSC were plated on MEF-seeded culture dishes $\left(6 \mathrm{~cm}^{2}\right)$. Cells were isolated (triplicates) for every 12 hrs with Trypsin/EDTA $(0.25 \%)$. The cell number was determined using a CASY cell counter (Model TT, Roche Innovatis AG). The doubling time was calculated from the linear interval of the resultant growth curve.

DoublingTime $=$ duration $\times \log (2) / \log ($ Final cell count $)-\log ($ Initial cell count $)$

\subsubsection{Assessment of cardiac differentiation}

To evaluate the efficiency of cardiac differentiation, each PSC clone was differentiated in vitro in hanging drop embryoid body (EB) cultures. For this, cell colonies were dissociated into single cell suspensions by trypsinization as described before. The feeder layer cells (MEFs) were removed by preplating for 30 minutes. After preplating, the supernatant was collected in $50 \mathrm{ml}$ tubes and the number of cells was counted using a CASY cell counter (Model TT, Roche Innovatis AG). After cell counting, cell suspensions were diluted to 500 cells per $20 \mu$ of differentiation medium (Appendix 2). $20 \mu \mathrm{l}$ drops were placed on the lids of $15 \mathrm{~cm}$ culture dishes using a multichannel pipette and carefully inverted to cover the dishes. Each dish contained $15 \mathrm{ml}$ DPBS to prevent the drops from drying out. The $15 \mathrm{~cm}$ dishes were incubated at $37^{\circ} \mathrm{C}$ in a humidified incubator with $5 \% \mathrm{CO}_{2}$. After 3 days, EBs were collected by rinsing the lids with $10 \mathrm{ml}$ differentiation medium and transferred to $10 \mathrm{~cm}$ petri dishes for suspension culture for 2 more days. After suspension culture, EBs was plated onto $10 \mathrm{~cm}$ cell culture dishes coated with $0.1 \%$ gelatin for adhesion culture. On day 11 ( 11 days after the initiation of hanging drops), $200 \mu \mathrm{g} / \mathrm{ml}$ of geneticin (G-418, PAA) was added into the differentiation 
medium to select for cardiomyocytes. The differentiation and selection were terminated on day 18. The morphology of the EBs and beating activities were observed daily throughout the period of differentiation. The clone with highest beating activity (aMHCNeo PSC clone 10) compared with other clones was chosen for further experiments.

\subsubsection{Differentiation in spinner flask cultures}

To enhance the culture process, spinner flask cultures were implemented. PSCs were cultured and passaged as described before. Before initiating differentiation, cells were passaged at least two times. PSC colonies were dissociated into single cells by trypsinization as described before. After preplating for 30 minutes to reduce the MEF content, cell suspensions were collected in $50 \mathrm{ml}$ tubes and cell number was counted. 10 million cells were transferred to another $50 \mathrm{ml}$ tube and pelleted by centrifugation at $300 \times \mathrm{g}$ and $4^{\circ} \mathrm{C}$ for 5 minutes. After centrifugation, the supernatant was removed and the pellet was resuspended with $25 \mathrm{ml}$ differentiation medium. The cell suspension was then transferred into a $125 \mathrm{ml}$ culture vessel (Techne, F7988) containing $25 \mathrm{ml}$ of differentiation medium. The stirring speed was set to $60 \mathrm{rpm}$ (day 0 ). On the next day (day 1), $50 \mathrm{ml}$ of differentiation medium was added into the culture vessel. Half of the medium was replaced every other day. On day $11,200 \mu \mathrm{g} / \mathrm{ml}$ of geneticin (G-418, PAA) was added to the medium for the selection of cardiomyocytes. After 7 days of selection, EBs were harvested and digested into single cardiomyocytes for further experiments.

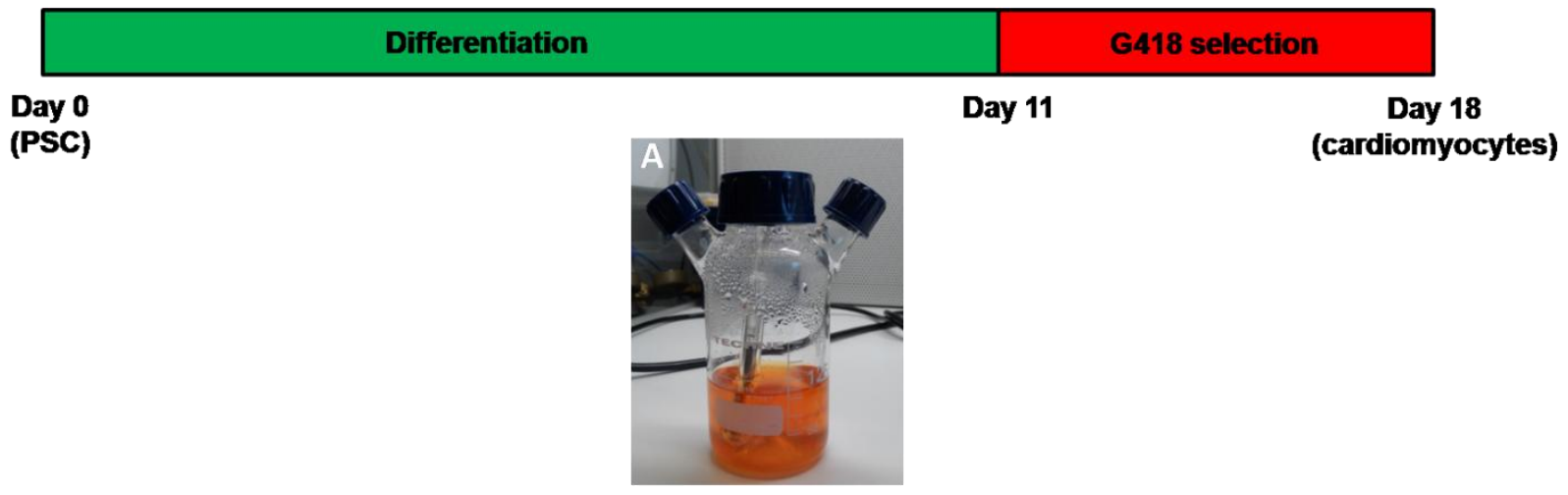

Figure 7: Schematic overview of PSC differentiation in spinner flasks. A. Stirred suspension culture in a spinner flask is depicted below. 


\subsubsection{Assessment of contractility in embryoid bodies}

EBs formed after 3 days of culture in spinner flasks were transferred into gelatin coated 48 well plates at a concentration of one EB per well. The number of beating EBs was counted in each well every alternate day (days 5, 7, 9,11,13,15 and 17).

\subsubsection{Dissociation of embryoid bodies}

EBs were collected from the culture vessel and transferred into two $50 \mathrm{ml}$ polypropylene tubes (Falcon). The tubes were placed upright for 5 minutes to allow EBs to sediment. The supernatant was aspirated and EBs were washed with $20 \mathrm{ml}$ of DPBS and resuspended with $6 \mathrm{ml}$ of collagenase I (Sigma) containing $20 \mu \mathrm{l} / \mathrm{ml}$ DNase I (Calbiochem). The tubes were incubated at $37^{\circ} \mathrm{C}$ for 1 hour in a warm chamber with shaking. $20 \mathrm{ml}$ of DPBS (w/o Ca ${ }^{2+} / \mathrm{Mg}^{2+}$ ) was added and single cells were obtained by triturating with a $10 \mathrm{ml}$ pipette few times. The cells were pelleted by centrifugation at $200 \times \mathrm{g}$ for 5 minutes at room temperature. For further digestion, the pellet was

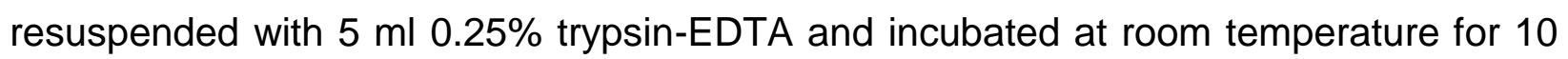
minutes. The trypsin suspension was gently triturated with $5 \mathrm{ml}$ pipette to yield single cell suspensions. The enzyme digestion was neutralized with $20 \mathrm{ml}$ differentiation medium containing $20 \mu \mathrm{l} / \mathrm{ml}$ DNase and then triturated further using a $10 \mathrm{ml}$ pipette. The cells were pelleted by centrifugation at $200 \times \mathrm{g}$ for 5 minutes at $4^{\circ} \mathrm{C}$. After resuspension in $10 \mathrm{ml}$ differentiation medium, the suspension was passed through a $70 \mu \mathrm{m}$ cell strainer to remove cell clumps. Number of cells was then counted by staining with trypan blue dye solution on a Neubauer counting chamber.

\subsubsection{Preparation of engineered heart muscle}

Self-made glass culture dishes consisting of 4 ring-shape molds (inner/outer diameter: 4 $/ 10.6 \mathrm{~mm}$ ) were used for casting the EHMs (Figure $8 \mathrm{~A}$ ). The volume inside each mold was $450 \mu \mathrm{l}$. All the pipetting steps were carried out on ice to prevent premature polymerization of the EHM reconstitution mixture. $1.5 \times 10^{6}$ cell mixture containing $70 \%$ of PSC-derived cardiomyocytes and 30\% non-cardiomyocytes (inactivated MEFs) were mixed and resuspended with appropriate volume of differentiation medium. An equal 
amount of $2 \mathrm{X}$ DMEM was added to collagen type I dissolved in $0.1 \%$ acetic acid (rat tail collagen). The $\mathrm{pH}$ was adjusted to ( 7.4) with $0.1 \mathrm{~N} \mathrm{NaOH}$. Finally, the proper amount of cell suspension was added into the mixture. A standard pipette scheme for generating four EHMs is given below. Homogeneity of cell-collagen mixtures was achieved by careful trituration with a pre-cooled $2 \mathrm{ml}$ pipette. $450 \mu \mathrm{l}$ of mixture was cast into each mold and incubated at $37^{\circ} \mathrm{C}$ in a humidified incubator with $5 \% \mathrm{CO}_{2}$ for one hour. After initial condensation of the collagen, $6 \mathrm{ml}$ of differentiation medium was added into each glass culture dish.

The EHMs were incubated at $37^{\circ} \mathrm{C}$ in a humidified incubator with $5 \% \mathrm{CO}_{2}$ for three days. On day 3, EHMs were transferred to static stretchers (Figure 8B) and kept in culture for 10 more days. Medium was changed every other day during the entire culture time.

\section{Pipette Scheme for preparation of 4 EHMs}
1. Collagen $(0.4 \mathrm{mg} / \mathrm{ml})$
$419 \mu \mathrm{l}$
2. $2 X$ DMEM
$419 \mu \mathrm{l}$
3. $\mathrm{NaOH}(0.1 \mathrm{~N})$
$82 \mu \mathrm{l}$
4. Cell Suspension
$1180 \mu \mathrm{l}$

\section{Composition of 2X DMEM:}

$\begin{array}{ll}\text { FCS (PAA-102) } & 40 \% \\ \text { 10X DMEM } & 20 \% \\ \text { P/S (100 units/ } 100 \mu \mathrm{g} / \mathrm{ml}) & 2 \%\end{array}$

Adjusted to the final volume with distilled water 
A

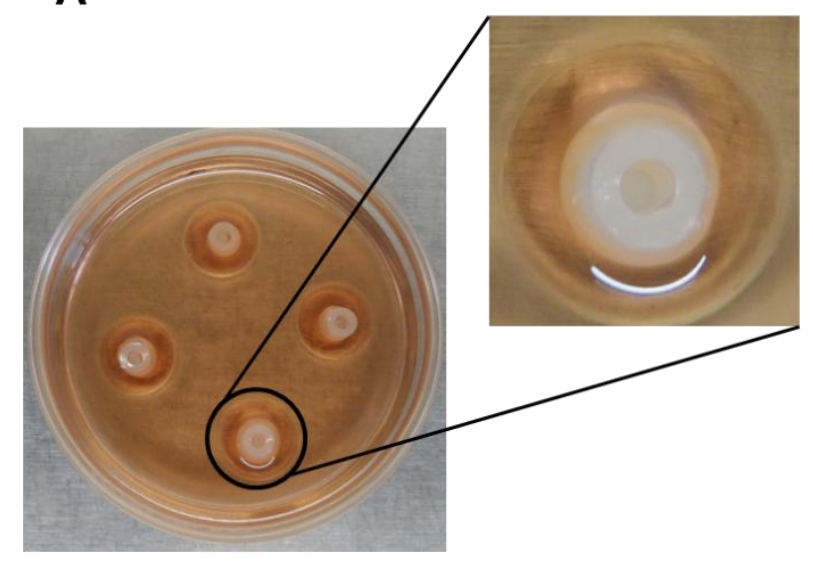

B

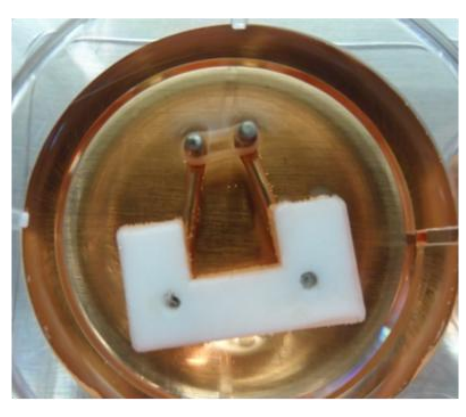

C

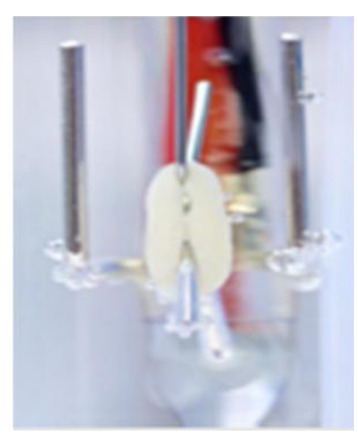

Figure 8: Preparation of EHM. A. 3 days of culture in casting molds B. EHMs transferred onto a static stretcher and cultured for 7 days C. EHM subjected to isometric force measurement in an organ bath.

\subsubsection{Isometric contraction measurements}

On day 10 12, EHMs were suspended between retaining hooks and force transducers inside organ baths containing Tyrode's solution (Appendix 2) (Figure 8C). The temperature in the organ baths was maintained at $37^{\circ} \mathrm{C}$ and the $\mathrm{pH}$ was adjusted to 7.4 with carbogen $\left(95 \% \mathrm{O}_{2}, 5 \% \mathrm{CO}_{2}\right.$ gas mixture). After 15 minutes of equilibration, EHMs were electrically stimulated at $4 \mathrm{~Hz}$ with pulse duration of $5 \mathrm{~ms}$ and $200 \mathrm{~mA}$ current. EHMs were pre-stretched under $1.8 \mathrm{mM}\left[\mathrm{Ca}^{2+}\right]$ till the force reached a stable maximal level (Lmax) according to Frank-Starling mechanism. The solution inside the organ baths was replaced with fresh Tyrode's solution containing $0.2 \mathrm{mmol} / \mathrm{L}\left[\mathrm{Ca}^{2+}\right]$. Contraction forces were initially measured under cumulatively increasing $\left[\mathrm{Ca}^{2+}\right](0.2-2.8$ $\mathrm{mmol} / \mathrm{L}$ ). Contractile force was recorded at steady state i.e. typically 5 minutes after addition of calcium. The maximum and minimum forces were measured by PC-based acquisition software (BMON, Engineering firm G. Jaeckel, Hanau). Force of contraction (FOC) was calculated by the difference between maximum (peak systolic force) and minimum (diastolic) forces. 


\subsubsection{Flow cytometry analysis}

Single cells were prepared as described above by trypsinization. The dissociated cells were centrifuged, washed and filtered through a $40 \mu \mathrm{m}$ cell strainer (BD Pharmingen).

\subsubsection{Live cell staining}

Cell count was determined using a CASY cell counter (Model TT, Roche Innovatis AG) before suspension in an appropriate volume of staining buffer (PBS supplemented with $5 \%$ FBS) to obtain a cell density of $0.5 \times 10^{6}$ cell/ $50 \mu \mathrm{l}$. Cells were then dispensed into FACS tubes and stained either with isotype control or antigen-specific antibodies diluted in the staining buffer. Cell-surface antigen expression was detected using fluorescently conjugated antigen-specific antibodies (direct staining) or labeling the cells with unconjugated primary antibody followed by fluorescently-tagged secondary antibody (indirect staining) by incubating at $4^{\circ} \mathrm{C}$ for 30 minutes (Appendix 2.2). The cells were washed two times with 1X PBS. Unstained samples were used as a negative control. The cell suspension was measured and data was acquired on flow cytometer (BD LSRII flow cytometer, FACSDiva software, BD Biosciences). Cells were gated on forward and side scatter dot plots. 10,000 events per sample were acquired and the data were analyzed with flowing software (free software version 2.5.1). Hoechst (BD biosciences) or sytox (life technologies) was used for gating of viable cells.

\subsubsection{Fixed cell staining}

Cells were counted and fixed in methanol stabilized $4 \%$ formaldehyde (Histofix) for 20 minutes at room temperature. Supernatant was discarded after centrifugation at $300 \times \mathrm{g}$ for 5 minutes and washed with 1X PBS once. Cells were then transferred to FACS tubes and incubated in blocking buffer (5\% FBS, 1\%BSA, 0.5\% Triton X-100 in PBS) for 10 minutes on ice. After incubation cells were centrifuged and the supernatant was drained by inversion of the tubes. Antibody solutions were prepared by diluting them in blocking buffer. Cells were incubated with primary antibody for 45 minutes followed by washing with blocking buffer for two times. Secondary antibody solution was then added and incubated for 30 minutes at room temperature in dark. The cells were than washed 
twice with blocking buffer and finally resuspended in $0.5 \mathrm{ml}$ of PBS and proceeded for flow cytometry analysis. Cells were gated on forward and side scatter dot plots. 10,000 events per sample were acquired and the data were analyzed with flowing software (version 2.5.1). Hoechst (BD biosciences) or sytox (life technologies) was used for gating cell viability.

\subsubsection{Flow cytometry of immunological molecules}

Approximately $5 \mathrm{ml}$ of the EB containing suspensions from spinner flask cultures were collected and seeded into a $10 \mathrm{~cm}$ bacterial suspension culture dish. EBs was collected before initiating the selection for cardiomyocytes. After selection with G-418, cardiac bodies were collected from the spinner flask and transferred into $10 \mathrm{~cm}$ bacterial suspension culture dish. Mouse recombinant interferon gamma (IFNy; peprotech) was added to unselected EBs and cardiac bodies at a concentration of $25 \mathrm{ng} / \mathrm{ml}$ and incubated at $37^{\circ} \mathrm{C}$ in a humidified incubator with $5 \% \mathrm{CO}_{2}$ for $48 \mathrm{hrs}$. After $48 \mathrm{hrs}$ these embryoid and cardiac bodies were dissociated as mentioned above and stained for the expression of MHC-I (H-2 ${ }^{\mathrm{Kd}}$ ) (Biolegend), MHC-II (I-A/I-E) (BDbiosciences),CD1d (Biolegend), CD40 (Biolegend), CD80 (Biolegend), CD86 (Biolegend), PD-L1 (Biolegend), PD-1 (Biolegend).Staining was done according to the protocol mentioned above. After staining the cells were analyzed by flow cytometry.

\subsubsection{Isolation of neonatal mouse cardiomyocytes}

Cardiomyocytes from DBA neonatal mice expressing GFP under alpha Myosin Heavy Chain (MHC) promoter were isolated by using then neonatal heart dissociation kit (mouse and rat, Miltenyi Biotec 130-098-373). Briefly 10-20 neonatal mouse hearts were harvested and transferred into a $10 \mathrm{~cm}$ dish containing PBS. Using forceps, remaining blood was pumped out. The blood vessels and remaining connective tissue were cut away from the ventricles. Enzyme mix 1 (enzyme P- $62.5 \mu \mathrm{l}$ ) and (buffer X$2,300 \mu \mathrm{l}$ ) was pre-heated for 5 minutes at $37^{\circ} \mathrm{C}$. 2,363 $\mu \mathrm{l}$ of enzyme mix 1 was added to $138 \mu \mathrm{l}$ of enzyme mix 2 (buffer Y- $25 \mu \mathrm{l}$, enzyme A- $12.5 \mu \mathrm{l}$ and enzyme D- $100 \mu \mathrm{l}$ ). The harvested tissue was transferred in to a gentle MACS C tube, $2.5 \mathrm{ml}$ of the enzyme mix 
was added and the lid of the "C-tube" was tightly closed. The "C-tube" was inverted and incubated at $37^{\circ} \mathrm{C}$ for 15 minutes. The "C-tube" was then attached onto the sleeve of the gentle MACS dissociator and gentle MACS program h_tumor_1 was run. This was repeated for two times and after termination of the gentle MACS program, the "C-tube" was detached and $7.5 \mathrm{ml}$ of differentiation medium was added. Cell suspension was resuspended and filtered through a $70 \mu \mathrm{m}$ cell strainer. The cells were than centrifuged at $600 \mathrm{xg}$ for 5 minutes and the supernatant was discarded. The cell pellet was resuspended in $10 \mathrm{ml}$ of differentiation medium and incubated on a gelatin coated 10 $\mathrm{cm}$ dish for 1 hour at $37^{\circ} \mathrm{C}$ in a humidified incubator with $5 \% \mathrm{CO}_{2}$. After one hour, the supernatant was collected and centrifuged at $300 \times \mathrm{g}$ for 5 minutes. The pellet was resuspended in $5 \mathrm{ml}$ of differentiation medium and the cells were counted in Neubauer chamber. The purity of cardiomyocytes was measured by flow cytometry.

\subsubsection{Isolation of cardiomyocytes by the Langendorff method}

For immunostainings of cardiomyocytes from adult mouse heart, cells were isolated from DBA mice by retrograde perfusion of the heart through the aorta with enzyme (Liberase/Trypsin) solution according to Langendorff. A $21 \mathrm{G}$ cannula connected to a peristaltic pump set was used to ensure constant perfusion at $3 \mathrm{ml} / \mathrm{min}$. All perfusion solutions (Appendix 2) were pre-warmed to $37^{\circ} \mathrm{C}$ for optimal digestion.

The Liberase concentration was adjusted to $0.021-0.042 \mathrm{mg} / \mathrm{ml}$ according to the mouse heart size and activity of the liberase batch. Prior to heart isolation, mice were heparinized (10 mg/kg), anesthetized (isoflurane) and sacrificed by cervical dislocation, the heart was removed quickly and mounted via the aorta onto the cannula, fastened (2 thread loops around the cannula) and perfused. After 3 minutes, the perfusion buffer was changed to a digestion buffer and perfused until the buffer was used up. The heart was demounted and transferred into the beaker with the $2.5 \mathrm{ml}$ digestion buffer. The atria were removed, and the heart was mechanically minced for 30 seconds using small scissors. To inhibit the enzymatic digestion, $2.5 \mathrm{ml}$ stopping buffer 1 were added. To further dissociate the remaining pieces of tissue by shearing force, the suspension was pulled up and down using a $1 \mathrm{ml}$ insulin syringe without a needle for 3 minutes. The 
suspension was filtered through a $150 \mu \mathrm{m}$ cell-culture mesh and the cells were sedimented for 5 minutes at room temperature. The cell pellet was resuspended in stopping buffer 2 .

Calcium concentration was slowly increased to $1 \mathrm{mmol} / \mathrm{L}$ by adding $50 \mu \mathrm{l}$ of $10 \mathrm{mmol} / \mathrm{L}$ calcium chloride solution twice, $100 \mu \mathrm{l}$ of $10 \mathrm{mmol} / \mathrm{L}$ calcium chloride solution, 30 and 50 $\mu \mathrm{l}$ of $100 \mathrm{mmol} / \mathrm{L}$ calcium chloride solution. The cardiomyocytes were left to equilibrate for 4 minutes at each step. Following calcium adaptation, cells were incubated at $37^{\circ} \mathrm{C}$ for 15 minutes to sediment the cardiomyocytes. After removal of most of the supernatant, cardiomyocytes were carefully resuspended in the remaining supernatant $(\sim 1 \mathrm{ml})$, and $50 \mu \mathrm{l}$ cell suspension was seeded on laminin-coated $(10 \mu \mathrm{g} / \mathrm{ml})$ coverslips. Next, cells were left to settle down and adhere to the laminin-coated coverslips for at least 45 minutes, before cell culture medium was added. Cells were cultured at $37^{\circ} \mathrm{C}$ and $5 \% \mathrm{CO}_{2}$ for $24 \mathrm{hrs}$ with and without IFNy $(20 \mathrm{ng} / \mathrm{ml})$ followed by a staining for $\beta-2-$ microglobulin.

\subsubsection{Immunofluorescence imaging}

Cardiomyocytes seeded on coverslips were fixed with acid free $(\mathrm{pH} 7)$, phosphatebuffered formaldehyde (4\%) solution (Histofix, Roth) for 10 minutes at room temperature, followed by washing with DPBS. The cells were permeabilized and the unspecific binding sites were saturated by incubating with blocking buffer containing $5 \%$ FBS (Gibco), 1\% bovine serum albumin (BSA, Sigma) and 0.5\% TritonX-100 (AppliCehm) in DPBS for 30 minutes at room temperature. The cells were incubated with primary antibodies developed to bind $\alpha$-actinin (Sigma), cardiac-troponin I (abcam), $\beta$ 2-microglobulin (abcam) for 60 minutes at room temperature (Appendix 2.2). Subsequently incubation with secondary antibody conjugated with fluorescent dye (antimouse Alexa Fluor ${ }^{\circledR}$ 546, anti-rabbit Alexa Fluor ${ }^{\circledR}$ 488, anti-mouse Alexa Fluor ${ }^{\circledR} 633$ Molecular Probe $\AA$ ) was performed for 60 minutes at room temperature. Nuclei were counterstained with 4', 6'-diamidino-2-phenylindole (DAPI; $1 \mu \mathrm{g} / \mathrm{ml}, 1: 1000$, Sigma). Samples were washed thoroughly with blocking buffer 3 times for 5 minutes with a final wash with only DPBS for 5 minutes. A drop of mounting medium (Fluoromount-G, 
SoutherBiotech) was put on the slide and the cover slip containing the cells was inverted over the medium carefully to prevent the trapping of air pockets within the sample. The slides were allowed to dry and then imaged. Fluorescent images were acquired using laser scanning confocal microscope (LSM710, Zeiss, Germany).

\subsection{Immunological techniques}

\subsubsection{Isolation of mouse splenocytes}

Mice (BL6-J and DBA2J) were sacrificed by cervical dislocation and then dissected under sterile conditions. Spleens were collected in a dish containing 1X PBS, a $70 \mu \mathrm{m}$ filter was placed into $50 \mathrm{ml}$ polypropylene tube and rinsed with RPMI medium. The spleen was then transferred on the filter. With the help of piston of a $5 \mathrm{ml}$ syringe the spleen was pressed against the filter to dissociate the cells and continuously rinsed with medium.

RBC lysis was done by incubating the splenocytes with 1X RBC lysis buffer (Biolegend) for $5 \mathrm{~min}$ at room temperature. The remaining splenocytes were then washed and resuspended in 10\% RPMI and counted in a Neubauer chamber. These splenocytes were used for the co- culture with PSC-derived cells.

\subsubsection{Immune cell proliferation assay}

The influence of PSC-derived cells on the activation or proliferation of splenocytes and T-lymphocytes was analyzed using a co-culture approach. $1 \times 10^{5}$ PSC-derived cells, in the form of EBs were transferred into suspension culture 48-well cell culture plates. Splenocytes were washed with PBS twice to remove serum. The cells were than resuspended at double the desired final concentration in PBS (pre-warmed to room temperature). $10 \mu \mathrm{mol} / \mathrm{L}$ solution of Cell Proliferation Dye eFluor ${ }^{\circledR} 670$ (ebioscience) in PBS (pre-warmed to room temperature) was prepared. This was mixed with the $2 \mathrm{X}$ cell suspension at $1: 1$ ratio and incubated for 10 minutes at $37^{\circ} \mathrm{C}$ in the dark. The eFluor ${ }^{\circledR}$ 670 dye (Appendix 2) labeling was stopped by adding 4-5 volumes of cold $10 \%$ RPMI 
and incubated on ice for 5 minutes. The cells were then washed 3 times with $10 \%$ RPMI.

$1 \times 10^{6}$ eFluor ${ }^{\circledR} 670$ labeled splenocytes were then added to $1 \times 10^{5}$ PSC-derived cells (non-myocytes/cardiomyocytes; NM/CM) and cultured for 4 days with 10\% RPMI at 37 ${ }^{\circ} \mathrm{C}$ and $5 \% \mathrm{CO}_{2}$. We used two different conditions: PSC-derivatives co cultured with DBA splenocytes (MHC-match for $\mathrm{H}-2^{\mathrm{d} / \mathrm{d}}$ locus) and PSC-derivatives co cultured with BL6 splenocytes ( $\mathrm{H}-2^{\mathrm{b} / \mathrm{b}}$, MHC-mismatch). Labeled splenocytes treated with $5 \mu \mathrm{g} / \mathrm{mL}$ concanavalin A (Con.A) served as positive control. Unlabelled splenocytes treated with Con.A served as negative control. Similarly EHMs made with PSC-CM $\left(\mathrm{H}-2^{\mathrm{d} / \mathrm{d}}\right)$ and DBA $\operatorname{MEF}\left(\mathrm{H}-2^{\mathrm{d} / \mathrm{d}}\right)$ were incubated with DBA $\left(\mathrm{H}-2^{\mathrm{d} / \mathrm{d}}\right)$ and BL6 $\left(\mathrm{H}-2^{\mathrm{b} / \mathrm{b}}\right)$ labeled splenocytes for 4 days on a shaker with RPMI medium (Appendix 2) at $37^{\circ} \mathrm{C}$ and $5 \% \mathrm{CO}_{2}$. Also EHMs made with PSC-CM $\left(\mathrm{H}-2^{\mathrm{d} / \mathrm{d}}\right)$ and BL6-MEF $\left(\mathrm{H}-2^{\mathrm{b} / \mathrm{b}}\right)$ were treated with DBA $\left(\mathrm{H}-2^{\mathrm{d} / \mathrm{d}}\right)$ and BL6 $\left(\mathrm{H}-2^{\mathrm{b} / \mathrm{b}}\right)$ splenocytes in the same way. A typical experimental set up is shown in Figure 9.

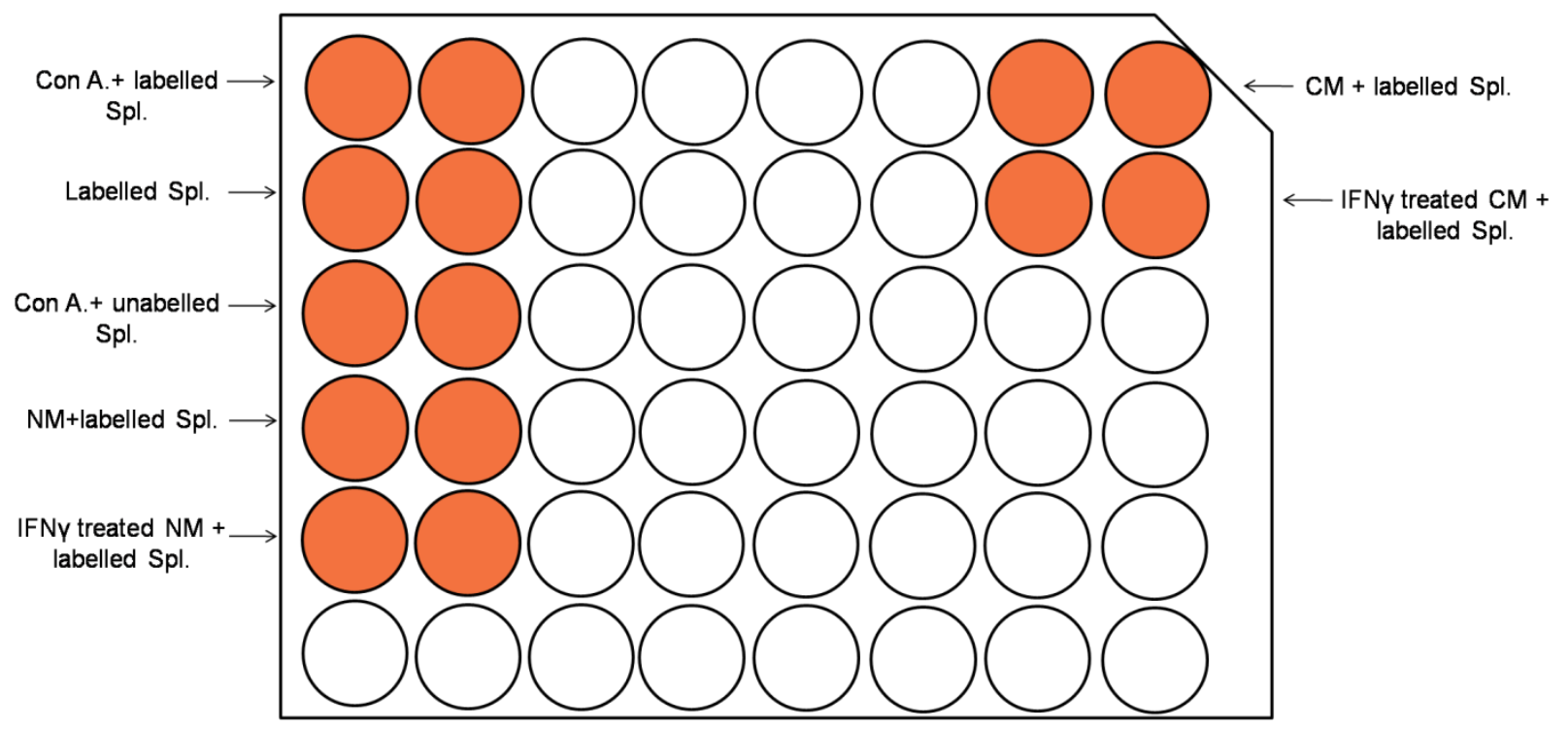

Figure 9: Experimental setup for in vitro proliferation assay. Different conditions were tested in a 48 well plate. Con.A: concanavalin A, NM: non-myocytes, CM: cardiommyocytes, Spl: splenocytes.

After 4 days of co-culture splenocytes were collected and filtered through $70 \mu \mathrm{m}$ cell strainer to remove the EBs. The strained splenocytes were than stained with Alexa 488 
labelled CD3 (Biolegend) and the proliferation of CD3 positive splenocytes was analyzed using flow cytometry.

\subsubsection{Isolation of T-lymphocytes from spleen}

Splenocytes were isolated from spleen as mentioned above. T-lymphocytes were isolated from splenocytes by using the mouse Pan T cell isolation kit II (Miltenyi biotec 130-095-130). $10^{7}$ splenocytes were resuspended in $40 \mu$ of buffer(containing PBS, pH 7.2, $0.5 \% \mathrm{BSA}$, and $2 \mathrm{mmol} / \mathrm{L}$ EDTA). $10 \mu \mathrm{l}$ of Biotin-Antibody Cocktail (Cocktail of biotin-conjugated monoclonal antibodies against CD11b, CD11c, CD19, CD45R [B220], CD49b [DX5], CD105, Anti-MHC class II, and Ter-119) was added to $10^{7}$ total cells. The cell suspension was mixed well and incubated for 5 minutes in the refrigerator $\left(4^{\circ} \mathrm{C}\right)$ followed by the addition of $30 \mu \mathrm{l}$ of buffer per $10^{7}$ total cells. Finally 20 $\mu \mathrm{l}$ of anti-biotin microbeads per $10^{7}$ total cells was added and mixed well. This cell suspension was incubated for 10 minutes at $4^{\circ} \mathrm{C}$ followed by magnetic separation on LS columns mounted on a quadro MACS separator (Miltenyi Biotec). A minimum of $500 \mu \mathrm{l}$ cell suspension was added to LS columns, the flow-through containing unlabeled cells was collected, representing the enriched T-cells. The column was washed with $3 \mathrm{ml}$ of buffer and the pass through was collected representing the enriched T-cells. The cells were counted using a Neubauer chamber. T-cell purity was measured by flow cytometry.

\subsubsection{In vitro cytotoxicity assay}

To assess cytotoxic effects of T-cells cardiomyocytes were obtained from the spinner flask cultures dissociated as mentioned above, and seeded on gelatin coated 96 well plates at a concentration of $10^{5}$ cells per well. T-lymphocytes were isolated from the spleens of BL6-J and DBA2J mice as mentioned above and added to the cardiomyocytes at a concentration of $10^{6}$ cells per well (CM: T-cells ratio, 1:10). The coculture was incubated at $37^{\circ} \mathrm{C}$ and $5 \% \mathrm{CO}_{2}$ for $4 \mathrm{hrs}$ and proceeded with the measurement of cell lysis by using the cytotox $96^{\circledR}$ non-radioactive cytotoxixity assay kit (promega). 
Briefly $100 \mu \mathrm{l}$ of $10 \%$ RPMI medium was added to all the wells of a 96 well plate. For maximum lysis, $10 \mu \mathrm{l}$ of lysis solution per $100 \mu \mathrm{l}$ of medium was added and incubated at $37^{\circ} \mathrm{C}$ for 45 minutes. The plate was than centrifuged at $250 \mathrm{xg}$ for 4 minutes. Then 50

$\mu \mathrm{l}$ of supernatant from all wells was transferred into a fresh 96-well flat-bottom (enzymatic assay) plate followed by the addition of $50 \mu \mathrm{l}$ of substrate mix to each well of the enzymatic assay plate. The plate was then covered with foil or an opaque box to protect it from light and incubated for 30 minutes at room temperature. Finally $50 \mu \mathrm{l}$ of stop solution was added to each well and the absorbance was recorded at $490 \mathrm{~nm}$ or $492 \mathrm{~nm}$ with the help of 96 well plate reader (Flexstation 3, molecular devices).

Percent cytotoxicity was measured by using the following formula:

$\%$ Cytotoxicity $=$ Experimental - Effector Spontaneous - Target Spontaneous $\times 100$

Target Maximum - Target Spontaneous

The average absorbance values of the culture medium background were subtracted from the average absorbance values of experimental, target spontaneous and effector spontaneous. Similarly the average absorbance values of volume correction control were subtracted from average absorbance values of target maximum.

\subsection{Animal experiments}

All the animal experiments were performed according to institutional and governmental guidelines. Animal studies were approved by the Niedersächsisches Landesamt für Verbraucherschutz und Lebensmittelsicherheit (LAVES; G15.1841).

\subsubsection{Cell implantation under the kidney capsule}

PSC-derived EBs and cardiac bodies were implanted under the kidney capsule (right kidney) of B6D2F1 mice and BL6-J mice (8-15 weeks age; Figure 10). The implantation was performed under isoflurane (3\%) anesthesia. A vertical incision was made through the skin along the animal's spine, about $2 \mathrm{~cm}$ from the base of the tail to the top curve of the spine. The kidney was accessed via a deeper $0.5 \mathrm{~cm}$ horizontal incision. With the 
aid of curved blunt glass pastuer pipette the kidney was pulled out gently and a small tear was made in the kidney capsule with the help of sharp needle. EBs and cardiac bodies were gently placed under the capsule via a blunt $21 \mathrm{G}$ cannula. The tear of the kidney capsule was then cauterized and the kidney was carefully relocated retroperitoneally. The incision closed with a 6-0 Prolene ${ }^{\circledR}$ (Ethicon) suture followed by suturing the skin. Upon completion of the surgery, the animal was placed on a warm heating pad, to aid in regaining its body temperature. For analgesia, buprenorphine $(0.05-0.1 \mathrm{mg} / \mathrm{kg})$ was administered subcutaneously in the right flank.

The kidneys were harvested from the mice at different time points of days $1,3,7,14$, and 28 followed by microscopic (Zeiss, Lumar.V12, SteREO) search for beating cardiac bodies and proceeded further for histological analysis. The kidneys were divided into two halves; one half was used for H\&E staining and the other half for immunofluorescence staining of $\alpha$-actinin and CD3.
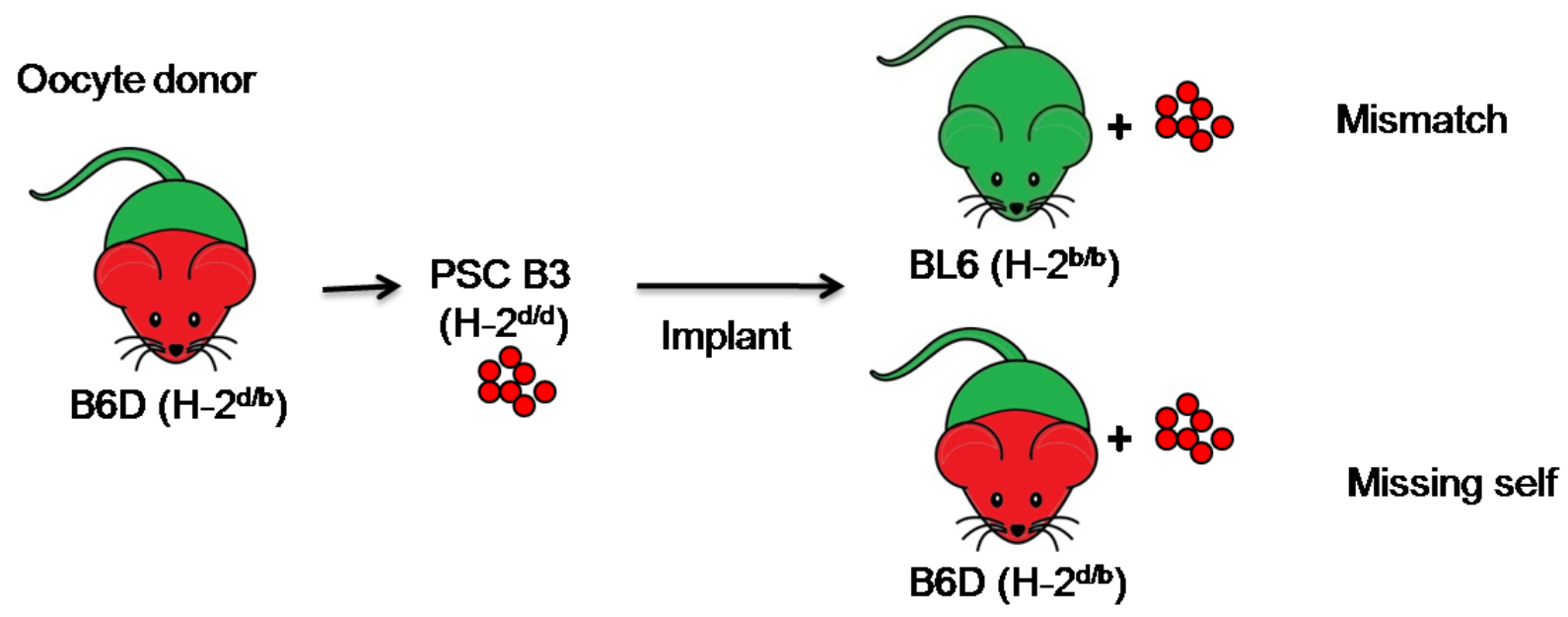

Figure 10: Schematic overview of implantation experiments. $\mathrm{H}-2$ homozygous PSCs obtained from B6D2F1 mice were used for implantation in MHC-match (B6D2F1) and mismatch (BL6) conditions.

\subsubsection{Histological analysis}

Explanted kidneys from the mice were fixed in $4 \%$ formaldehyde (in PBS) overnight at $4^{\circ} \mathrm{C}$. Half of each kidney was paraffin-embedded, and sectioned using Leica RM 2165 microtome (Leica). For hematoxylin-eosin (H\&E) staining, tissue slides were 
deparaffinized and rehydrated by performing 9 washing steps (2X xylene for 20 minutes, $100 \%$ ethanol, $90 \%$ ethanol, $80 \%$ ethanol, $65 \%$ ethanol, $50 \%$ ethanol, $25 \%$ ethanol, tap water; incubation for 5 minutes each). Kidney sections were stained three times with hematoxylin and twice with eosin for 2 minutes each at the Department of Pathology, University Medical Center, Goettingen. Thanks to Ines Müller from Department of Pharmacology and Toxicology for helping with the H\&E staining. The slides were imaged with an upright microscope (Zeiss, Imager.M2).

\subsection{Statistics}

GraphPad Prism software (GraphPad Software Inc; San Diego) was used to convert data sets into graphs (displayed as mean \pm SEM) and subjected to Student's t-test, oneway, or two-way ANOVA test where appropriate. $\mathrm{P}<0.05$ was considered to be significant. Sample number $(n)$, statistical test and $p$-value are presented with each data set. 


\section{Results}

\subsection{Genetic modification of a parthenogenetic stem cell line}

The aim was to stably integrate an antibody resistance gene (NeoR) transcribed under the control of the cardiomyocyte specific a-myosin heavy chain promoter (MYH6 gene)(Klug et al., 1996) into a previously established PSC-line (Didie et al., 2013).

\subsubsection{Determination of growth rate of non-transgenic parthenogenetic stem cell lines}

Several of the previously established PSC-lines (Didie et al., 2013) were screened for MHC homozygosity by microsatellite marker analysis; the target sequence was located on chromosome 17 and its PCR amplification allowed for a differential analysis of the DBA $\left(\mathrm{H}-2^{\mathrm{d} / \mathrm{d}}\right)$-and BL6 $\left(\mathrm{H}-2^{\mathrm{b} / \mathrm{b}}\right)$-mouse H2-locus (D17Mit178; Figure 11A). In order to identify whether the established PSC-lines exhibit differences in proliferation rate and exclude PSC-lines with low proliferation rate 3 different PSC-lines were randomly chosen and compared. These analysis confirmed a similar population doubling time in PSCA3 (13 \pm 1 hours), PSC30B3 (14 \pm 0.1 hours) and PSC32D1 (12 \pm 1 hours); (Figure 11B). Finally, the PSC30B3line was chosen randomly for the generation of stable transgenic cell lines and further studies. 


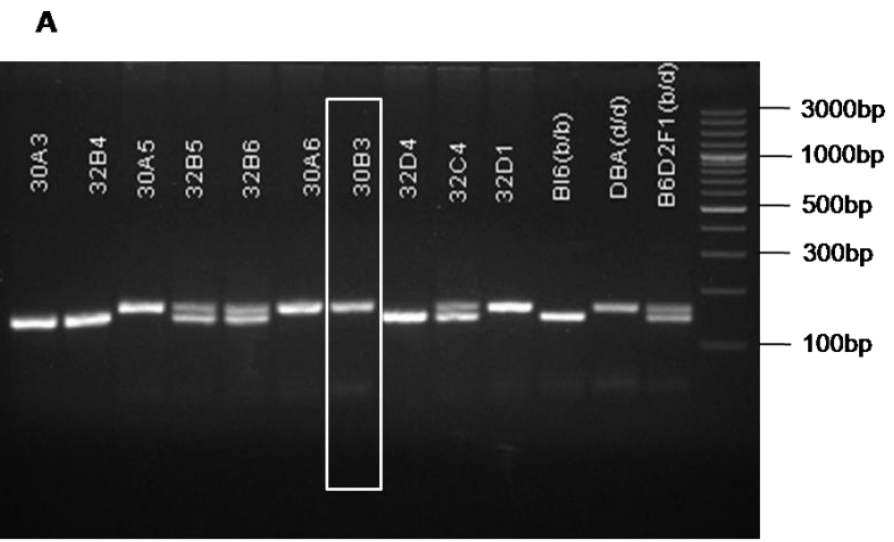

B

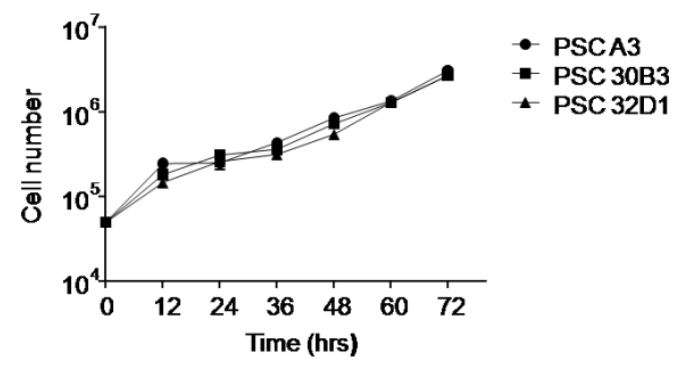

Figure 11: MHC genotyping and assessment of PSC growth. A. Amplification of microsatellite marker D17Mit178 on chromosome 17; DNA from BL6, DBA, and B6D2F1 was used as positive control; DNA fragment sizes: $164 \mathrm{bp}\left(\mathrm{DBA}-\mathrm{H}-2^{\mathrm{d} / \mathrm{d}}\right) ; 144 \mathrm{bp}\left(\mathrm{BL} 6-\mathrm{H}-2^{\mathrm{b} / \mathrm{b}}\right)$. B. Comparison of the proliferation rate in $\mathrm{H} 2$ haploidentical PSC-cell lines PSCA3, PSC30B3, and PSC32D1 ( $n=3$ for each time point and PSC-line).

\subsubsection{Confirmation of transgene identity}

A vector encoding for a neomycin resistance (NeoR) gene under the control of the cardiomyocytes specific a-myosin-heavy-chain promoter (MYH6 gene-Figure 12A; kindly provided by Loren J. Field, Indianapolis; Klug et al. 1996) was amplified in bacterial cultures. Five bacterial colonies were picked and plasmid DNA was isolated. Restriction enzyme digestion with Aflll (cutting site 5,362bp) and Hindlll (cutting site $8,335 \mathrm{bp})$ confirmed the presence of the aMHC-Neo vector: double digestion with Alfll and HindlII resulted in the anticipated two fragments $(8,004 \mathrm{bp}$ and 2,973bp; Figure $12 B)$. 

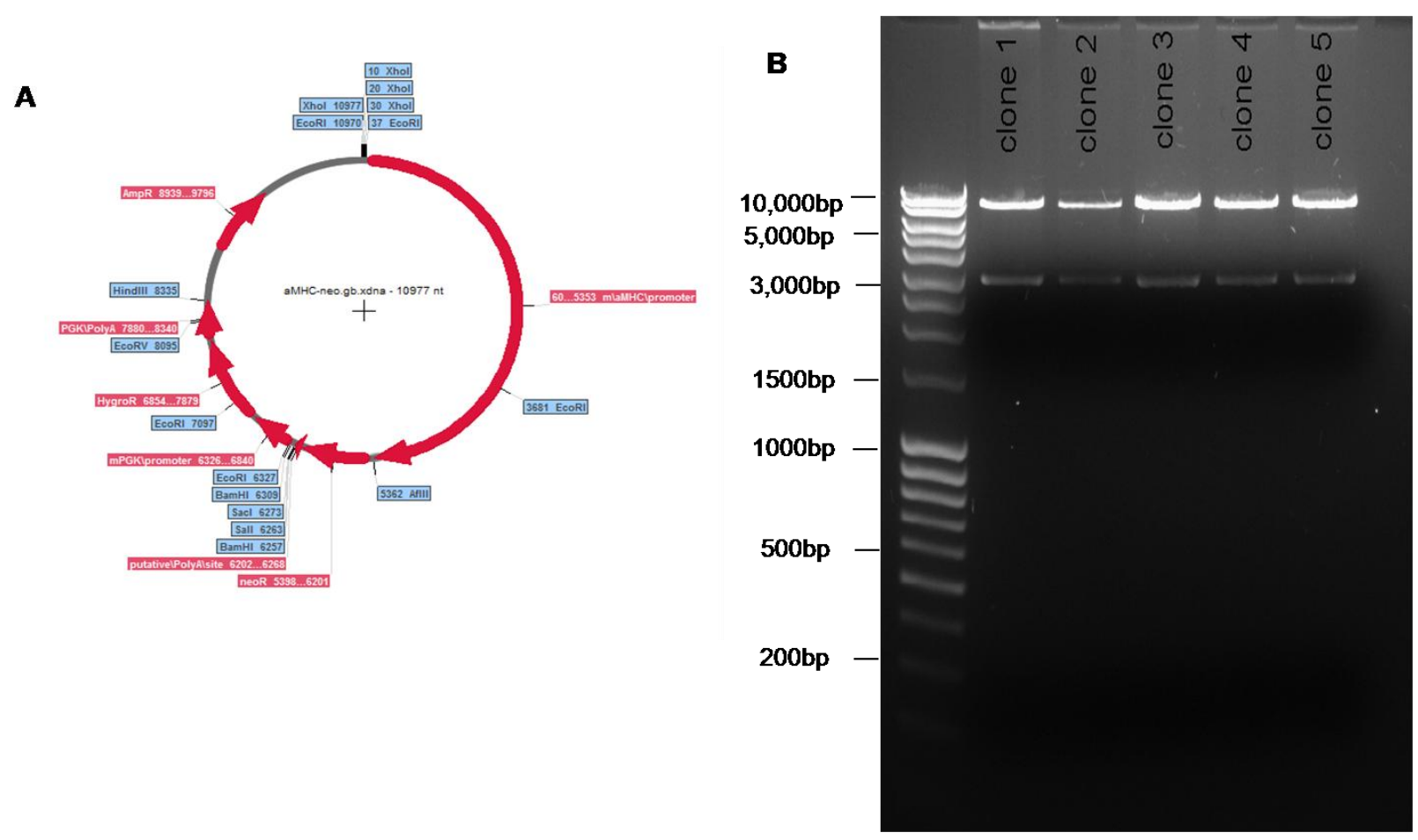

Figure 12: Confirmation aMHC-Neo plasmid identity. A. Vector map of aMHC-Neo plasmid with selected restriction sites and relevant inserts highlighted. B. Restriction digests of aMHC-Neo plasmid with AfIII and HindIII generated the anticipated 8,004bp and 2,973bp fragments.

\subsection{3 aMHC-Neo parthenogenetic stem cell line}

The aMHC-Neo plasmid was amplified and linearized by digestion with HindIII and Xhol (Figure $13 \mathrm{~A}$ ) to remove the ampicillin gene from the vector backbone. The Hindll//Xhol fragment (8335bp) was purified and subsequently transfected into the PSC30B3 line using electroporation. Following hygromycin selection for 2 weeks (plasmid also encodes a ubiquitously expressed hygromycin resistance); DNA was extracted from 11 cell clones and subjected to PCR for the detection of neomycin resistance (NeoR) gene (Figure 13B). PSC30B3 Clone 10 was randomly chosen for further experiments in this study. 

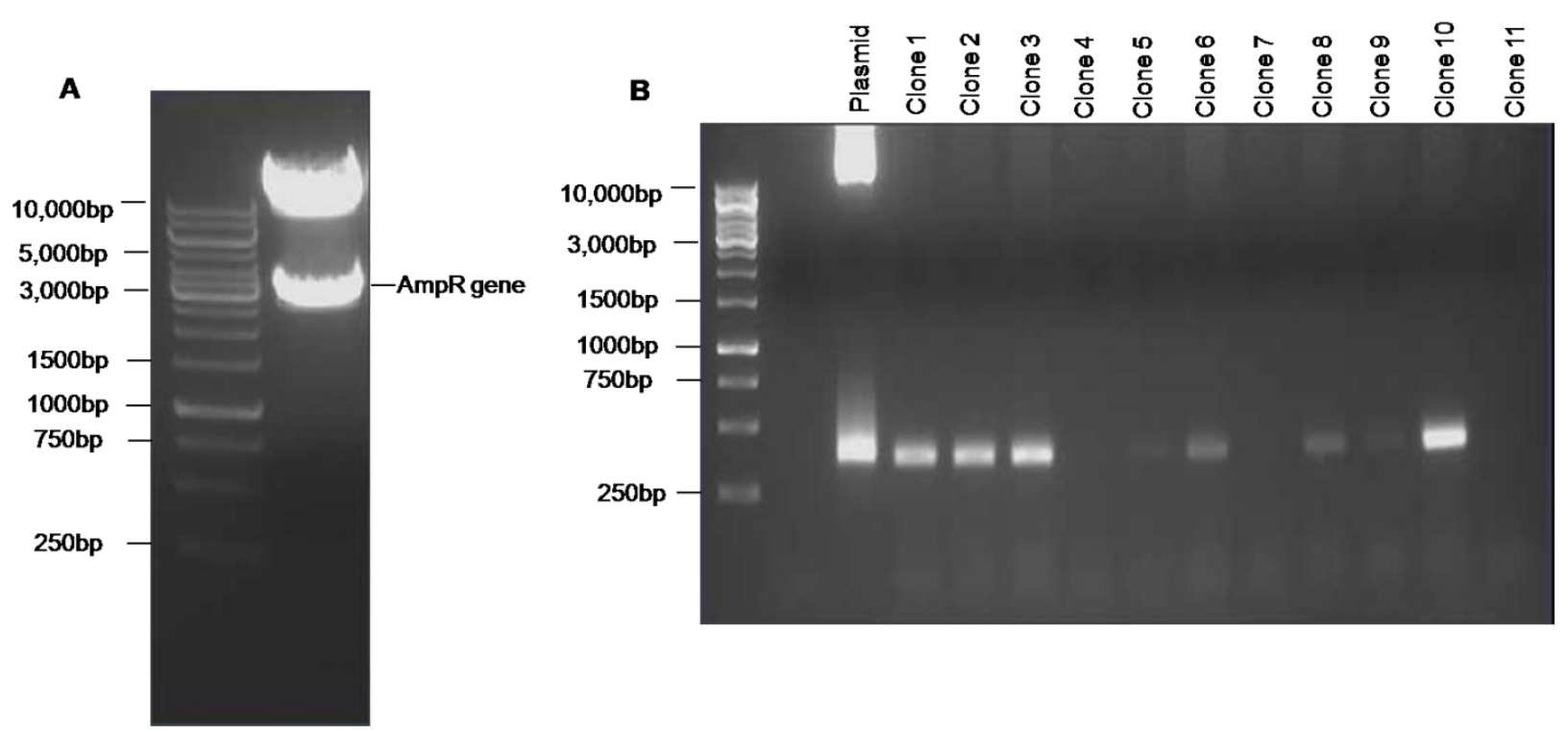

Figure 13: Identification of transgenic PSC clones by PCR. A. Restriction digestion of the aMHC-Neo plasmid with HindIII and Xhol. The upper band (8,335bp) was cut out and used for transfection after purification. B. clones $1,2,3,6,8$, and 10 were detected as transgenically modified based on the amplification of the transgenic NeoR (383bp) sequence. The aMHC-Neo plasmid was run on the gel as positive control.

\subsubsection{Morphological and molecular evidence for pluripotency}

After transfection, PSC30B3-MHCNeo clone 10 was further cultured and expanded. The colonies represented a compact homogeneous morphology characteristic for murine pluripotent stem cell cultures (Figure 14A). Semi-quantitative reverse transcription (RT)PCR was performed on RNA extracted from the undifferentiated PSC30B3-MHCNeo cultures. All investigated pluripotency markers (Oct3/4, Sox-2, Nanog, and Rex-1) were expressed (Figure 14B). 
A

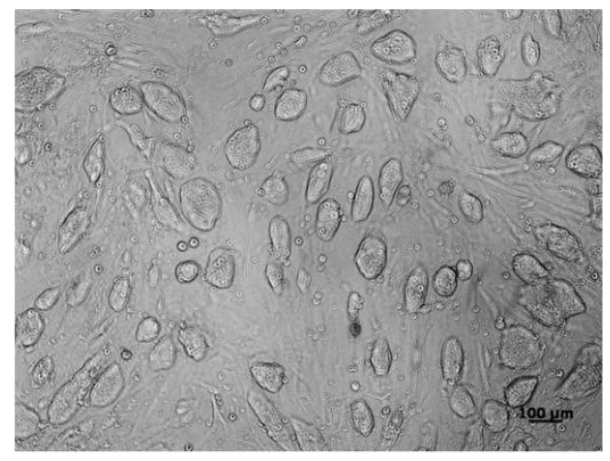

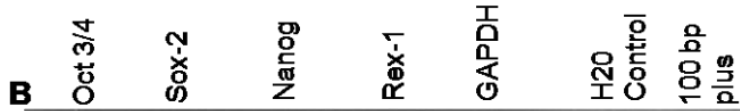

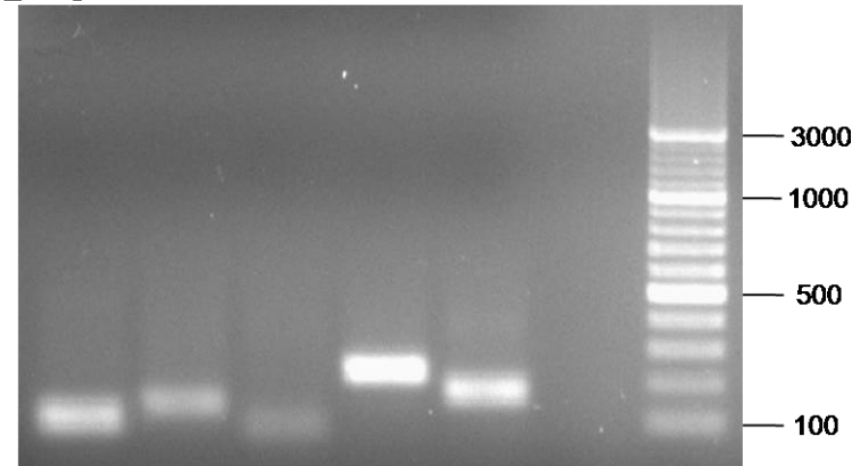

Figure 14: Morphological and molecular evidence for pluripotency. A. Morphology of PSC30B3 colonies at passage 21. B. Stemness markers/pluripotency genes (Oct3/4: 101bp, Sox-2:131bp, Nanog: $71 \mathrm{bp}$, Rex-1: 232bp) and GAPDH (171bp- used as housekeeping gene for normalization) was amplified as an internal loading control.

\subsubsection{Cardiomyocyte differentiation and purification in spinner flasks}

Differentiation of the B3line was established in spinner flasks for 11 days to form EBs followed by selection with G-418 for 7 days to eliminate non-myocytes (NM) and support the formation of cardiac bodies. Beating of EBs/cardiac bodies from spinner flask cultures was systematically evaluated 3 days after additional plating on gelatin-coated 48-well plates (plating of one EB/cardiac body/well at the indicated time point; Figure 15). EBs before selection with G-418 (spinner flask culture day 11; Figure 15A) showed a heterogeneous morphology and were larger in size compared to cardiac bodies formed after selection with G-418 (spinner flask culture day 18; Figure 15B). First beating areas in EBs were noticed from day 5 on with $100 \%$ of the EBs beating by culture day 11(Figure 15C). After addition of G-418 for the removal of non-myocytes $100 \%$ beating was maintained in the resulting cardiac bodies. 


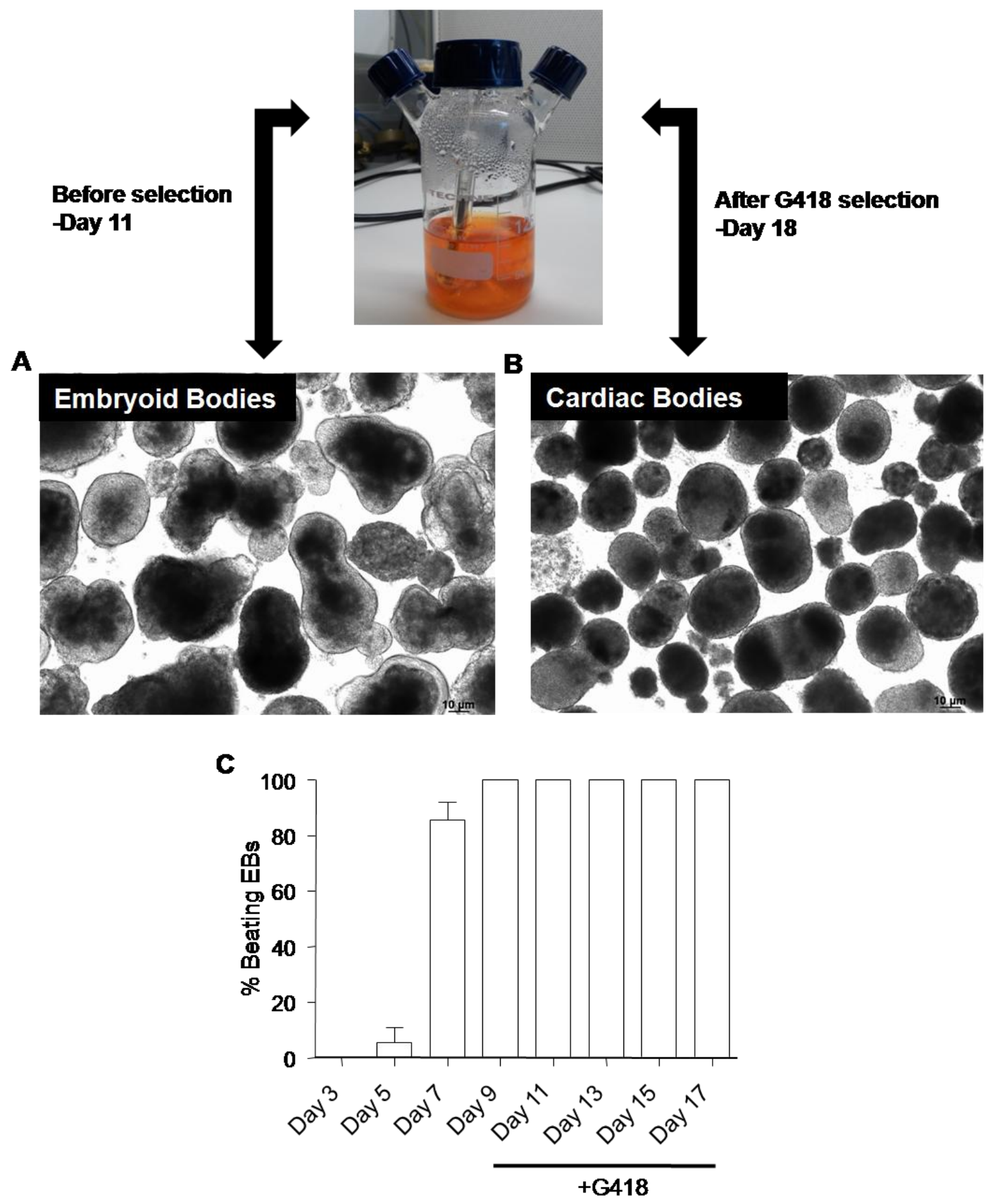

Figure 15: Morphology and beating in PSC-derived EBs and cardiac bodies. A. Morphology of unselected EBs (day 11 in spinner flask culture). B. Cardiac bodies after G-418 selection (day 18 in spinner flask culture).C. Percentage of beating EBs/cardiac bodies 3 days after plating at the indicated time point. 


\subsubsection{High cardiomyocyte purity after selection}

The cardiac bodies obtained after G-418 selection for 7 days were dissociated and the cells were stained for the expression of $\alpha$-actinin, cardiac-troponin I and myosin heavy chain (MF-20) to analyze the purity of cardiomyocytes by flow cytometry. These analysis demonstrated $91 \pm 2 \%$ actinin positive cells, $91 \pm 2 \%$ of troponin I positive cells and $88 \pm 3 \%$ MF-20 positive cells (Figure 16). Stirred suspension spinner flask cultures with an input quantity of $10 \times 10^{6}$ PSCs resulted in $25 \pm 5 \times 10^{6}$ cardiomyocytes $(n=12$ spinner flask cultures). Note that cardiomyocyte isolation from EBs/cardiac bodies requires careful handling and adaptations of the dissociation protocol according to the EB/cardiac body size, structure, age and morphology.
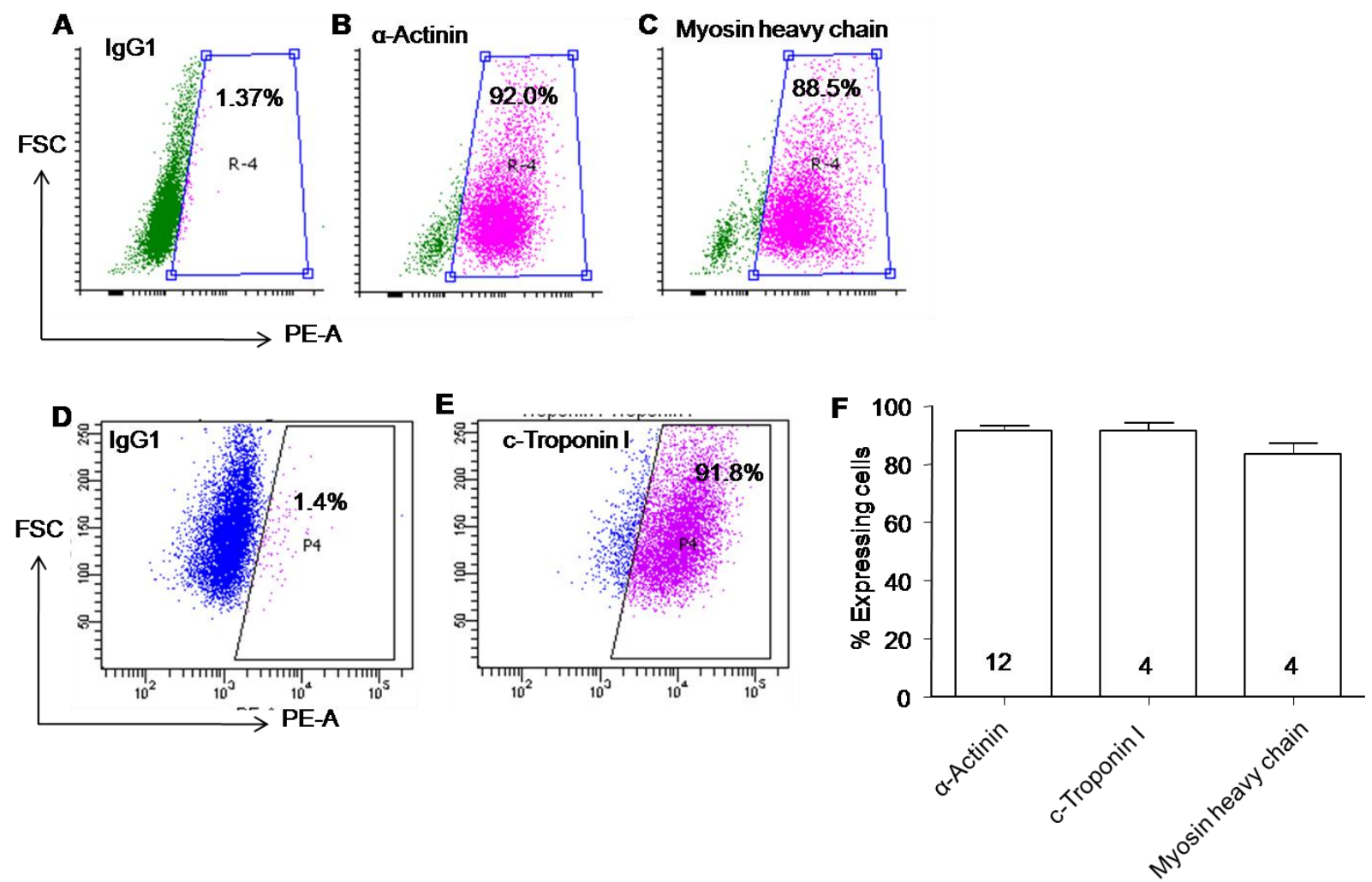

Figure 16: Cardiomyocyte purity after selection in spinner flask cultures. Depicted are isotype (IgG1) control data (A and D) and detection of canonical cardiomyocyte expressed proteins such as $\alpha$ actinin (B), myosin heavy chain (MF-20; C) and cardiac troponin I (E). F. Bar graph shows a summary of the flow cytometry data with n-numbers indicated inside the bars. 


\subsubsection{Morphological properties of PSC-derived cardiomyocytes}

We analyzed the morphology of PSC-derived cardiomyocytes obtained from spinner flask cultures after enzymatic digestion. CMs were cultured on gelatin coated cover slips for 2 additional days before immunofluorescence labeling of $f$-actin, $\alpha$-actinin, and cardiac troponin I. Confocal microscopy confirmed the flow cytometry data on cardiomyocyte purity and demonstrated the characteristic morphology of stem cell derived cardiomyocytes in monolayer culture with the formation of sarcomeres (Figure 17).

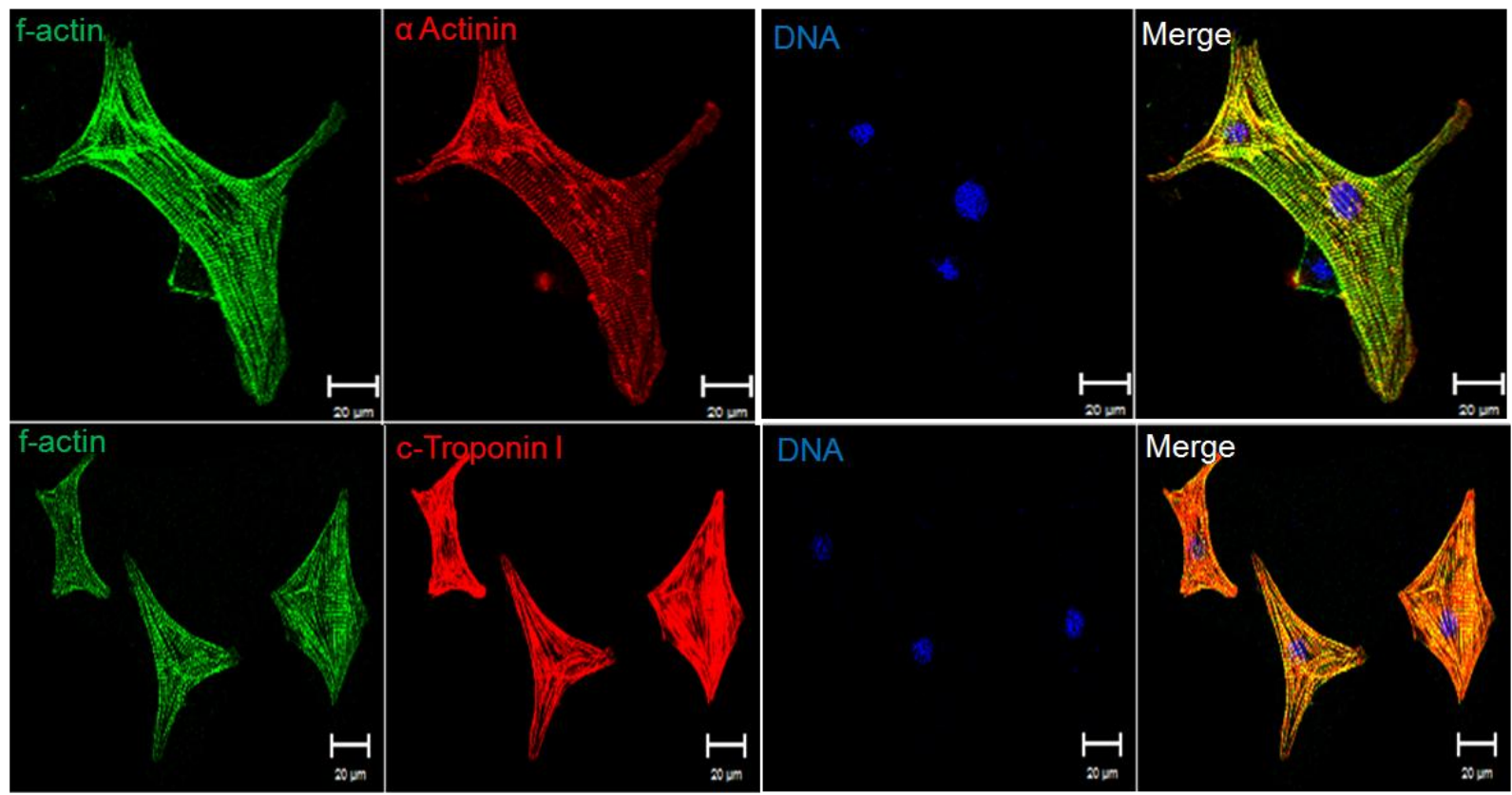

Figure 17: Morphology of PSC-derived cardiomyocytes. Confocal microscopy of PSC-derived cardiomyocytes. Panels indicate the respectively labeled structures. Scale bars: $20 \mu \mathrm{m}$.

\subsection{Immunological properties of PSC-derived cells}

After successful generation of transgenic PSC-lines to facilitate purification of PSCderived cardiomyocytes, we analyzed the expression levels of immunological molecules like MHC antigens, co-stimulatory molecules and immunomodulatory molecules like PDL1 in PSC-cardiomyocytes. These molecules play an important role in the antigen presentation and activation of the immune system. We have also analyzed the 
expression of immunological molecules on PSC-derivatives (non-myocytes) obtained after differentiation of PSC.

\subsubsection{PSC-derivatives express immunologically relevant surface markers}

PSC-derived cells before selection with G418 (non-myocytes - NM) and after G418 selection (cardiomyocytes - CM) were treated with mouse recombinant IFNY $(25 \mathrm{ng} / \mathrm{ml}$ ) for $48 \mathrm{hrs}$. After treatment with IFNy the cells were dissociated and analyzed by live cell flow cytometry. NM showed the expression of MHC-I $\left(\mathrm{H}-2 \mathrm{~K}^{\mathrm{d}}\right)$ on $35 \pm 15 \%$ of all cells and no MHC-II (I-A/I-E) expression at unstimulated conditions, which was further upregulated to $85 \pm 3 \%$ and $12 \pm 2.3 \%$ after IFNy stimulation. CM did not apparently show expression of $\mathrm{MHC}-\mathrm{I}\left(\mathrm{H}-2 \mathrm{~K}^{d}\right)$ and $\mathrm{MHC}-\mathrm{II}(\mathrm{I}-\mathrm{A} / \mathrm{I}-\mathrm{E})$ under baseline conditions; IFNY treatment resulted in $\mathrm{MHC}-\mathrm{I}$ and $\mathrm{MHC}-\mathrm{II}(\mathrm{I}-\mathrm{A} / \mathrm{I}-\mathrm{E})$ expression in $55 \pm 8 \%$ and $35 \pm 8 \%$ of the CMs respectively (Figure 18A,B,C).

CD1d is a non-classical MHC molecule generally expressed on antigen presenting cells such as dendritic cells, activated monocytes, B lymphocytes and T-cells. It was shown by many groups that CD1d was upregulated on cardiomyocytes during inflammatory conditions like myocarditis and coxsakievirus B3 (CVB3) infections (Huber et al., 2003). Taking this into consideration we analyzed the expression of CD1d before and after IFNy stimulation. CD1d expression was not influenced by inflammatory condition. A basal expression of CD1d on $20 \pm 15 \%$ of all NM and on $40 \pm 9 \%$ of all CM was observed (Figure 18D). No significant upregulation of the co-stimulatory proteins CD40, CD80, and CD86 was observed in the absence and presence of IFNy (Figure 18E). In one out of 3 experiments CD80 expression on CM and CD86 expression on NM appeared to be upregulated. 

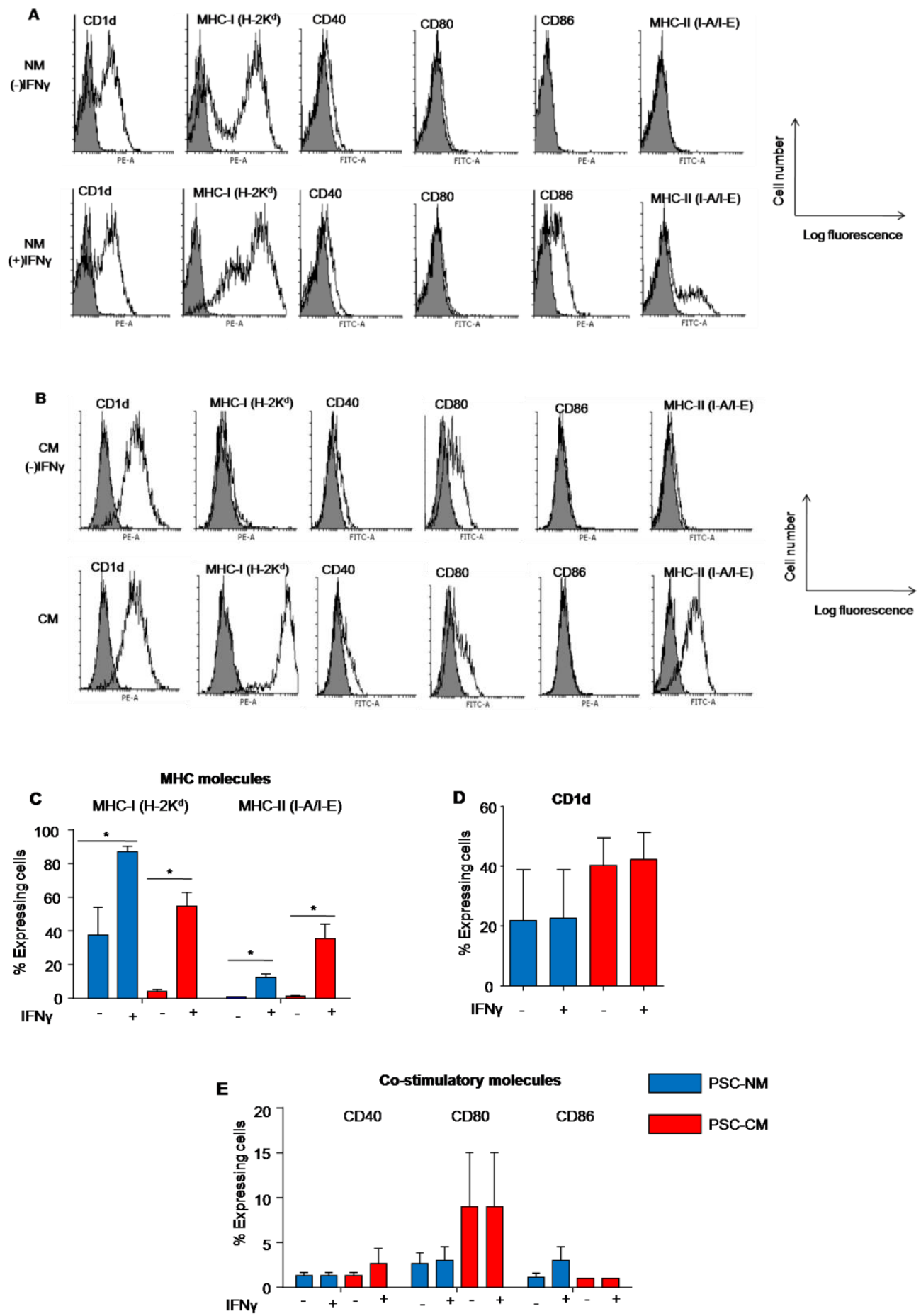

Figure 18: Flow cytometry analysis of cell surface markers associated with immune responses. A and B represent individual histograms obtained from NM and CM cultures with and without IFNy exposure; grey histogram represent the isotype controls. C-E Bar graphs summarizing the flow cytometry data obtained from NM (blue) and CM (red) cultures with and without IFNy exposure ( $25 \mathrm{ng} / \mathrm{ml}$ for $48 \mathrm{hrs}$ ). ${ }^{*} p<0.05$, (two-tailed, unpaired Student's t-test, $n=3$ ). 
PD-1/PD-L1 pathway plays an important role in the immune regulation mainly in immune escape mechanism of transplanted cells (Riella et al., 2012). PD-1 was not expressed on PSC-NM and PSC-CM even after IFNy stimulation (Figure 19A). In contrast PD-L1 expression was up-regulated in both NM to $30 \pm 7 \%$ and CM to $40 \pm 9 \%$ after IFNy treatment (Figure 19B).

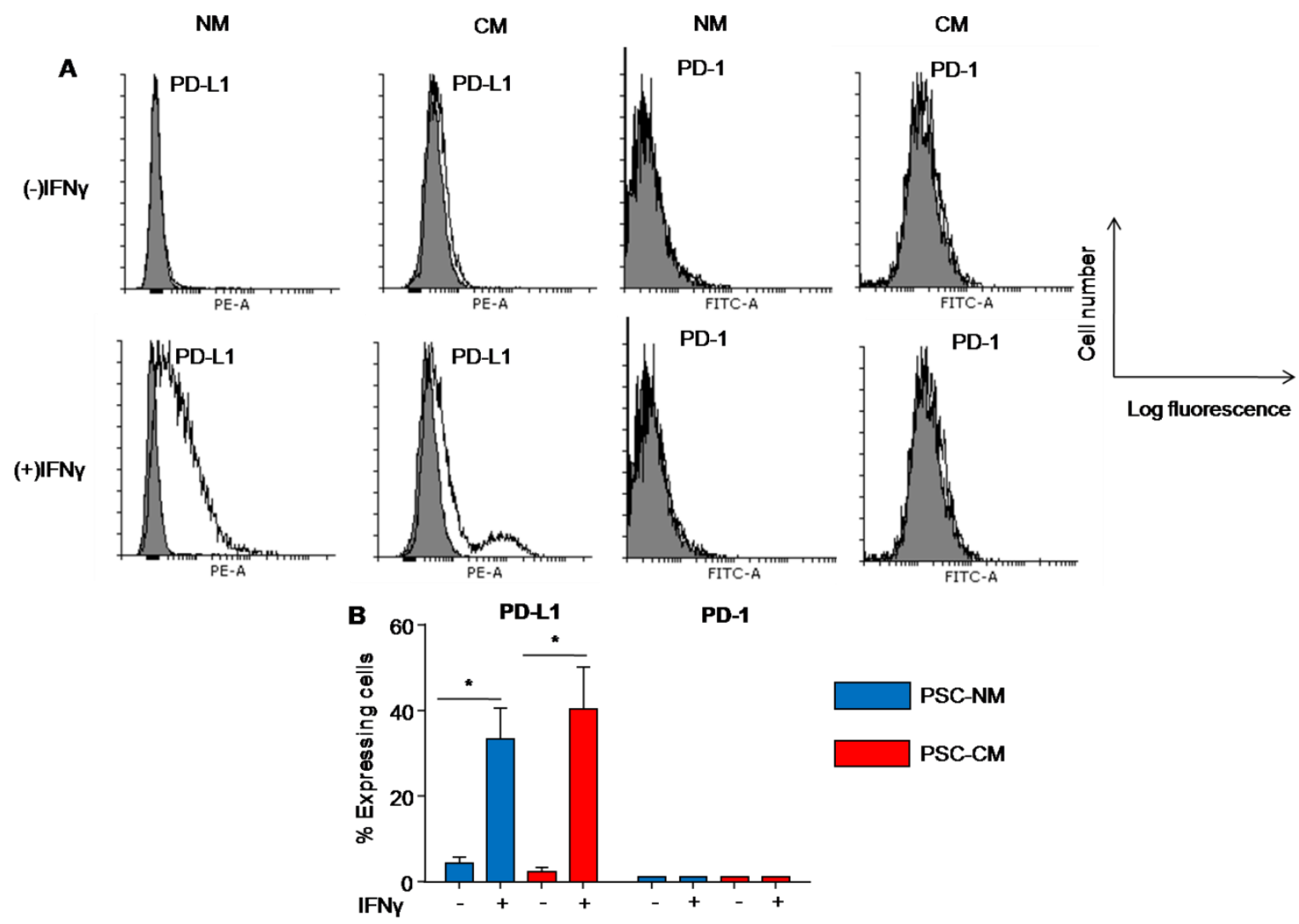

Figure 19: Flow cytometry analysis of PD-L1 and PD-1 associated with immune escape. A. Represents individual histograms obtained from NM and CM cultures with and without IFNy exposure; grey histograms represent the isotype controls. B. Bar graphs summarizing the flow cytometry data obtained from NM (blue) and CM (red) cultures with and without IFNy exposure (25 ng/ml for $48 \mathrm{hrs}$ ). ${ }^{*} p<0.05$, (two-tailed, unpaired Student's t-test, $n=3$ ).

\subsubsection{Sustained expression of MHC-I on PSC-derivatives}

IFNy abundance is increased in the overloaded or inflamed heart, mainly because of enhanced homing of T-cells, macrophages and dendritic cells under these conditions (Levick and Goldspink, 2014). In the previous experiments, the presence 
immunologically relevant surface markers were assessed either in the absence or presence of IFNY. To test whether transient inflammation would result in sustained immune activation, indicated by sustained expression of MHC-I $\left(\mathrm{H}-2 \mathrm{~K}^{\mathrm{d}}\right), \mathrm{NM}$ and $\mathrm{CM}$ were stimulated transiently with IFNy for 48 hours and thereafter kept in culture for additional 4 days with regular medium change every other day without IFNy. The cells were dissociated and analyzed by flow cytometry for $\mathrm{MHC}-\mathrm{I}\left(\mathrm{H}-2 \mathrm{~K}^{\mathrm{d}}\right)$ expression. Abundance of MHC-I remained high in $\mathrm{NM}$ and $\mathrm{CM}$ even 4 days after withdrawal of IFNy (Figure 20). This experiment suggested that short episodes of IFNy stimulation may lead to long lasting alterations in PSC-immunogenicity.

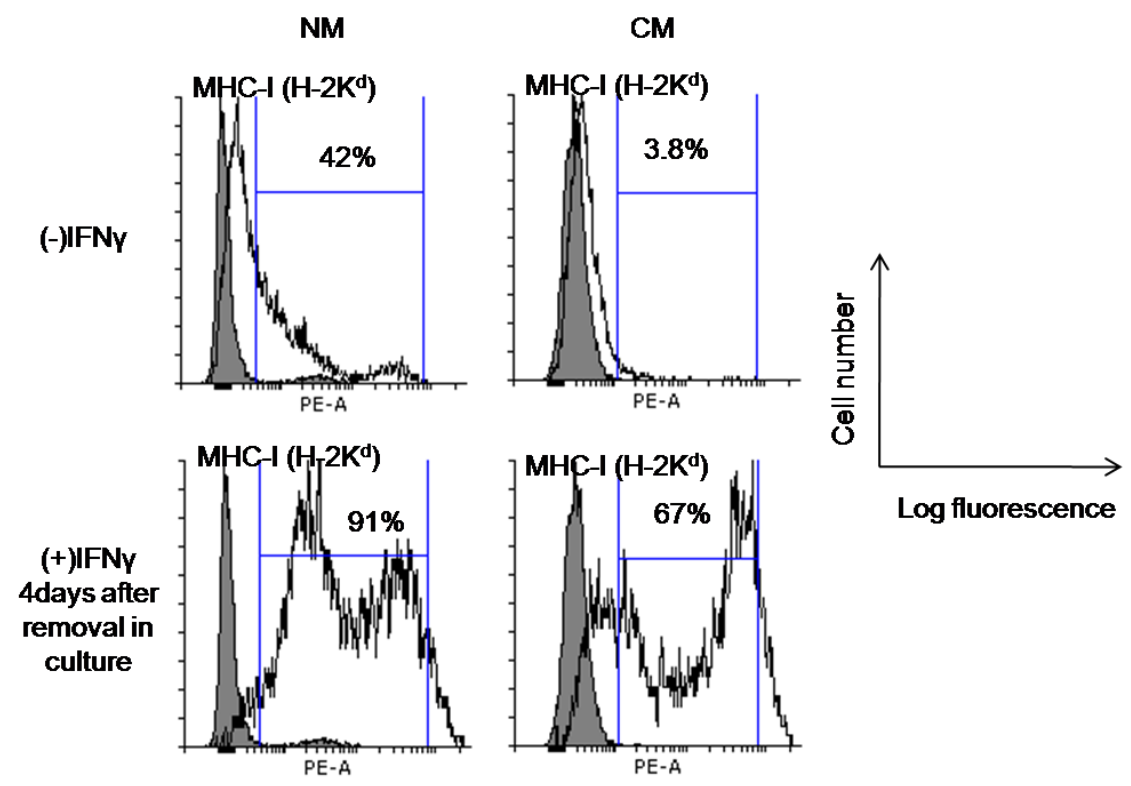

Figure 20: Sustained MHC-I expression after transient IFNy stimulation. Individual histograms obtained from NM and CM cultures with transient and without IFNy exposure; grey histograms represent the isotype controls. $(n=1)$.

\subsection{Functional and immunological properties of engineered heart muscle}

EHM can be generated from mixtures of PSC-derived cardiomyocytes, inactivated NMRI murine embryonic fibroblasts, and rat tail collagen (Didie et al., 2013). In addition to contractility measurements in EHM from the newly generated selectable PSC-line (B3) and immunological properties of CM in matured in EHM were assessed by flow cytometry. 


\subsubsection{Contractile parameters of engineered heart muscle}

EHMs were generated from PSC-derived cardiomyocytes supplemented with $30 \%$ inactivated MEFs. EHMs showed spontaneous contraction after 4 days in culture (one day after transferring to stretchers). Isometric force measurements at culture day 10 demonstrated positive inotropic response to increasing extracellular calcium concentrations with maximal contractile force $(0.30 \pm 0.04 \mathrm{mN} ; \mathrm{n}=7)$ at $0.8 \pm 0.4 \mathrm{mmol} / \mathrm{L}$ extracellular calcium (Figure 21A). The apparent $\mathrm{EC}_{50}$ for calcium was found to be $0.4 \pm 0.04 \mathrm{mmol} / \mathrm{L}$. Contraction experiments were performed under $4 \mathrm{~Hz}$ electrical field stimulation in Tyrode's solution. EHMs showed a slight but not significant positive inotropic response to adrenergic stimulation. Subsequent muscarinergic stimulation with carbachol elicited a negative inotropic response (Figure 21B).
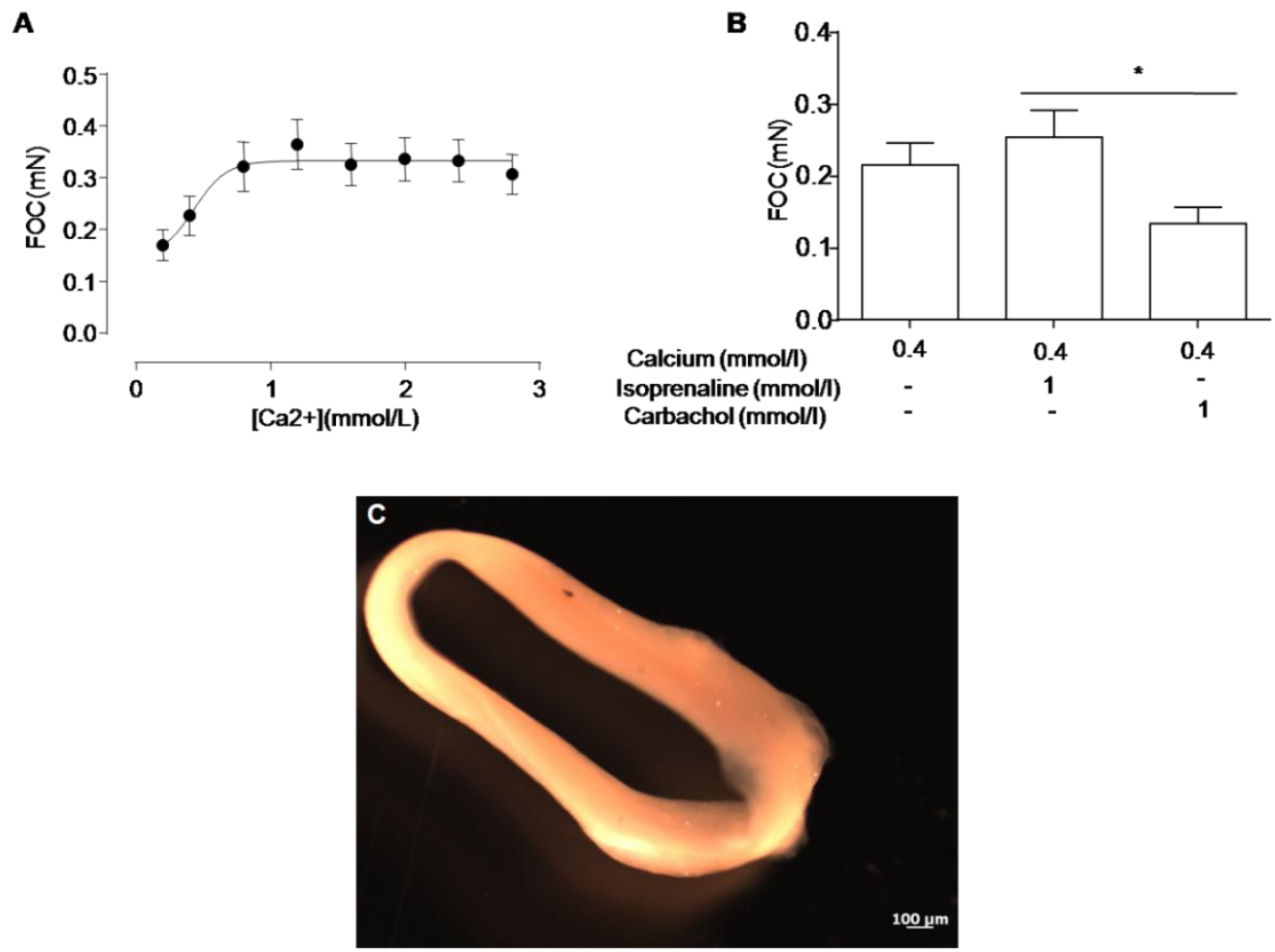

Figure 21: Contractile properties of PSC-EHM. The ordinates indicate force of contraction (FOC) of EHM exposed to increasing extracellular calcium (A) or isoprenaline followed by carbachol stimulation at the indicate concentrations (B) ${ }^{*} \mathrm{p}<0.05$ (two-tailed paired Student's t-test, $n=7$ ). C. Bright field image of EHM. 


\subsubsection{Morphological analysis of engineered heart muscle}

The morphology of cardiomyocytes within the EHM was analyzed by whole mount staining of EHM for a-actinin, connexin 43, and cardiac troponin I. Whole mount staining of EHMs for a-actinin showed that cardiomyocytes in EHM are anisotropically arranged (Figure 22). The EHMs also showed positive staining for the gap junction protein connexin 43 in a diffuse pattern along the cell surfaces, providing morphological evidence for cardiomyocyte coupling within the EHMs.

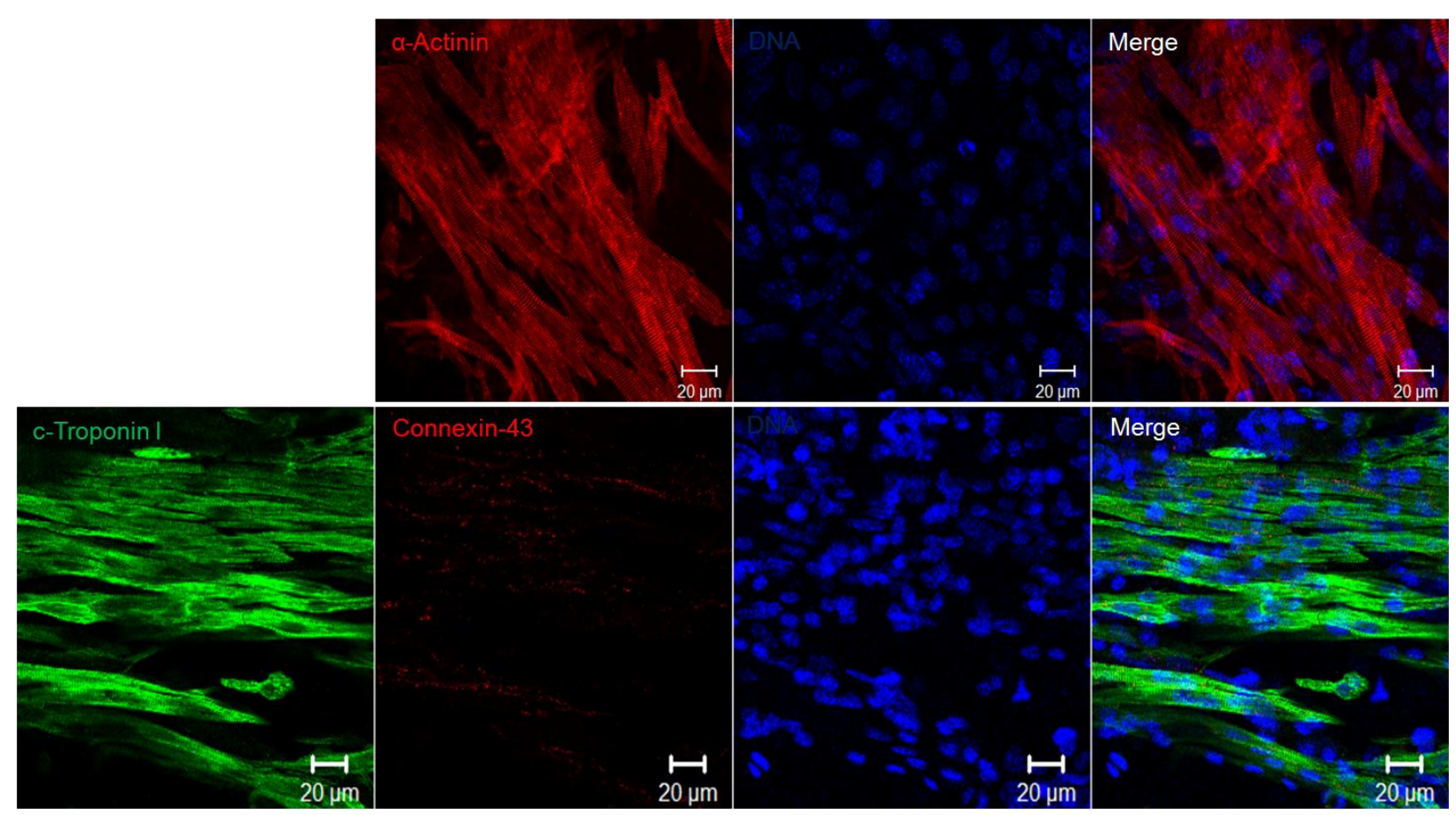

Figure 22: Morphological characterization of engineered heart muscle. Immunfluorescence stainings and confocal microscopy of whole mount EHMs. Immunolabeled structures are indicted in the respective panels. DNA (in blue) was labelled with Hoechst. Scale bars: $20 \mu \mathrm{m}$

\subsubsection{Immunologically relevant proteins in engineered heart muscle}

EHMs from PSC-derived CMs and inactivated NMRI MEFs were dissociated into single cells. Flow cytometry identified $49 \pm 3 \%(n=7)$ of the cells as a-actinin positive CMs (Figure 23). 


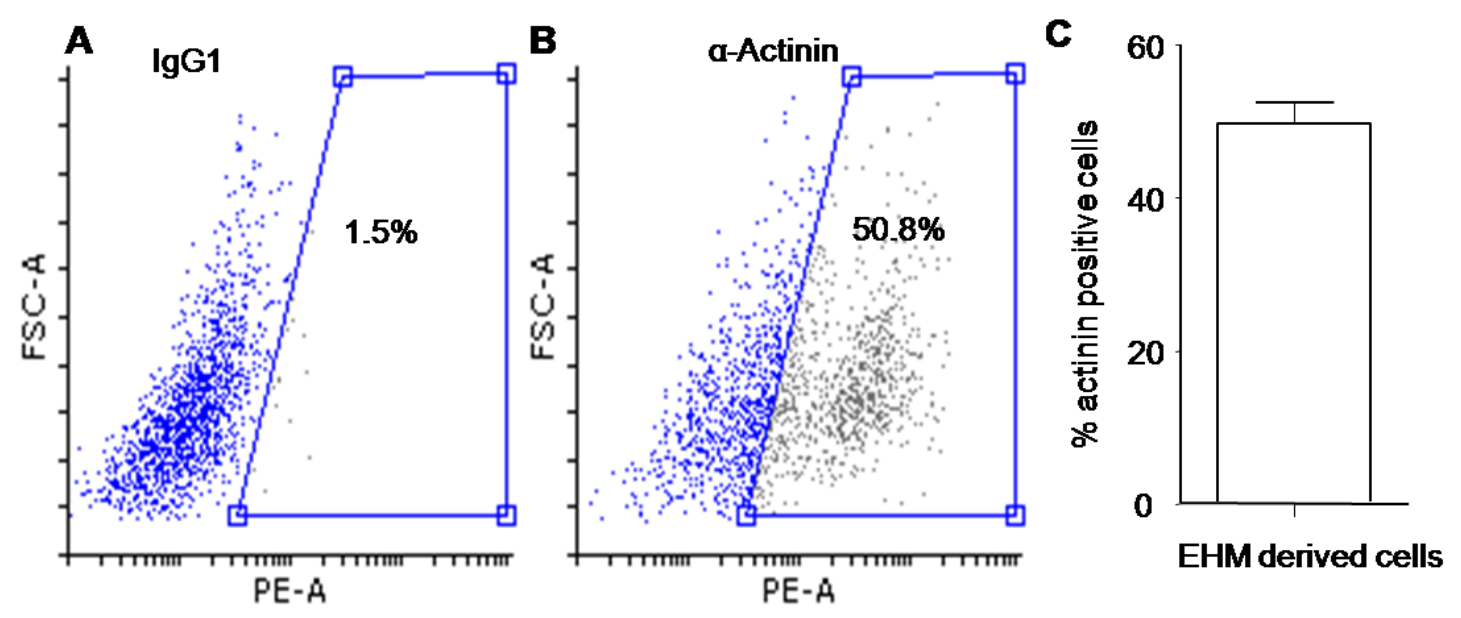

Figure 23: Cardiomyocyte content in EHM. Representative scatter plot of EHM-derived cells labelled with isotype control (A) and $\alpha$-actinin (B). C. Bar graph summarizes the data obtained from seven EHMs.

Similarly as for PSC-cells directly from spinner flask cultures, EHM were analysed under basal and IFNy (25 ng/mL; 48 hrs prior to dissociation) stimulated conditions by flow cytometry. EHM-derived cells showed no detectable MHC-I (H-2K $\left.\mathrm{K}^{\mathrm{d}}\right), \mathrm{MHC}-\mathrm{II}(\mathrm{I}-\mathrm{A} / \mathrm{I}-\mathrm{E})$, CD86, PD-1, and PDL-1 (Figure 24A and 24B). CD40 and CD80 were identified in $2 \pm 0.5 \%$ and $7 \pm 2.5 \%$. CD1d was detected in $5.5 \pm 2.5 \%$ of the EHM-cells. IFNy increased the amount of EHM-cells expressing MHC-I (H-2K $)$, MHC-II (I-A/I-E), PD-1, and PD-L1 to $32 \pm 1.5 \%, 1.3 \pm 0.3 \%, 1 \pm 0.5 \%$, and $28 \%$. Conversely, CD40 positive cells appeared to be reduced to $1.5 \pm 0.5 \%$ of the EHM cells (Figure $24 \mathrm{C}-\mathrm{F}$ ). 


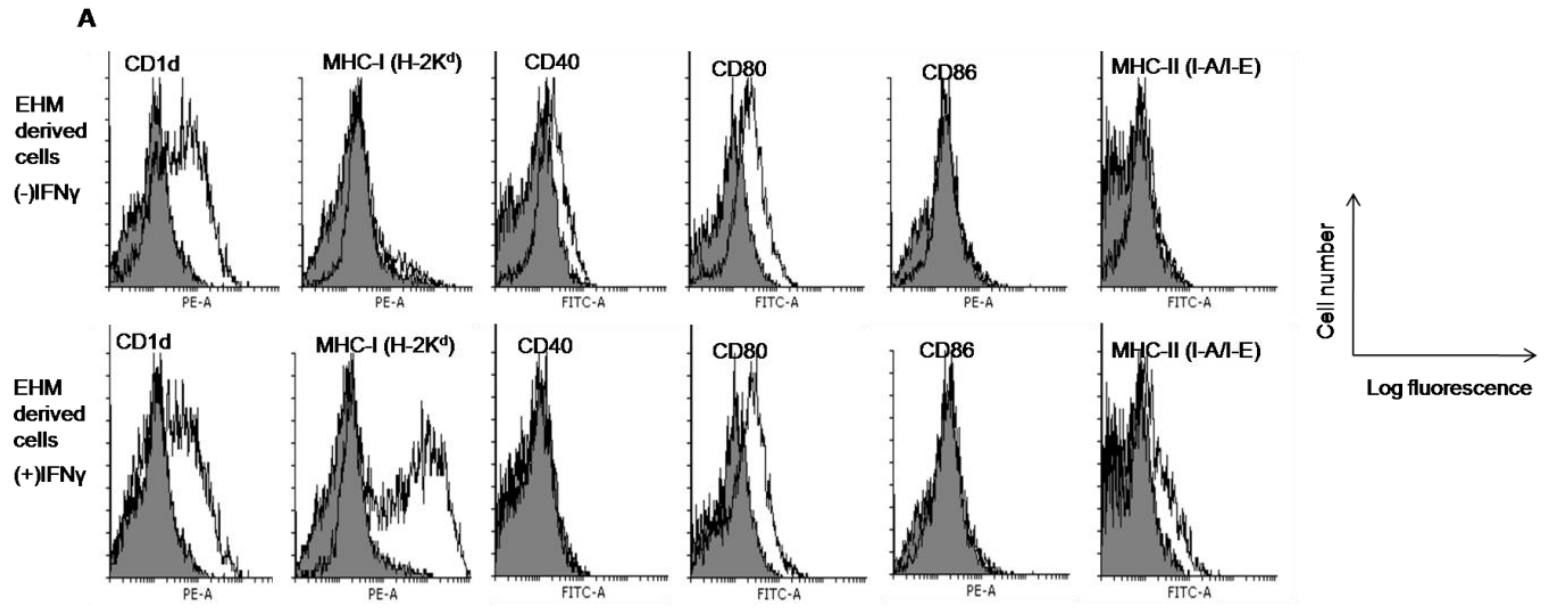

B
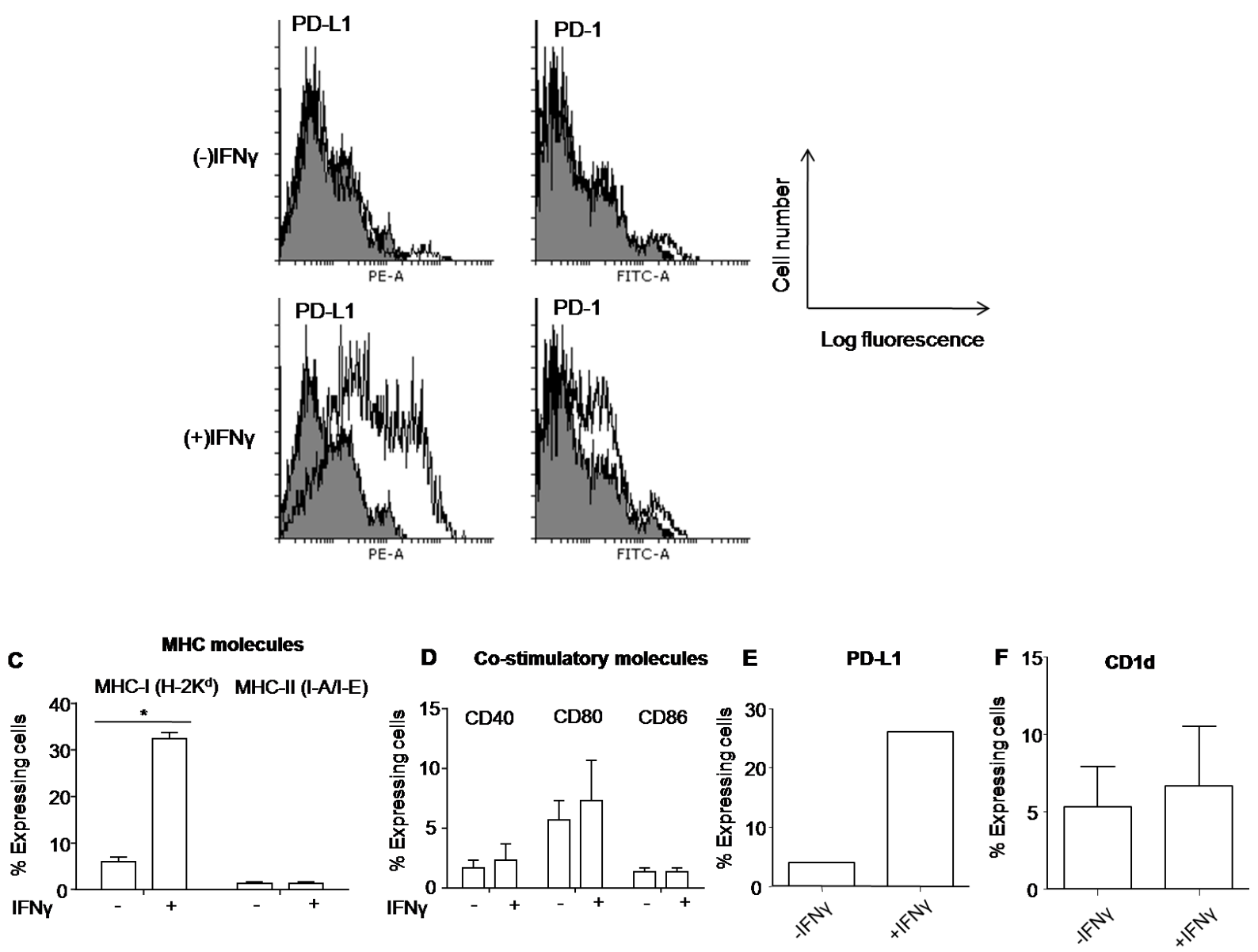

Figure 24: Immunological properties of PSC-EHM derived cells. A and B represent individual histograms obtained from EHM derived cells with and without IFNy exposure ( $25 \mathrm{ng} / \mathrm{ml}$ for $48 \mathrm{hrs}$ ); grey histogram represent the isotype controls. C-F Bar graphs summarize the flow cytometry data. * $p<0.05$, (two tailed, unpaired Student's t-test, $\mathrm{n}=3$ ). 


\subsection{Immunological properties of native cardiomyocytes}

After finding surprisingly little MHC-I expression on unstimulated PSC-derived cardiomyocytes, we wanted to confirm expression of $\mathrm{MHC}-\mathrm{I}$ also in cardiomyocytes isolated from neonatal $(n=1)$ and adult $(n=1)$ mice.

\subsubsection{Expression of MHC-I on cardiomyocytes from neonatal mice}

Cardiomyocytes were isolated enzymatically from neonatal DBA $\left(H-2^{d / d}\right)$ mice $(n=1)$, expressing GFP under the control of the alpha myosin heavy chain (MYH6) promoter (Figure 25B). The isolated cells were then stained for MHC-I expression and analyzed by flow cytometry. $47 \%$ of the cardiomyocytes (GFP-positive) were found to be MHC-I $\left(\mathrm{H}-2 \mathrm{~K}^{\mathrm{d}}\right)$ positive (Figure 25A).
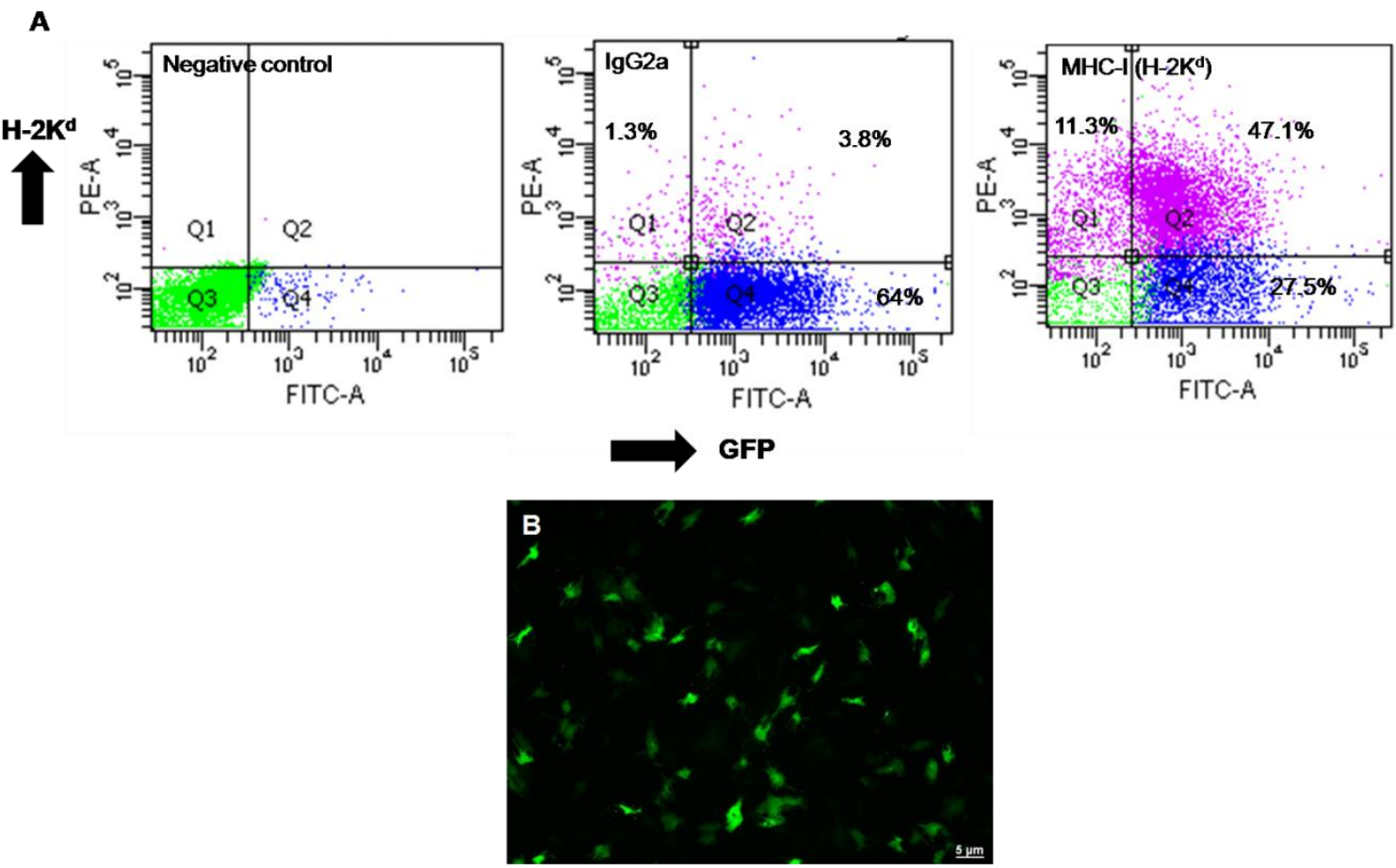

Figure 25: MHC-I expression on neonatal mouse cardiomyocytes. A. Flow cytometry analysis for $\mathrm{H}-$ $2 \mathrm{~K}^{\mathrm{d}}$ staining on cardiomyocytes derived from DBA neonatal mice. Scatter blot on the left represents negative control for GFP; middle plot represents isotype control and the scatter plot on the right represents MHC-I staining $(n=1)$. B. GFP expression on cardiomyocytes from aMHC-GFP mice in culture. 


\subsubsection{Expression of MHC-I on cardiomyocytes from adult mice}

After finding high basal MHC-I expression in neonatal mouse cardiomyocytes in contrast to PSC-derived $\mathrm{CM}$, we analyzed $\mathrm{MHC}$-expression on adult murine cardiomyocytes.

Cardiomyocytes were isolated from adult aMHC-GFP transgenic DBA mice heart by Langendorff perfusion method and seeded on laminin coated cover slips for 24 hours with IFNy treatment. Flow cytometry of adult cardiomyocytes is challenging because of their size. Thus the cells were stained after fixation for $\beta-2$ microglobulin, a surrogate for MHC-I. Adult cardiomyocytes showed very low basal B2M protein abundance, with enhanced B2M after IFNy stimulation (Figure 26).
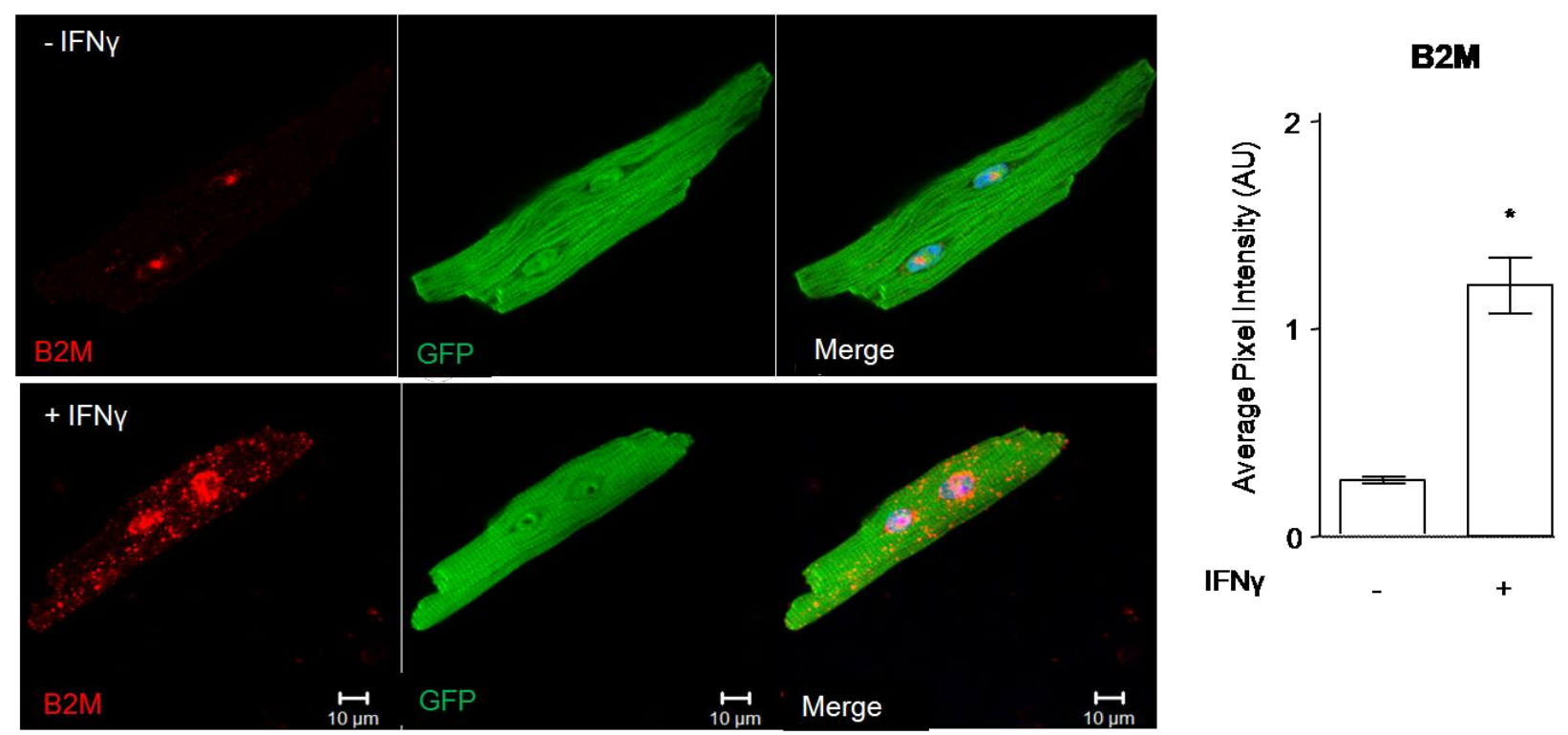

Figure 26: MHC-I expression on adult mouse cardiomyocytes. Representative immunofluorescence stainings for $\beta-2$ microglobulin (B2M, red) in adult GFP-positive cardiomyocytes (aMHC-GFP model; green). Bar graph summarizing the data from comparative analyses of cardiomyocytes with or without IFNy treatment ( $25 \mathrm{ng} / \mathrm{mL}$ for $24 \mathrm{hrs}$ ). Blue: nuclear DAPI staining ( ${ }^{*} p<0.05 \mathrm{vs}$-IFNy, two tailed, unpaired Student's t-test, 10 cells per group, AU: Arbitrary units). 


\subsection{In vitro immunogenicity analysis of PSC-cardiomyocytes}

For the analysis of in vitro immune stimulatory properties of PSCs, we employed a coculture system of splenocytes from DBA $\left(\mathrm{H}-2 \mathrm{~K}^{\mathrm{d} / \mathrm{d}}\right)$ and BL6 $\left(\mathrm{H}-2^{\mathrm{b} / \mathrm{b}}\right)$ mice with PSCderived cells $\left(\mathrm{H}-2^{\mathrm{d} / \mathrm{d}}\right)$ and IFNy treated PSC-derivatives $\left(\mathrm{H}-2^{\mathrm{d} / \mathrm{d}}\right)$ to simulate "inflammation" in the dish. In this co-culture system the immune cells from a crude or Tcell selected splenocyte population (responders) are in direct contact with the PSCderived cells (stimulators; $\mathrm{NM} / \mathrm{CM}$ ). Activation of lymphocytes results in their proliferation and enhanced cytotoxic effects.

\subsubsection{Isolation of T-lymphocytes from spleen}

T-lymphocytes were isolated from mouse spleen by depletion of cells expressing CD11b, CD11c, CD19, CD45R (B220), CD49b (DX5), CD105, Anti-MHC-class II, and Ter-119(magnetic activated cell sorting method- MACS). After isolation, the cells were screened for viability and purity by flow cytometry. Viability was tested by staining with sytox and purity by staining for CD3. Flow cytometry data showed that $28 \%$ of the splenocyte population was CD3 positive (Figure 27A). T-lymphocyte enrichment by MACS resulted in 98\% CD3+ cells (Figure 27B). 

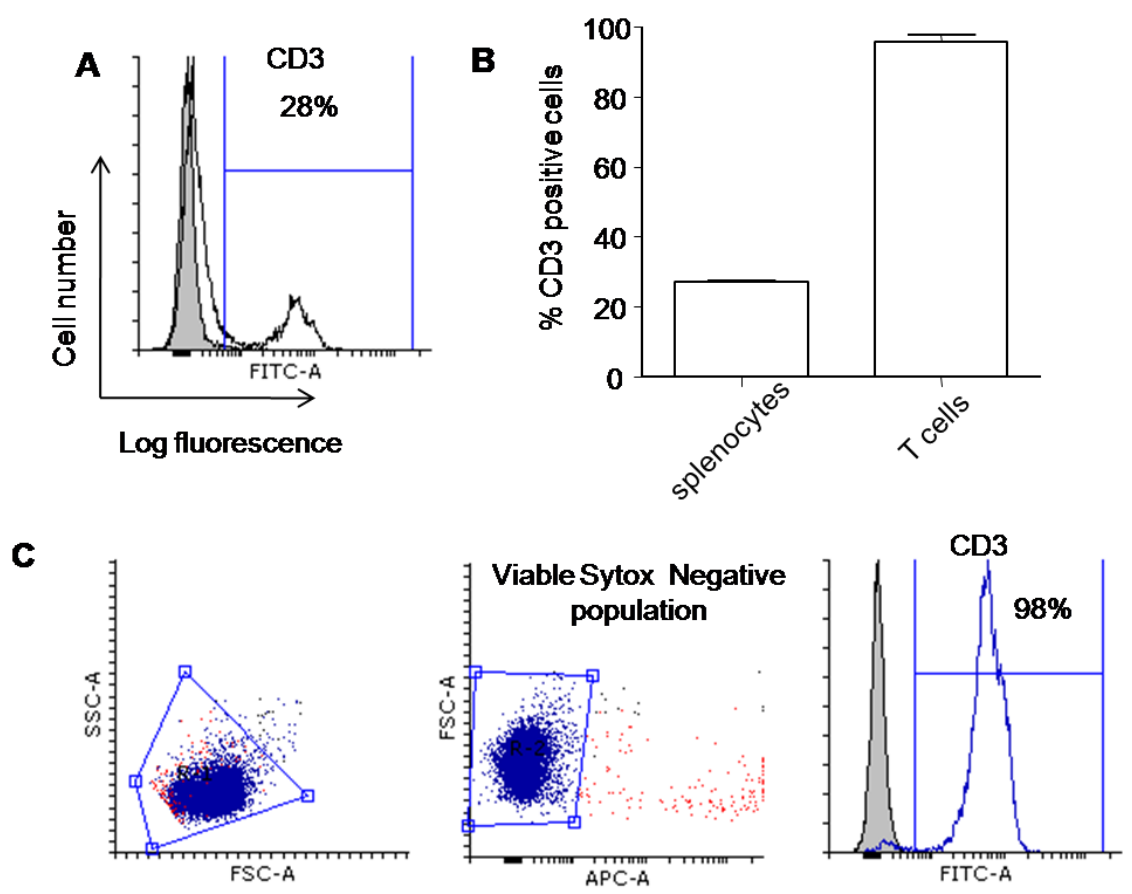

Figure 27: Assessment of splenocyte identity by flow cytometry. A. Representative histogramoverlay showing $28 \%$ CD3 positive cells in the crude splenocyte populations. B. Bar graph showing the percentage of CD3 positive cells before and after MACS enrichment $(n=3)$. C. Gating strategy showing the viability (Sytox negative) of the CD3 positive population (middle panel); $98 \%$ of the cells from this population were identified as CD3 positive T-lymphocytes. Grey filled histograms represents isotype controls.

\subsubsection{Validation of immune cell activation assay}

eFluor 670 is a red fluorescent dye that binds unspecifically to intercellular proteins. It is very stable and upon cell division is distributed equally between the daughter cells. Thus "dilution" of the dye with every cell division can be analysed by flow cytometry (Figure 28A), allowing for a precise assessment of proliferative activity over several cell divisions (Quah et al., 2007).

After validation of the assay with $T$-lymphocytes from Balb/c mice and concanavalin $A$ (Con.A) activation (Figure 28A), splenocytes were isolated from BL6 $\left(\mathrm{H}-2^{\mathrm{b} / \mathrm{b}}\right)$ and DBA $\left(\mathrm{H}-2^{\mathrm{d} / \mathrm{d}}\right)$ mice and labelled with eFluor 670 . These labelled cells were co-cultured with PSC-derived NMs $\left(\mathrm{H}-2^{\mathrm{d} / \mathrm{d}}\right)$ and CMs $\left(\mathrm{H}-2^{\mathrm{d} / \mathrm{d}}\right)$ for 4 days with and without IFNY $\left.(25 \mathrm{ng} / \mathrm{ml})\right)$ 
treatment and monitored for cell proliferation as described above. Splenocytes from BL6 and DBA mice treated with Con.A served as positive controls, showing higher rate of cell proliferation compared to all other conditions. Unlabeled cells treated with Con.A were investigated to define autofluorescence. eFluor 670 labels cells without Con.A treatment served as a baseline fluorescence control. After co-culture of eFluor 670 labelled splenocytes (responders) with PSC-derivatives (stimulators), the immune cells in the splenocytes are activated and proliferated which resulted in the dilution of the dye in the splenocytes (the peak observed between the unstained stimulated cells and stained unstimulated cells). In the co-culture models; these division peaks were not clearly evident likely because of the heterogeneous splenocyte cell population (Figure 28B). We thus calculated the complete fraction of cells with lower eFluor 670 signal and compared it to the high eFluor 670 non-proliferative cell fraction.

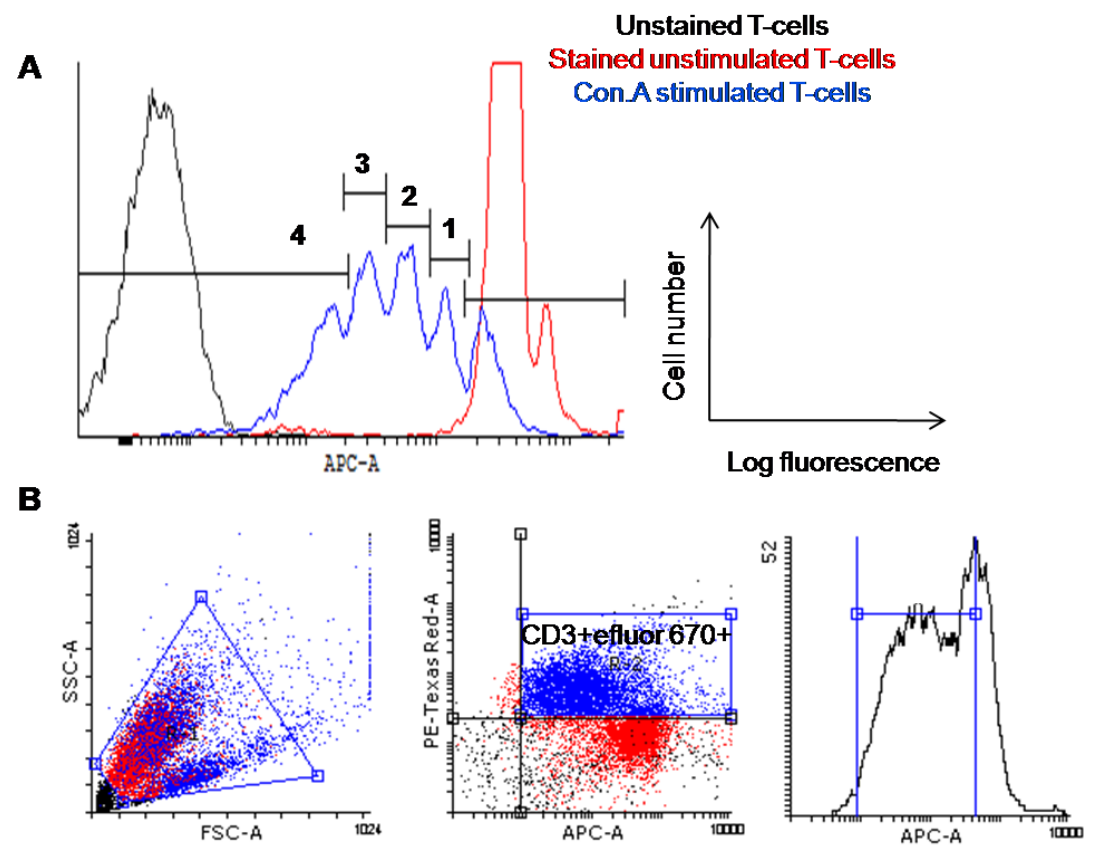

Figure 28: T-lymphocyte proliferation assay. A. Control experiment: treatment of purified eFluor670 (APC-A) T-lymphocytes isolated from Balb/c spleen with the unspecific T-cell stimulator concanavalin A for 4 days resulted in approximately 4 consecutive cell divisions (see peaks in histogram). B. Splenocyte proliferation: treatment of eFluor670 (APC-A) labelled splenocytes isolated from spleen with concanavalin A for 4 days. Live cells were gated based on cell size (FSC-A) and granularity (SSC-A; left dot plot); double positive T-lymphocyte population stained with alexa 594 CD3 (PE-Texas Red-A) and eFluor 670 (APC-A; middle plot); the histogram delineates the proliferating T-lymphocyte population. 


\subsubsection{Strong leukocyte activation by PSC derivatives in monolayer culture}

Under basal conditions, CM and NM enhanced leukocyte proliferation (Figure 29-30). In the T-cell enriched populations proliferation was enhanced massively to Con.A control levels irrespective of the simulated autograft (DBA model; Figure 29) and allograft (BL6 model; Figure 30 ) scenario. IFNy $(25 \mathrm{ng} / \mathrm{ml})$ stimulated cells (48 hours) did not further enhance T-cell proliferation. Only in the unselected splenocyte population cultured with MHC-mismatching PSC-NM allografts there appeared to be enhanced proliferation under IFNy stimulation (Figure 30B).
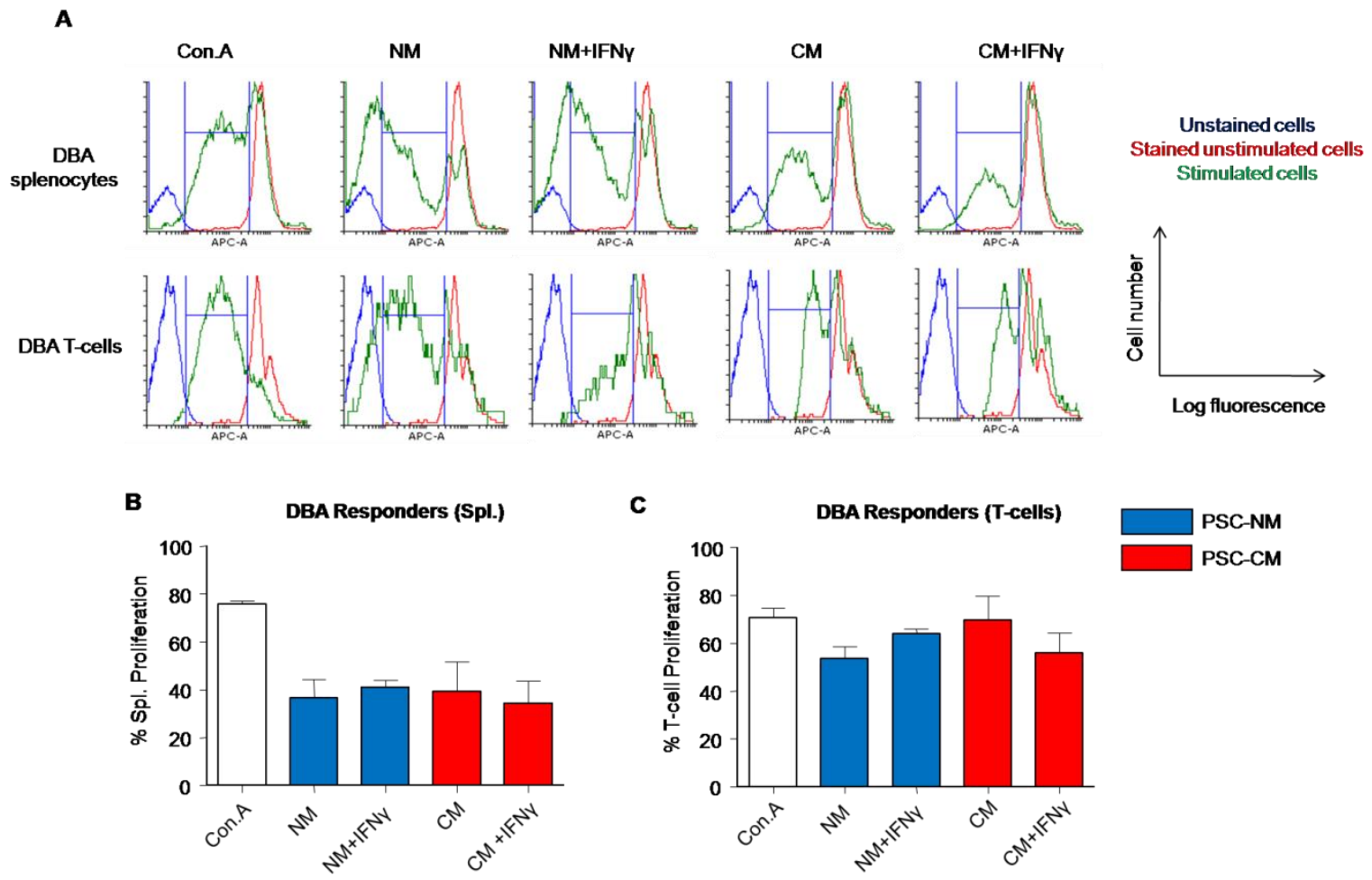

Figure 29: In vitro immunogenicity induction by MHC-matched PSC-derivatives. A. Representative histogram-overlays of unstained cells, stained unstimulated cells and stimulated cells under different conditions. Bar graphs summarizing the data on splenocyte (Spl.) (B) and T-cell (C) proliferation. Con.A Concanavalin A, Spl. Splenocytes. 


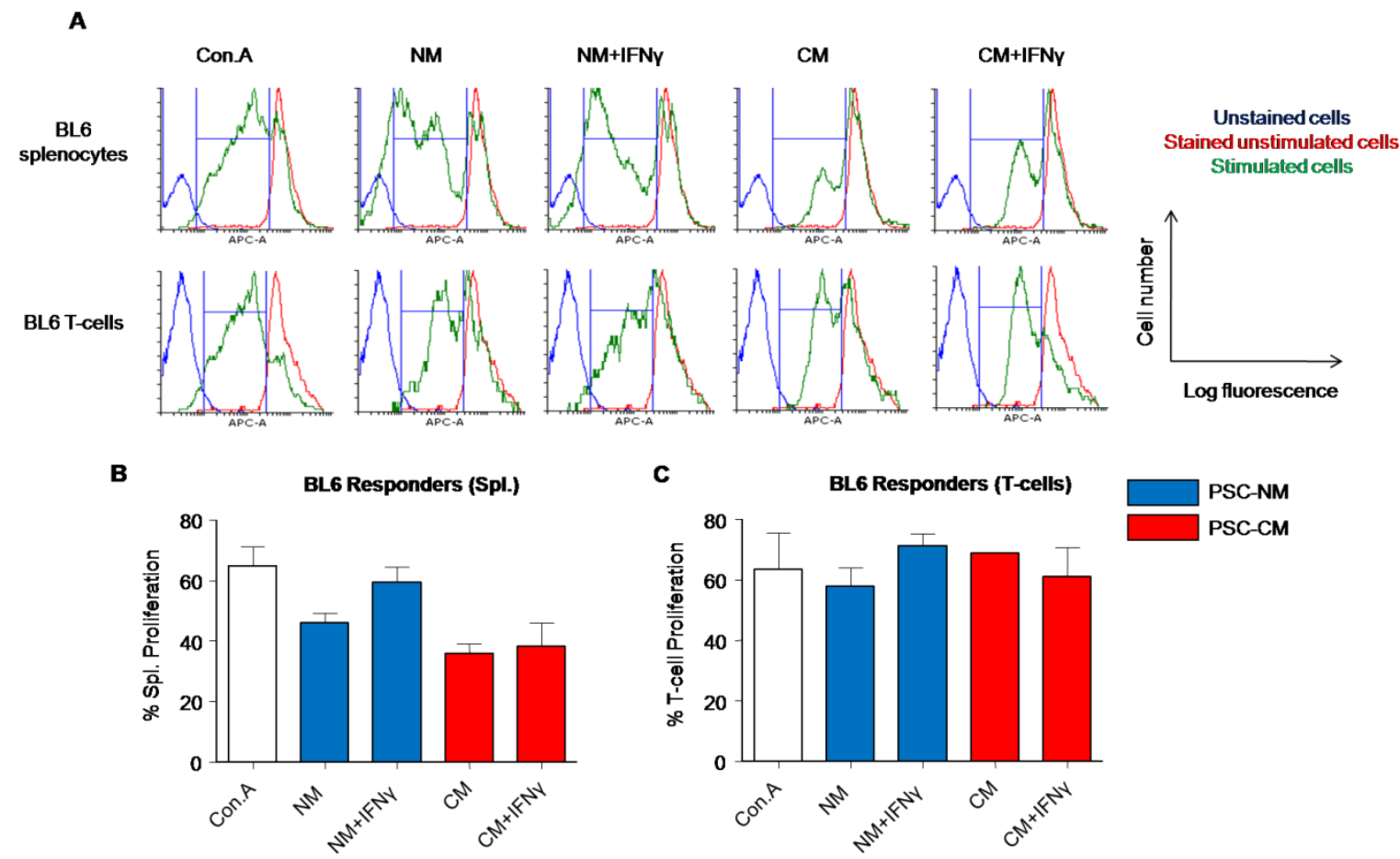

Figure 30: In vitro immunogenicity induction by MHC-mismatched PSC-derivatives. A. Representative histogram-overlays of unstained cells, stained unstimulated cells and stimulated cells under different conditions. Bar graphs summarizing the data on splenocyte (Spl.) (B) and T-cell (C) proliferation. Con.A Concanavalin A, Spl. Splenocytes.

\subsubsection{No leukocyte activation by PSC-engineered heart muscle}

Next, immunogenicity of PSC-EHM was assessed. Similarly as outlined above, eFluor 670 dye labelled splenocytes from BL6 $\left(\mathrm{H}-2^{\mathrm{b} / \mathrm{b}}\right)$ and DBA $\left(\mathrm{H}-2^{\mathrm{d} / \mathrm{d}}\right)$ were co-cultured with EHMs generated from PSC-CM (B3 line-H-2 ${ }^{\mathrm{d} / \mathrm{d}}$ ) and inactivated BL6-MEFs or inactivated DBA-MEFs. In addition, EHMs were treated with IFNy for 48 hours and then co-cultured with eFluor 670 dye labelled splenocytes for 4 days. Inclusion of different MEFs in the EHM resulted either in a complete MHC match or MHC mismatch for the NM-fraction, allowing analysis of different MHC-I match and mismatch combinations between $\mathrm{CM}, \mathrm{NM}$ and responder cells. After 4 days of co-culture, splenocytes were collected and measured for cell proliferation by flow cytometry.

DBA and BL6 responder splenocytes co-cultured with DBA-EHMs and BL6-EHMs did not show significant differences in proliferation, irrespective of IFNy treatment or MHC- 
match situation. A basal proliferation rate of $20 \pm 4.5 \%$ with splenocytes and $15 \pm 3.5 \%$ with T-cells was seen in the matched allograft DBA model (Figure 31A-C). Similarly a minimal proliferation of $12 \pm 3 \%$ in splenocytes and $9 \pm 2 \%$ in T-cells was seen in all the mismatch conditions with BL6 splenocytes (Figure 32A-C).

A
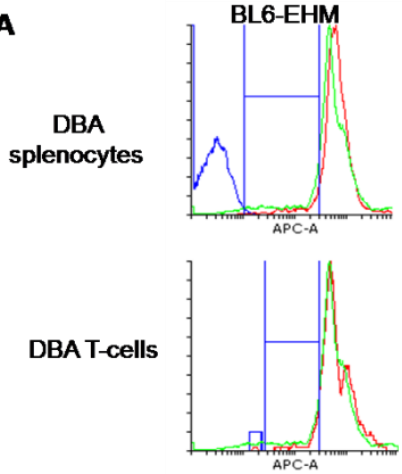

B

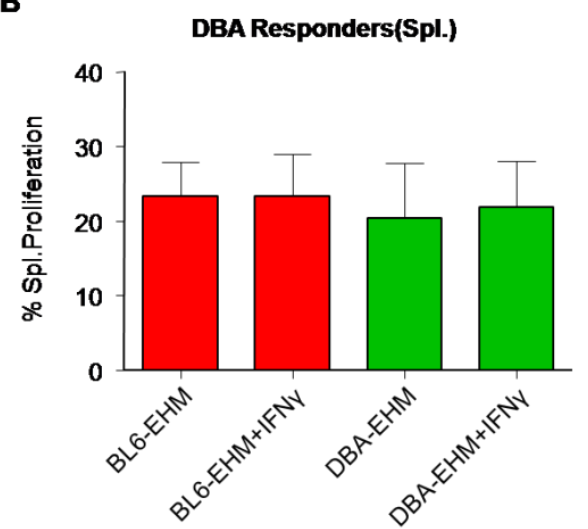

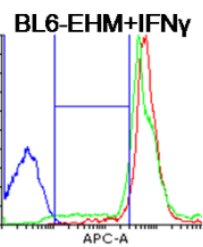
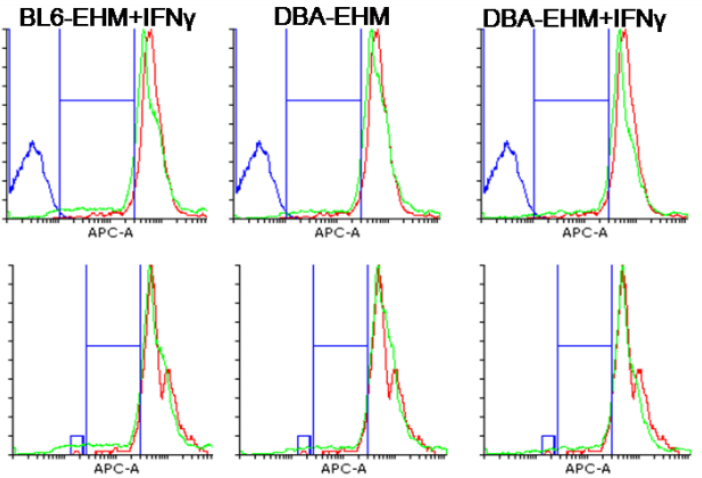

C
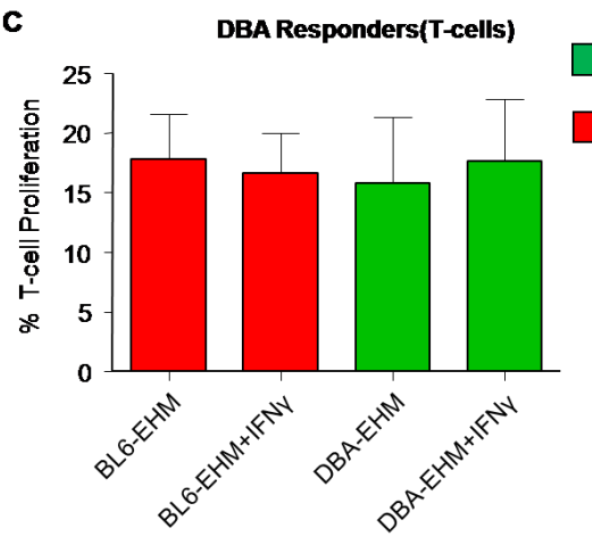

Unstained cells Stained unstimulated cells Stimulated cells

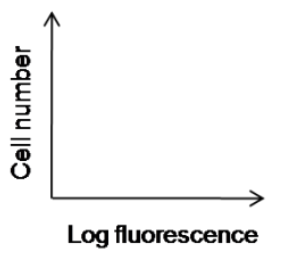

EHM with DBA-MEFs

EHM with BL6-MEFs

Figure 31: In vitro immunogenicity induction by MHC-matched PSC-EHM. A. Representative histogram-overlays of unstained cells, stained unstimulated cells and stimulated cells under different conditions. Bar graphs summarizing the data on splenocyte (Spl.) (B) and T-cell (C) proliferation. Data from three independent experiments. BL6-EHM: CMs + inactivated BL6-MEFs; DBA-EHM: CMs + inactivated DBA-MEFs; with or without IFNy stimulation: 25 ng/mL for 48 hrs. 
A
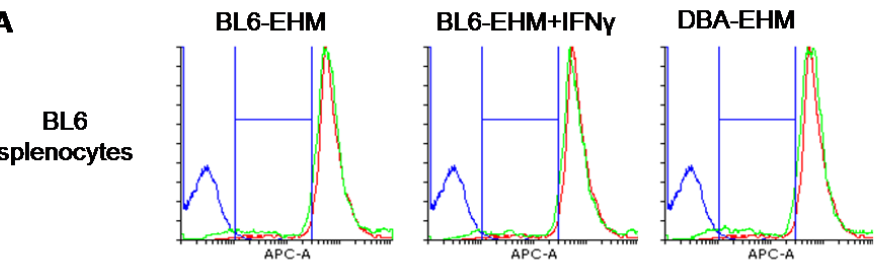

\section{DBA-EHM+IFNy}

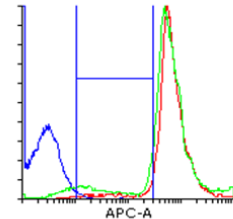

Stained unstimulated cells

Stimulated cellls

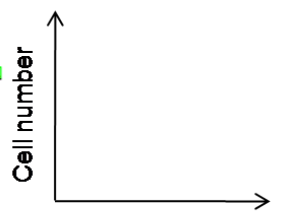

BL6 T-cells
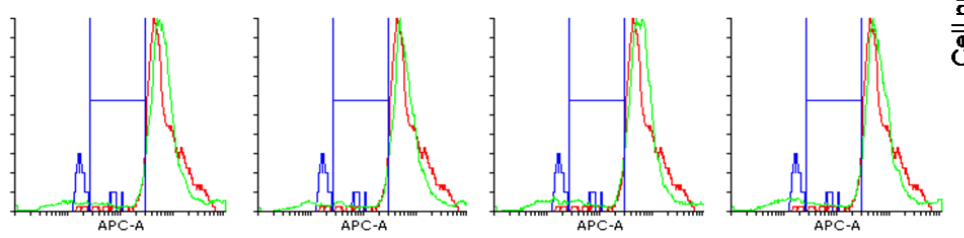

Log fluorescence

B

BL6 Responders (Spl.)

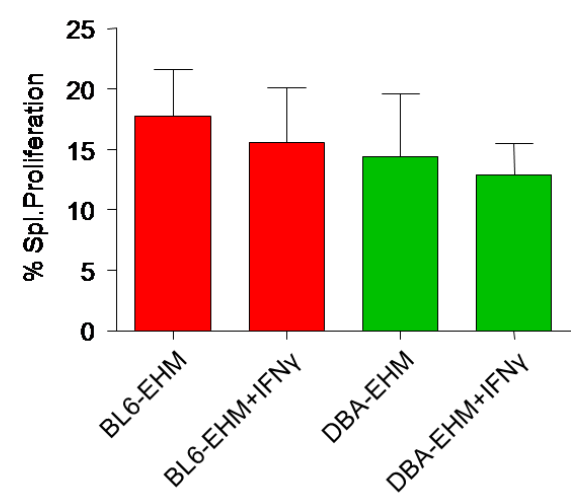

c
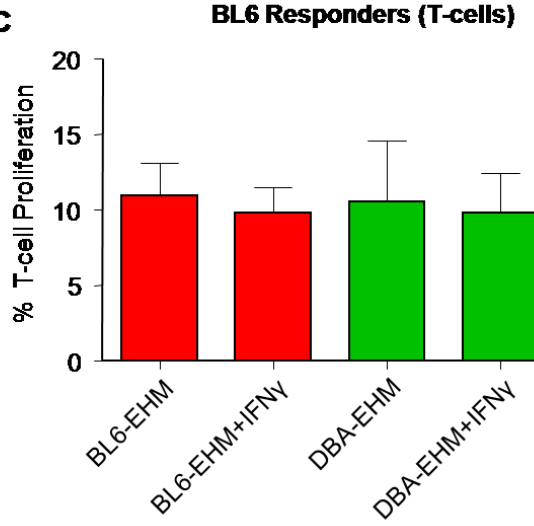

EHM with DBA-MEFs

EHM with BL6-MEFs

Figure 32: In vitro immunogenicity induction by MHC-mismatched PSC-EHM. A. Representative histogram-overlays of unstained cells, stained unstimulated cells and stimulated cells under different conditions. Bar graphs summarizing the data on splenocyte (Spl.) (B) and T-cell (C) proliferation. Data from three independent experiments. BL6-EHM: CMs + inactivated BL6-MEFs; DBA-EHM: CMs + inactivated DBA-MEFs; with or without IFNy stimulation: $25 \mathrm{ng} / \mathrm{mL}$ for $48 \mathrm{hrs}$.

\subsubsection{Activation of cytotoxic T-Lymphocytes}

In the previous experiments the stimulation of splenocyte and T-cell proliferation by PSC-derivatives in monolayer and EHM co-culture were analysed. Proliferation and activation of T-cells can lead to target cell lysis by cytotoxic (CD8 positive) T-cells. To investigate if the PSC-derived CMs can induce a cytotoxic reaction we employed a nonradioactive lactate dehydrogenase (LDH) release assay.

Briefly in this method, T-cells isolated from BL6 and DBA spleens were co-cultured with PSC-CM treated with and without IFNy for 4 hrs which allows the direct contact of T- 
cells with PSC-CM (Figure 33A). Depending on the amount of lysis, lactate dehydrogenase (LDH) is released in to the culture medium. After $4 \mathrm{hrs}$ of co-culture, the medium supernatant is removed and the lysis was measured spectrophotometrically at $490 \mathrm{~nm}$. There was a very low LDH-release with no difference between CM co-cultured with MHC-matched (DBA) and mismatched (BL6) T-cells. After IFNy treatment there was a trend towards a higher $\mathrm{LDH}$-release which was more pronounced in the mismatch condition (Figure 33B).

A
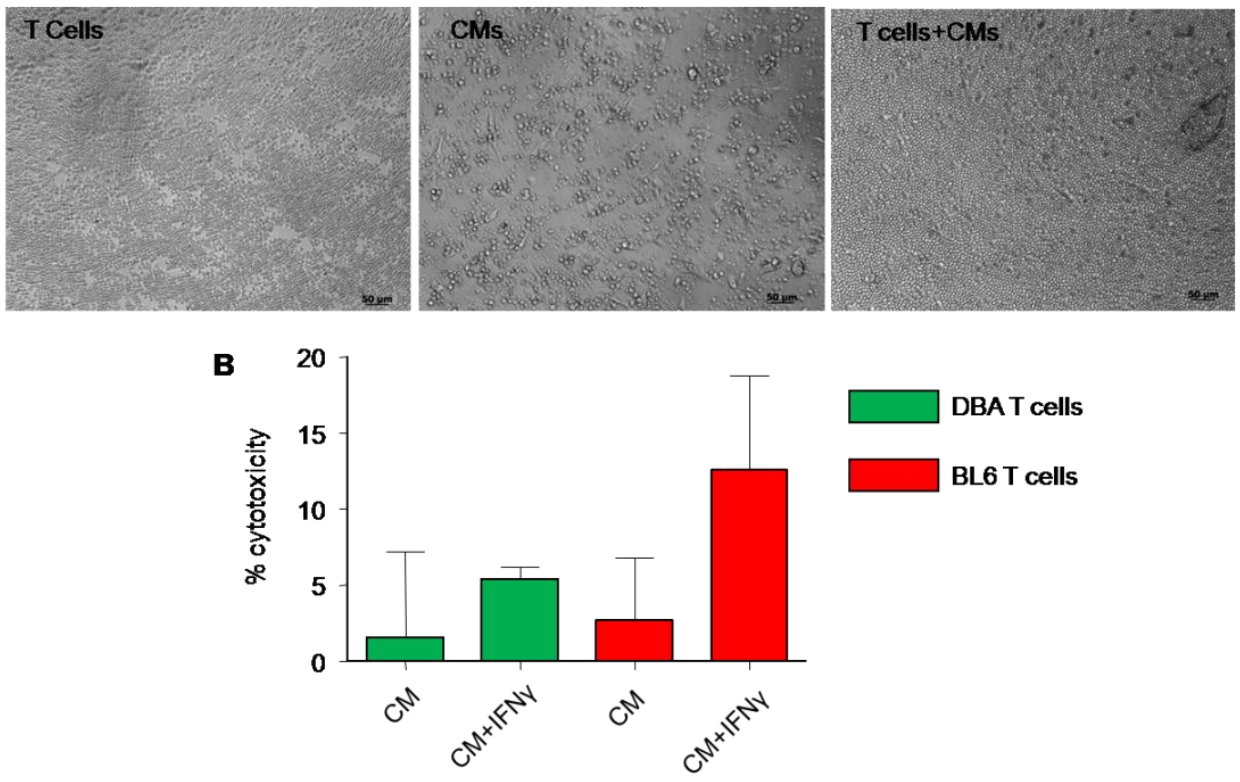

Figure 33: Activation of cytotoxic T-lymphocytes by PSC-CM A. Morphology of T-cells, CMs and coculture. B. Percentage lysis of the target cells was compared between different conditions. Effector cells (T-cells) to target cells (CM) ratio was 10:1. ( $n=3 /$ group).

\subsection{In vivo immunogenicity analysis of PSC-derivatives}

Finally, we evaluated the immunogenicity of PSC-derivatives (NM/CM) in mice with a MHC-match (B6D2F1, H-2 $2^{\mathrm{b} / \mathrm{d}}$; PSC-B3 were derived from B6D2F1 chimeras) and MHCmismatch (BL6, $\mathrm{H}-2^{\mathrm{b} / \mathrm{b}}$ ) background. B6D2F1 mice were chosen to simulate the anticipated clinical scenario of perfect MHC-I matching of PSC-derivatives $\left(\mathrm{H}-2^{\mathrm{d} / \mathrm{d}}\right)$ in an MHC-mismatch recipient with heterozygote expression from the MHC locus (Didie et al., 2013). PSC-derivatives were implanted underneath the kidney capsule either as EBs 
mainly consisting of NMs (Figure 34A) or PSC-derived cardiac bodies mainly consisting of CMs (Figure 34B).

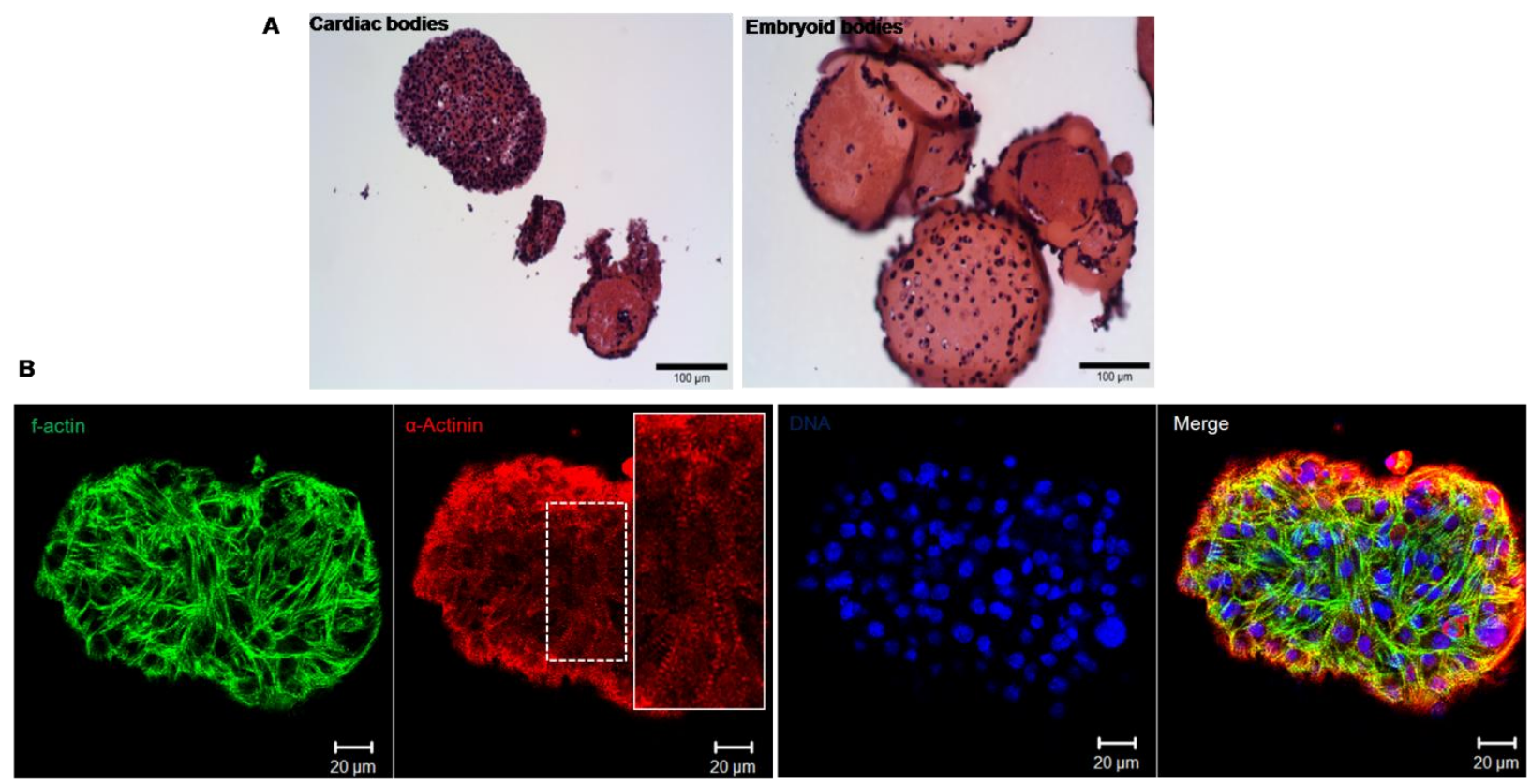

Figure 34: Morphological analysis of PSC-derived cardiac bodies and EBs. A. H\&E staining for cardiac and embryoid bodies. B. Cardiac bodies obtained after selection with G418 were stained for $\alpha$ actinin (red) and f-actin (green); nuclei were labelled in blue (DAPI).

\subsubsection{Retention of PSC-derived cardiac body implants}

Implantation underneath the kidney capsule was chosen to evaluate the effect of MHC-I match and mismatch on immune cell infiltration. The kidney capsule was chosen as implantation site, because of rapid vascularisation and an easy identification of the implants even after weeks (Figure 35A). Kidneys were harvested 1, 3, 7, 14, and 28 days after implantation of cardiac bodies and monitored for graft survival and cellular infiltration. Spontaneous contraction could be observed macroscopically until day 3 and in one animal until day 28 after implantation under MHC-matched conditions and until day 7 under MHC-mismatched conditions (Figure 35). Despite selection to cardiac bodies, one mouse showed a large teratoma in the MHC-matched condition. 


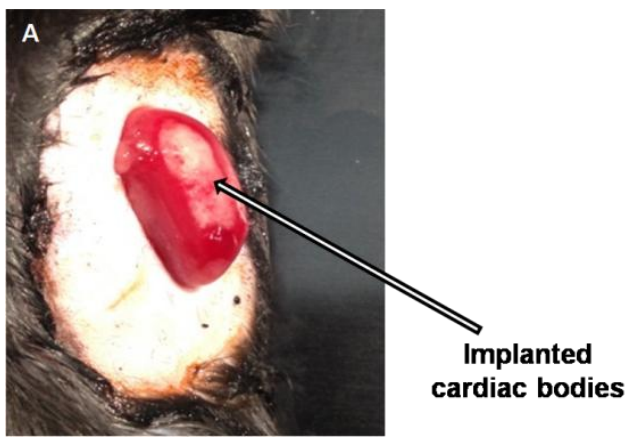

B
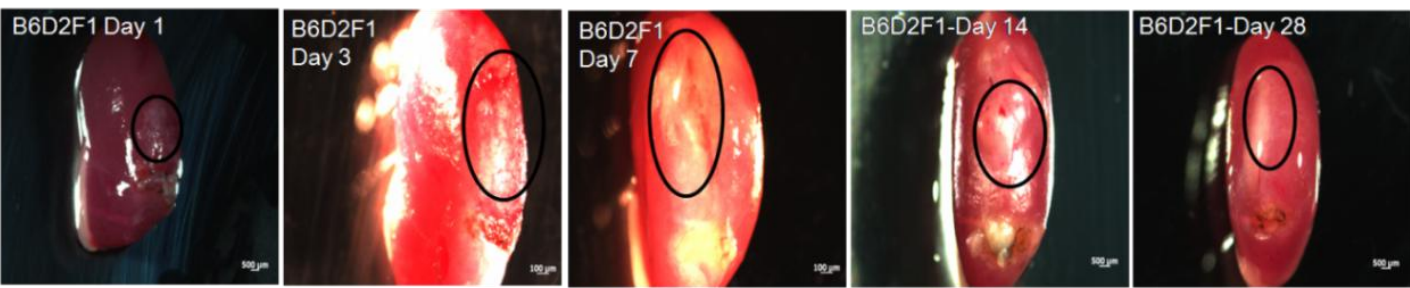

BL6-J Day 1
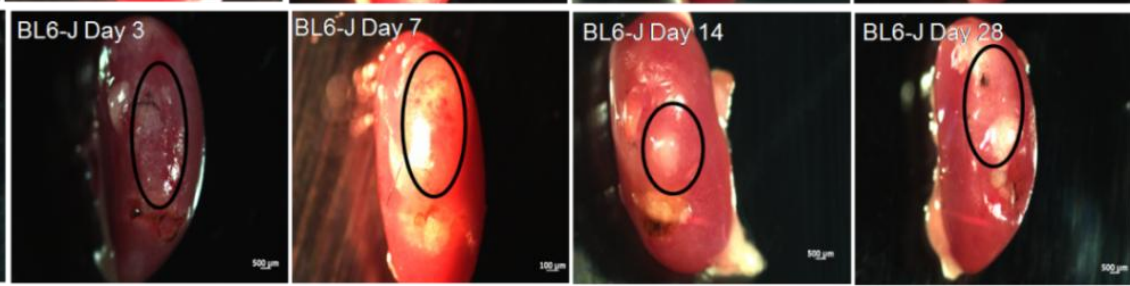

C

\begin{tabular}{|c|c|c|}
\hline Time in days & $\begin{array}{l}\text { Beating activity of MHC-matched } \\
\text { cardiac body implants }\end{array}$ & $\begin{array}{l}\text { Beating activity of MHC- } \\
\text { mismatched cardiac body } \\
\text { implants }\end{array}$ \\
\hline 1 & $\checkmark(n=2)$ & $\checkmark(n=2)$ \\
\hline 3 & $\checkmark(n=2)$ & $\checkmark \checkmark(n=2)$ \\
\hline 7 & $\sec x(n=3)$ & $\checkmark(n=2)$ \\
\hline 14 & $\sec x(n=3)$ & $\sec x(n=3)$ \\
\hline 28 & $\checkmark x x(n=3)$ & $x \operatorname{cx}(n=3)$ \\
\hline
\end{tabular}

Figure 35: Retention of PSC-derived cardiac body implants. A. Macroscopic appearance of a cardiac body implant underneath the kidney capsule (immediately after implantation). B. Representative images of kidneys implanted with cardiac bodies $\left(\mathrm{H}-2^{\mathrm{d} / \mathrm{d}}\right)$ : upper panels show kidneys harvested from B6D2F1 mice $\left(\mathrm{H}-2^{\mathrm{b} / \mathrm{d}}, \mathrm{MHC}-\mathrm{match}\right)$ at the indicated time points after cardiac body implantation; bottom panels show kidneys harvested from BL6 mice ( $\mathrm{H}-2^{\mathrm{b} / \mathrm{b}}, \mathrm{MHC}$-mismatch) at the indicated time points after cardiac body implantation. The site of implantation is highlighted with a black circle. C. Summary of observed beating activity of cardiac bodies immediately after harvesting the kidney from MHC-matched and MHCmismatched mice on the indicated days. The tick mark $(\checkmark)$ represents a beating graft/mouse and a cross mark $(\mathbf{x})$ represents no beating upon visual inspection. 


\subsubsection{Histological analysis}

Kidney explants were subjected to morphological analyses in paraffin sections after H\&E staining to evaluate the status of inflammation and cellular infiltration after implantation in the MHC-match and mismatch conditions. The degree of cellular infiltrates after implantation of cardiac bodies in the MHC-match with missing allele (B6D2F1) and mismatched (BL6) conditions were similar with low to moderate amounts of infiltration at days 7, 14 and 28 after implantation (Figure 36).In contrast, after implantation of EBs a high cellular infiltration could be observed within 7 days after implantation in both matched and mismatched conditions. At day 14 and day 28 the EB grafts were mostly rejected (Figure 37 ). 

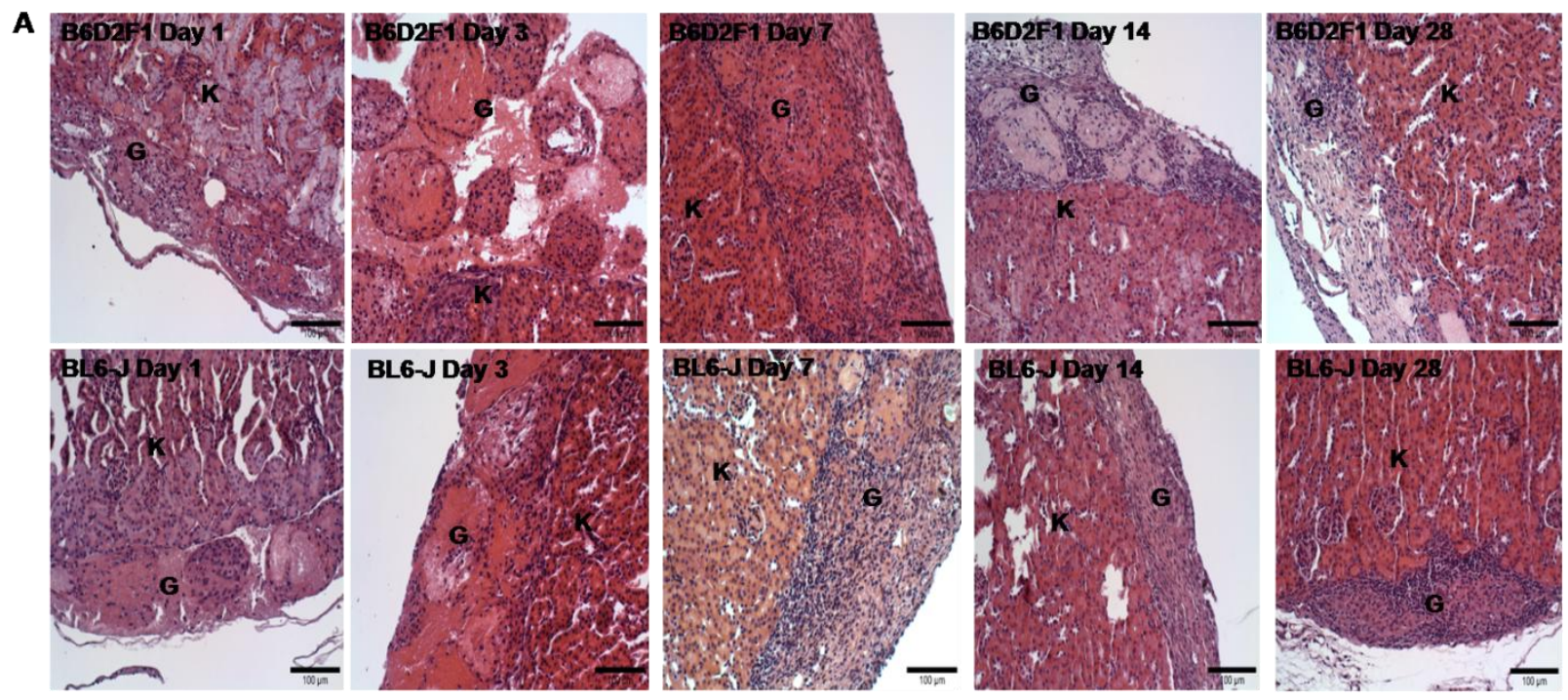

B

\begin{tabular}{|c|c|c|}
\hline Time in days & $\begin{array}{c}\text { Cellular infiltration in MHC- } \\
\text { matched mice after cardiac body } \\
\text { implantation }\end{array}$ & $\begin{array}{c}\text { Cellular infiltration in MHC- } \\
\text { mismatched mice after cardiac } \\
\text { body implantation }\end{array}$ \\
\hline 1 & $(-)(+)(n=2)$ & $(-)(-)(n=2)$ \\
\hline 3 & $(-)(-)(n=2)$ & $(+)(++)(n=2)$ \\
\hline 7 & $(-)(+)(++)(n=3)$ & $(+)(++)(n=2)$ \\
\hline 14 & $(-)(+)(++)(n=3)$ & $(-)(+)(++)(n=2)$ \\
\hline 28 & $(-)(+)(++)(n=3)$ & $(+)(++)(-)(n=3)$ \\
\hline
\end{tabular}

Figure 36: H\&E staining of kidney sections implanted with cardiac bodies. A. Upper panels show kidneys harvested from B6D2F1 mice $\left(\mathrm{H}-2^{\mathrm{b} / \mathrm{d}}, \mathrm{MHC}\right.$-match) at the indicated time points after cardiac body implantation $\left(\mathrm{H}-2^{\mathrm{d} / \mathrm{d}}\right)$. The lower panel show kidneys harvested from BL6-J mice $\left(\mathrm{H}-2^{\mathrm{b} / \mathrm{b}}, \mathrm{MHC}-\mathrm{mismatch}\right)$ at the indicated time points after implantation. K: kidney; G: graft. B. Summary of morphological findings with a focus on inflammatory responses i.e., round cell infiltration, in MHC-matched implants (in B6D2F1 mice) and MHC-mismatched implants (in BL6-J mice) at the indicated time points after implantation; semi quantitative score: - No, + little, ++ moderate, +++ extensive. 
A
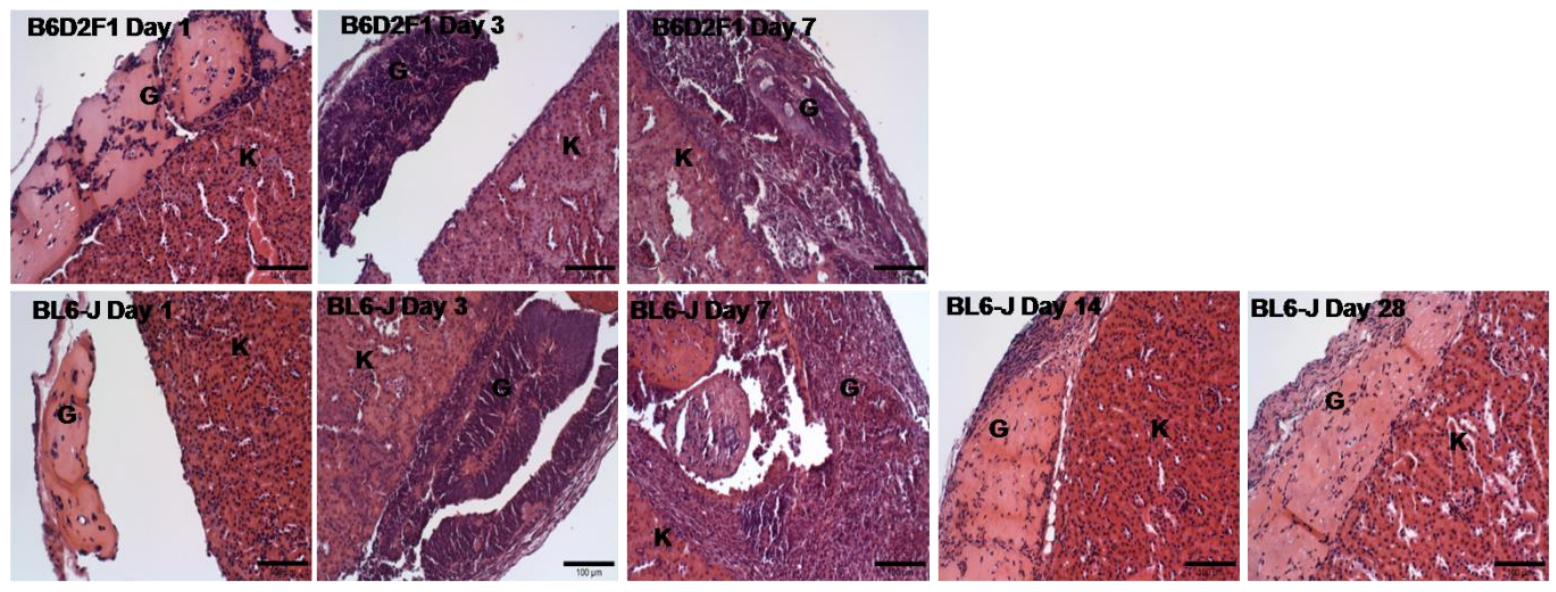

B

\begin{tabular}{|c|c|c|}
\hline Time in days & $\begin{array}{c}\text { Cellular infiltration in MHC- } \\
\text { matched mice after EB } \\
\text { implantation }\end{array}$ & $\begin{array}{c}\text { Cellular infiltration in MHC- } \\
\text { mismatched mice after EB } \\
\text { implantation }\end{array}$ \\
\hline 1 & $(+)(\mathbf{n}=1)$ & $(+)(\mathbf{n}=1)$ \\
\hline 3 & $(+)(+)(-)(\mathbf{n}=3)$ & $(++)(\mathbf{n}=1)$ \\
\hline 7 & $(+++)(\mathbf{n}=1)$ & $(+++)(\mathbf{n}=1)$ \\
\hline 14 & & $(-)(\mathbf{n}=1)$ \\
\hline 28 & & $(-)(\mathbf{n}=1)$ \\
\hline
\end{tabular}

Figure 37: H\&E staining of kidney sections implanted with embryoid bodies. Upper panels show kidneys harvested from B6D2F1 mice $\left(\mathrm{H}-2^{\mathrm{b} / \mathrm{d}}, \mathrm{MHC}\right.$-match) at the indicated time points after EB implantation $\left(\mathrm{H}-2^{\mathrm{d} / \mathrm{d}}\right)$. Lower panels show kidneys harvested from BL6-J mice $\left(\mathrm{H}-2^{\mathrm{b} / \mathrm{b}}, \mathrm{MHC}-\mathrm{mismatch}\right)$ at the indicated time points after EB implantation $\left(\mathrm{H}-2^{\mathrm{d} / \mathrm{d})}\right)$. K: kidney; G: graft. B. Summary of morphological findings with a focus on inflammatory responses, i.e., round cell infiltration, in MHC-matched EB implants (B6D2F1 mice) and MHC-mismatched EB implants (in BL6-J mice) at indicated time points after implantation; semi quantitative score: - No, + little, ++ moderate, +++ extensive. 


\section{Discussion}

The largely haploidentical genome of parthenogenetic stem cells, generated by artificial activation in MII oocytes (Figure $5 \mathrm{C}$ ), makes them immunologically attractive for cell based organ repair applications. MHC-haploidentical cells may be applicable broadly with minimal transient or even without immune suppression as allografts in MHCmatched recipients (Nakajima et al., 2007; Taylor et al., 2005). In this study we generated a novel transgenic H-2 haploidentical PSC line carrying a NeoR gene expressed under the control of the cardiomyocyte restricted a-myosin heavy chain (MYH6) promoter (Klug et al., 1996). Bioreactor protocols for scalable cardiomyocyte differentiation as well as selection and subsequent application in myocardial tissue engineering were established. As to their immunological properties, we found that PSCderived cardiomyocytes (CM) exhibited little to no MHC-I and MHC-II, little to no CD40 and CD86 as well as little to no PD-L1 and PD-1, but notable CD80 and CD1d expression under basal conditions. PSC-derived non-myocytes (NM) showed little to no MHC-II, little to no CD40, CD80, and CD86 as well as little to no PD-L1 and PD-1, but notable MHC-I and CD1d expression under basal conditions. Simulated "inflammation" by stimulation with IFNY increased MHC-I, MHC-II, and PD-L1 in all investigated cells. CD86 was enhanced in PSC-derived NMs under IFNY in 1 out of 3 experiments. Interestingly, transient IFNy resulted in sustained activation of MHC-I in PSC-derived CMs and NMs. PSC-EHM were in general less susceptible to IFNY with only enhanced MHC-I and PD-L1. In a mixed lymphocyte reaction type experiment, massive lymphocyte activation by autologous or allogeneic PSC-derivatives was observed in monolayer culture. Conversely, no lymphocyte activation under basal and IFNY stimulated conditions was observed in EHM culture. Finally, cytotoxicity appeared to be enhanced in a simulated allograft scenario. Implantation of PSC-CM and PSC-NM (H$\left.2^{\mathrm{d} / \mathrm{d}}\right)$ under the kidney capsule in two allogeneic mouse models with a MHC-match $(\mathrm{H}-$ $\left.2^{\mathrm{b} / \mathrm{d}}\right)$ and a complete MHC-mismatch $\left(\mathrm{H}-2^{\mathrm{b} / \mathrm{b}}\right)$ showed no obvious difference in immune cell infiltration (implant study for 4 weeks). However, in one mouse with a MHC-matched implant beating was observed even after 4 weeks. Collectively, these data support the 
notion that PSC-derivatives are not immunologically naive, but may be suitable for MHC-matching without immune suppression

\subsection{Generation and differentiation of a neomycin selectable PSC line}

A selectable marker gene (NeoR) was introduced into the B3 PSC line with confirmed haploidentity in the $\mathrm{H}-2$ locus. Although derived from B6D2F1 chimeras this line expresses only the DBA H-2-haplotype $\mathrm{H}-2^{\mathrm{d} / \mathrm{d}}$. Haploidentity is a common feature in PSC-lines, rendering them potentially advantageous for allograft applications with MHCmatching (Didie et al. 2013). We chose a NeoR as a well-established selectable marker gene under transcriptional control by the cardiomyocytes-specific alpha myosin heavy chain (MYH6) promoter. MYH6 is detectable early in the developing heart in vivo and it is specific for cardiomyocytes in differentiating ES cells (Boheler et al., 2002; Gulick et al., 1991). After successful integration of the aMHC-NeoR transgene into the B3-PSC line, a spinner flask suspension culture was established to allow scaling of cardiomyocyte differentiation. In the presence of G418 spontaneously beating EBs could be converted into cardiac bodies comprised of $>90 \%$ cardiomyocytes. This was in line with the original description of this selection procedure in mouse embryonic stem cells (Klug et al., 1996) and our recent study on the genetic manipulation of PSCs using a similar strategy (Didie et al., 2013). In spinner flasks we succeeded to produce $25 \pm 5 x$ $10^{6}$ cardiomyocytes from $10 \times 10^{6}$ input PSCs. We have not attempted to apply directed differentiation (Kattman et al., 2011) or metabolic (Tohyama et al., 2013) selection which may achieve similar numbers and purity without the need for genetic manipulation. These protocols are well established in human models, but so far not used widely in the mouse. For a clinical approach it is very important to generate a pure population of cardiomyocytes from any stem cell source, since after implantation the presence of proliferating stem cells might lead to the formation of teratoma. It was shown that as few as 1950 pluripotent stem cells can lead to teratoma formation (Hentze et al., 2009). 


\subsection{Immunologically relevant proteins on PSC-derived cardiomyocytes and non- myocytes}

PSC and PSC-derivatives have unique immunological properties because they are typically homozygous at the MHC locus (Didie et al., 2013). This is because the MHC locus in mouse and human is located near the centromere and thus does typically not crossover during meiosis (Revazova et al., 2008). There is very little information available on the expression of immunologically relevant molecules on PSC-derivatives. Thus we assessed the expression of MHC-I, MHC-II, CD-40, CD-80, CD-86, CD1d, PDL1 and PD-1 in cardiomyocytes (CM) and non-myocytes (NM) derived from the $\mathrm{H}-2^{\mathrm{d} / \mathrm{d}}$ B3 line. NMs showed significant expression of MHC-I and CD1d, whereas CMs showed no expression MHC-I, MHC-II but CD80 and CD1d expression was observed under basal conditions. This argues for low MHC-related immunogenicity of $\mathrm{CM}$. In order to mimic inflammatory conditions that generally occur during cardiovascular diseases like myocardial infarction or viral myocarditis, PSC-NM and PSC-CM were treated with IFNY. After IFNY stimulation, MHC-I $\left(H-2 K^{d}\right)$, MHC-II $(I-A / I-E)$ and PD-L1 were upregulated significantly in PSC-NM and PSC-CM. This data is in accordance with observations in ESC derivatives (Bonde and Zavazava, 2006; Lampton et al., 2008). The demonstration that MHC-I is expressed in CM under IFNy stimulation did however suggest that immunological competence may be achieved quickly under in vivo conditions. Up-regulation of MHC-I expression after IFNy treatment was persistent; suggesting that PSC-derivatives, once immunologically challenged, obtain sustained MHC-I $\left(\mathrm{H}-2 \mathrm{~K}^{\mathrm{d}}\right)$ with associated immunogenicity.

The expression levels of immunological molecules such as MHC-I, MHC-II and co stimulatory molecules (CD80, CD86, CD40) was very low in undifferentiated PSC which was hardly influenced by IFNY treatment. It has been shown that human ES cells express MHC-I proteins in very low levels (Suarez-Alvarez et al., 2010). Although most somatic cells express high levels of $\mathrm{MHC}-\mathrm{I}$, the in vitro and in vivo differentiated derivatives of human ESCs apparently retain a low level of MHC-I expression. Consistent with our data, addition of IFNs in particular IFNy to the growth media of differentiated human ES cells resulted in high levels of MHC-I protein expression 
(Drukker et al., 2002). In NM we observed high (35\% of all PSC-NM) expression of MHC-I under basal conditions which could be increased to nearly $100 \%$ after IFNY treatment. Consequently, it may be anticipated that NMs trigger rejection more strongly than CMs.

When T-cells recognize mismatched antigen presented by either a donor or recipient APC, a signal is delivered to the T-cell via the TcR/CD3 complex. Immediately a second co-stimulatory signal is received that activates the T-cell, triggering it to divide or proliferate to differentiate and communicate with other leukocytes that can then participate in the rejection response. This second signal is delivered for CD4+ T-cells when a co-stimulatory B7.1 (CD80) molecule on the APC binds with the CD28 receptor on the T-cell. On the other hand CD8+ T-cells receive their co-stimulation and definitive activation by helper T-cells. An absence of co-stimulation will render a T-cell anergic, i.e., non-responsive to further stimulation by the antigen (Boyd et al., 2005). In this study we could detect only a very low expression of co-stimulatory molecules (CD40, CD80 and CD86) on PSC-NM and PSC-CM even after IFNY stimulation. Theoretically this should ameliorate or completely inhibit a rejection of PSC-derivatives in vivo despite MHC-I expression.

CD1d molecule was significantly expressed at basal conditions on PSC-derivatives and was not altered after IFNy treatment. CD1d is a non classical MHC-I like molecule generally expressed on thymocytes, dendritic cells, activated monocytes and B lymphocytes. It is also expressed on T-cells and non-haematopoetic cells like CMs and endothelial cells, CoxsakievirusB3 (CVB3) myocarditis infections can enhance CD1d expression (Liu and Huber, 2011). NKT-cells kill CVB3 infected CD1d positive CMs in a Fas-dependent manner, which aids in viral control by eliminating infected cells early in the virus replication cycle (Huber, 2005). In a mouse model of CVB3 induced myocarditis, an infection activates heart-specific, autoimmune CD8+ cytolytic Tlymphocytes (NKT cells) (Guthrie et al., 1984; Huber and Lodge, 1984) which kill uninfected cardiomyocytes through recognition of cardiac myosin epitopes. All this data suggests that expression of CD1d on cardiomyocytes might activate the NKT cells which further results in death of CMs. Intrestingly CD1d expression on PSC-EHM- 
derived cells was low compared to its expression on PSC-CM in a monolayer culture suggesting a low propensity for NKT cell activation.

An important mechanism regulating the peripheral tolerance and autoimmunity is the expression of programmed death-1 (PD-1) receptor (Francisco et al., 2010; Tarrio et al., 2012). Binding of PD-1 to its ligand programmed death ligand 1 (PD-L1) results in the upregulation of suppressive functions such as T-cell anergy or stimulation of Tregs in the immune system. PD-L1 is broadly expressed on hematopoietic cells and nonhematopoietic cells such as vascular endothelial cells, epithelial cells, muscle cells, hepatocytes, placental cells and islet cells (Riella et al., 2012). Myocardial injury is associated with up regulation of endogenous inflammatory mechanisms (Baban et al., 2014). It has been shown that expression of PD-1 and PD-L1 were significantly increased in the ischemic-reperfused heart (Baban et al., 2015). PSC-derived CMs showed an upregulation of PD-L1 after IFNy stimulation. In contrast PD-1 expression was not observed even after IFNy stimulation. Absence of PD-1 and presence of PD-L1 on PSC-CM might have important role in the immunoregulatory mechanism of CMs and lead to an immune suppressive effect of cardiomyocytes.

\subsection{Expression of immunologically relevant molecules in EHM}

Expression of immunological molecules MHC-I, MHC-II, CD40, CD80, CD86 and CD1d was studied on EHM derived PSC-CM. EHMs were generated from 70\% PSC-CM and $30 \%$ NMRI MEF and showed functional properties similar to native myocardium. With respect to adrenergic stimulation with isoprenaline the EHM derived from PSC30B3 cell line did not show any significant effect in contrast to the EHM made from PSCA3 (Didie et al., 2013). The positive inotropic response of cardiomyocytes after beta-adrenergic stimulation increases in parallel with a maturation of the cells. Thus CMs derived from PSCA3 might be more matured compared to CMs derived from PSC30B3. However immunofluorescence staining for $\alpha$-actinin and troponin I after additional 7 days of culture under constant load demonstrated the presence of well developed cardiomyocytes with regular sarcomeric cross-striations and expression of gap-junction proteins (Connexin-43). It has been shown that immature cardiomyocytes terminally 
differentiate and mature in an organotypic manner in engineered heart tissue model with time (Tiburcy et al., 2011). With this information one can assume that PSC-CM might also immunologically mature in the EHM model. PSC-CMs in EHM showed negligible expression of $\mathrm{MHC}$-molecules and co-stimulatory molecules. Even after IFNY stimulation only MHC-I and PD-L1 was significantly up regulated and other molecules were unchanged. Taken together, we assume that lack of MHC-II expression on EHM derived cells argues for the immunological maturity of PSC-CM in EHM model.

\subsection{MHC-I expression on neonatal and adult heart cardiomyocytes}

After finding low MHC-I expression on PSC-CM we were investigating if this is a feature of PSC-derived CM or if it is a general characteristic of CM. To this means we stained $\beta$ 2 microglobulin on adult $\mathrm{CM}$. The rationale for choosing $\beta$-2-microglobulin for immunofluroscence was because there is no optimal antibody available for staining of MHC-I $\left(\mathrm{H}-2 \mathrm{~K}^{\mathrm{d}}\right)$ in fixed cells and tissue samples and because $\beta-2$ microglobulin is a component of MHC-I molecules. Staining for $\beta-2$ microglobulin after IFNY stimulation showed that this protein was mostly localized surrounding the nucleus with a spotty appearance through put the cell. $\beta-2$ microglobulin is processed in the endoplasmic reticulum before it is transported to the membranes (Dargemont et al., 1991). Better resolved microscopy would need to be performed to identify whether the spotty $\beta-2$ microglobulin signals are located at the outer cell membrane including its invaginations (t-tubules). In line with our in vitro observation Rose et al. showed that normal myocardium does not express MHC-antigens, however after transplantation MHC-I antigens can be induced (Rosa and Fellous, 1988). Wang et al. showed that hESC cells lacking $\beta-2$ microglobulin show reduced killing by CD8+ T-cells (Wang et al., 2015).

Two fold recognition of MHC-I and MHC-II antigens is necessary for activation by cytotoxic T-cells for lysis of virus-infected cells and cells bearing alloantigens (transplanted cells) (Zinkernagel and Doherty, 1979). The MHC-II antigens are involved in cellular communication that regulates the immune response. These antigens are found primarily on interstitial dendritic cells in the heart (Daar et al., 1984). It was demonstrated that normal fetal and adult myocytes express very low levels of MHC-I 
antigens and do not have detectable levels of MHC-II antigens (Seko et al., 1990). Endothelial cells lining the microvasculature might express both MHC-I and MHC-II antigens (Rose et al., 1985). In conclusion these findings might explain why the heart is relatively resistant to organ rejection after transplantation and why the chronic rejection after heart transplantation is mainly directed against the vasculature.

\subsection{In vitro immunogenicity of PSC-derived cardiomyocytes and non-myocytes}

In order to study the susceptibility of PSC-derivatives to elicit an immune reaction, we employed in vitro proliferation assay. In this assay haploidentical PSC-NM $\left(\mathrm{H}-2^{\mathrm{d} / d}\right)$ and haploidentical PSC-CM $\left(\mathrm{H}-2^{\mathrm{d} / \mathrm{d}}\right)$ were co-cultured with labeled splenocytes from related MHC-match DBA $\left(\mathrm{H}-2^{\mathrm{d} / \mathrm{d}}\right)$ and unrelated MHC-mismatch BL6 $\left(\mathrm{H}-2^{\mathrm{b} / \mathrm{b}}\right)$ mice. Many groups have used $\left[{ }^{3} \mathrm{H}\right]$ thymidine labeling of cells for measuring the proliferative response of responder cells (splenocytes). We attempted to label $\mathrm{CMs}$ with $\left[{ }^{3} \mathrm{H}\right]$ thymidine and encountered problems with background release, which required the use of an alternative method (eFluor 670 labeling). The use of fluorescence cell labeling for cell migration and proliferation under in vitro and in vivo conditions has been shown by many groups, it was also demonstrated that these fluorescent dyes show low variance and low toxicity (Quah and Parish, 2012; Quah et al., 2007).

Proliferation of the T-lymphocyte population from the splenocytes was investigated by staining with CD3. In the MHC-match condition PSC-NM and PSC-CM show a similar degree of splenocytes and T-lymphocytes activation ( $35 \pm 3 \%$ and $55 \pm 3 \%$ ); IFNy did not enhance lymphocyte proliferation. This data suggests that upregulation of MHC-I, MHCII after IFNy stimulation does not have any effect in stimulating the proliferation of MHCmatched splenocytes or T-lymphocytes in vitro. Poor resolution of division peaks in the co-culture set up might be because of heterogeneous responders (splenocytes) population, whereas pure T-lymphocytes stimulated with mitogen concanavalin A (Con. A) showed clear division peaks (Figure 29A).

In MHC-mismatch condition BL6 $\left(\mathrm{H}-2^{\mathrm{b} / \mathrm{b}}\right)$, splenocyte proliferation appeared to be stimulated by PSC-NM after IFNy treatment. Conversely, PSC-CM did not show any 
effect on proliferation of splenocytes and T-lymphocytes with IFNy treatment. Our data is in accordance with Malliaras et.al where they have showed that allogeneic rat cardiosphere derived cells (CDCs) elicited negligible lymphocyte proliferation comparable to that seen with syngeneic CDCs (Malliaras et al., 2012). In contrast it has been demonstrated that undifferentiated syngeneic iPSC and their derivatives lack immunogenicity in vitro, whereas with allogeneic iPSC and their derivates a strong stimulation to proliferation was observed (Guha et al., 2013). Baban et al. showed that cells prepared from normal hearts increased T-cell proliferation suggesting their role in antigen presentation, whereas ischemic reperfused cardiac cells significantly reduced the percent of proliferating T-lymphocytes which can be reversed by treatment with PDL1 blocking antibody (Baban et al., 2015). However, we did not find significant differences in PD-L1 expression between PSC-CM and PSC-NM. H-2K ${ }^{b}$ specific T-cells analyzed in the spleen after 25 days of post transplantation with heart allograft showed that $\sim 50 \%$ of carboxyfluorescein succinimidyl ester (CFSE) labeled T-cells divided six times in response to the graft. These $\mathrm{H}-2 \mathrm{~K}^{\mathrm{b}}$ specific $\mathrm{T}$-cells that responded to the graft showed characteristics of memory cells and were capable of producing IL-2 and IFNY on restimulation (Jones et al., 2001). Finally, splenocytes obtained from a mouse which is pre-sensitized with PSC-derivatives might be immunologically more active and might show an immune reaction. Taken together, our in vitro proliferation data suggests that PSC-CM exhibit a limited effect on splenocyte and T-lymphocyte proliferation from MHC-match (DBA) and MHC-mismatch conditions (BL6).

In this study we show that DBA $\left(\mathrm{H}-2^{\mathrm{d} / \mathrm{d}}\right)$ splenocytes and T-lymphocytes after co-culture with EHM generated from PSC-CM $\left(\mathrm{H}-2^{\mathrm{d} / \mathrm{d}}\right)$ and DBA-MEF $\left(\mathrm{H}-2^{\mathrm{d} / \mathrm{d}}\right)$ as well as EHM made with PSC-CM $\left(\mathrm{H}-2^{\mathrm{d} / \mathrm{d}}\right)$ and BL6-MEF $\left(\mathrm{H}-2^{\mathrm{b} / \mathrm{b}}\right)$ show an average proliferation rate of $15 \pm 10 \%$, MHC-I upregulation in the EHM after IFNY has no effect on the immune cell proliferation rate. Also an MHC-mismatch of the MEFs failed to stimulate the proliferation of splenocytes and T-lymphocytes. This might be either because of less duration of co-culture of EHMs and splenocytes (4 days) or improper contact of responder (splenocytes/T-lymphocytes) and stimulator (CM/MEF) cells or lack of sufficient stimulation on the stimulator cells. Similar results were seen when BL6 $\left(\mathrm{H}-2^{\mathrm{b} / \mathrm{b}}\right)$ 
splenocytes and T-lymphocytes were co-cultivated with DBA-EHM (with DBA-MEF) and BL6-EHM (with BL6-MEF) with an average proliferation rate of $10 \pm 5 \%$. The rationale behind using MHC-matched and -mismatched MEFs was because we know from studies in our group that for the successful generation of EHM, non-myocytes are essential. Non-cardiomyocytes can be allogeneous, e.g. PSC-derived, but also easily generated autologously, e.g. by generating fibroblasts from skin-biopsies, in a clinical application.

Pluripotent stem cell derived cells stimulated with IFNY present MHC-I antigens on their cell surface, these antigens with specific peptide interact with cytotoxic T-lymphocytes (Varda-Bloom et al., 2000). To confirm that cytotoxic lymphocytes are involved in lysis of PSC-CM we used non radioactive method of cytotoxicity measurement. Our results suggested that the killing of PSC-CMs by CTLs was negligible (10\%) even after IFNY stimulation in the complete MHC-mismatch condition (BL6). This data contradicts with a study where murine ESCs are lysed by allogeneic CTLs after treating the ESCs with IFNy (Bonde and Zavazava, 2006). It has been shown that susceptibility to lysis of the ESC derivatives could be increased through pre-incubation with IFNy for 48 hrs, the resulting lysis efficiency was however lower than lysis of normal fibroblasts (Kadereit and Trounson, 2011). This data strongly confirms that PSC-CMs have immune privileged properties under normal conditions.

\subsection{In vivo immunogenicity of PSC-derived cardiomyocytes and non-myocytes}

In this study we investigated the immunological tolerance of PSC-CM $\left(\mathrm{H}-2^{\mathrm{d} / \mathrm{d}}\right)$ after allograft implantation in MHC-matched (B6D2F1, $\mathrm{H}-2^{\mathrm{d} / \mathrm{b}}$, with missing allele) and $\mathrm{MHC}$ mismatched ( $\mathrm{BL6}, \mathrm{H}-2^{\mathrm{b} / \mathrm{b}}$ ) mouse models under the kidney capsule. The rationale behind choosing kidney as the site of implantation was because it is easily accessible and transplanted EBs are well contained under the kidney capsule in a highly vascularized site (DeWard et al., 2014). Many groups have shown that cells injected directly into myocardium are mostly lost in the blood circulation and their viability is highly compromised (Paulis et al., 2013; Roell et al., 2007). PSC-CM implanted under the kidney capsule of MHC-matched mice survived at least until 28 days after 
implantation suggesting immune resistance. A minimal amount of cellular infiltration was observed in the initial time intervals (day 1 , day 3 , day 7 ) in haematoxylin and eosin staining suggesting this inflammation might be because of the surgery procedure. In one of the three MHC-match mice implanted with PSC-CM at day 28, teratoma formed indicating the presence of proliferating cells even after CM-purification. This data is in accordance with Hentze et al. where they observed that ESC differentiated cells even after extended culture time formed teratoma in mice (Hentze et al., 2009). This might be a major limitation when using stem cell derived-CMs for clinical applications.

T-cells, B cells and macrophages have been shown to infiltrate teratomas in syngeneic mice (de Almeida et al., 2013). Although they were incapable of preventing tumor growth, these lymphocyte infiltrates did reduce tumor appearance (Dressel et al., 2008). It was demonstrated that when a small number of syngeneic ES cells were implanted, teratomas were not formed. Implantation of $5 \times 10^{5}$ undifferentiated or differentiated syngeneic ES cells has been shown to result in teratoma formation in $33 \%$ and $17 \%$ of recipients respectively. However, implantation of high numbers of undifferentiated or differentiated cells $\left(2 \times 10^{6}\right)$ produced teratoma formation in $100 \%$ of recipients (Dressel et al., 2008; Lee et al., 2009). From this data one can assume that when low numbers of cells are implanted, cells either die instantly after transplantation or are rejected.

In the MHC-mismatch (BL6, H-2 ${ }^{\mathrm{b} / \mathrm{b}}$ ) setting, after implantation of PSC-CM $\left(\mathrm{H}-2^{\mathrm{d} / \mathrm{d}}\right)$ under the kidney capsule, beating was noticed until day 7. No beating cells were observed after 28 days. These especially need to be repeated to finally draw a conclusion as to the immune privilege of PSC-derivatives in vivo. The results from the implantation data, where PSC-NM implanted under the kidney capsule have shown similar results to that of PSC-CM in MHC-match (B6D2F1, H-2 ${ }^{\mathrm{b} / \mathrm{d}}$ ) and strong rejection in MHC-mismatch (BL6, $\mathrm{H}-2^{\mathrm{b} / \mathrm{b}}$ ) mouse models. Implantation of PSC-NM in the MHC-match setting showed significant cellular infiltration until 7 days of implantation. This might be either because the in vitro maintenance of PSC-NM might have altered the immunological property or the surgical procedure, which has to be further evaluated with further animal experiments. In the MHC-mismatch setting high cellular infiltration was also observed until 7 days of implantation and most of the implanted PSC-NM seems to be rejected 
and killed after 28 days of implantation. Very few of the implanted cells remained after 4 weeks of implantation in the allogeneic setting. This suggests that significant amount of MHC-I expression on PSC-NM, results in the development of a strong immune rejection in the allogeneic setting. In contrast to our data, it was also reported that male EBs implanted under the kidney capsule of female mice survived indefinitely despite of occurrence of T-cells specific for $\mathrm{mH}$ antigen (Robertson et al., 2007).

In contrast it has been shown that induction of MHC-I expression by the use of IFNY under in vitro condition improve the subsequent survival and immune integration of ESC derived vascular progenitor cells in the syngeneic setting (Ma et al., 2010). It has also been demonstrated that the immunogenicity of iPSC derived tissues is comparable to that of ESC derived tissues in murine models; terminally differentiated cells from iPSC show limited immune response in vivo (Araki et al., 2013). In contrast, other group demonstrated that iPSC-derived CMs transplanted in the myocardium of syngeneic mice were rejected; they also show that immunogenicity of iPSC-derivatives was increased after differentiation (Liu et al., 2013b). Recently it was shown that cardiomyocytes derived from MHC-homozygous iPSC exhibited reduced allogeneic immunogenicity in MHC-matched non-human primates (Kawamura et al., 2016). In contrast to the above data shown, it was reported that co-transplantation of dendritic cells along with iPSC derived grafts under kidney capsule results in the immune rejection of iPSC grafts (Todorova et al., 2015). Many groups have shown that dendritic cells with immature phenotype (low expression of MHC-II molecules and co-stimulatory molecules like CD40, CD80, CD86) can induce anergic state in T-lymphocytes (Lipscomb and Masten, 2002; Lutz and Schuler, 2002; Lutz et al., 2000), so these immature cells when implanted along with the grafts might prolong the survival of the graft. 


\section{Conclusions}

Based on the results obtained in this study we can conclude the following points.

- Parthenogenetic stem cells can be successfully differentiated into cardiomyocytes in large scale using suspension spinner flask culture.

- Parthenogenetic stem cell derived cardiomyocytes do not express MHC molecules (MHC-I and MHC-II) until they are stimulated with IFNY.

- Engineered heart muscle can be generated from PSC-derived cardiomyocytes.

- Immunological maturation of PSC-derived CM in relation to their MHC-II expression was observed in EHM model.

- PSC-derived cells activate lymphocytes under MHC-match and MHC-mismatch settings.

- PSC-CM retention appeared to be enhanced under MHC-matching. 


\section{Bibliography}

Abdullah Z, Saric T, Kashkar H, Baschuk N, Yazdanpanah B, Fleischmann BK, Hescheler J, Kronke M, Utermohlen O (2007) Serpin-6 expression protects embryonic stem cells from lysis by antigen-specific CTL. J Immunol 178, 3390-3399.

Abranches E, Bekman E, Henrique D, Cabral JM (2007) Expansion of mouse embryonic stem cells on microcarriers. Biotechnol Bioeng 96, 1211-1221.

Agnetti G, Piepoli MF, Siniscalchi G, Nicolini F (2015) New Insights in the Diagnosis and Treatment of Heart Failure. Biomed Res Int 2015, 265260.

Allen ND, Barton SC, Hilton K, Norris ML, Surani MA (1994) A functional analysis of imprinting in parthenogenetic embryonic stem cells. Development 120, 1473-1482.

Anderson D, Self T, Mellor IR, Goh G, Hill SJ, Denning C (2007) Transgenic enrichment of cardiomyocytes from human embryonic stem cells. Mol Ther 15, 2027-2036.

Araki $R$, Uda $M$, Hoki $Y$, Sunayama $M$, Nakamura $M$, Ando $S$, Sugiura $M$, Ideno $H$, Shimada A, Nifuji A, Abe M (2013) Negligible immunogenicity of terminally differentiated cells derived from induced pluripotent or embryonic stem cells. Nature 494, 100-104.

Baban B, Liu JY, Mozaffari MS (2014) SGK-1 regulates inflammation and cell death in the ischemic-reperfused heart: pressure-related effects. Am J Hypertens 27, 846-856.

Baban B, Liu JY, Qin X, Weintraub NL, Mozaffari MS (2015) Upregulation of Programmed Death-1 and Its Ligand in Cardiac Injury Models: Interaction with GADD153. PLoS One 10, e0124059.

Bach EA, Aguet M, Schreiber RD (1997) The IFN gamma receptor: a paradigm for cytokine receptor signaling. Annu Rev Immunol 15, 563-591.

Balaji KN, Schaschke N, Machleidt W, Catalfamo M, Henkart PA (2002) Surface cathepsin $B$ protects cytotoxic lymphocytes from self-destruction after degranulation. $J$ Exp Med 196, 493-503.

Bauwens CL, Peerani R, Niebruegge S, Woodhouse KA, Kumacheva E, Husain M, Zandstra PW (2008) Control of human embryonic stem cell colony and aggregate size heterogeneity influences differentiation trajectories. Stem Cells 26, 2300-2310.

Bergmann O, Zdunek S, Felker A, Salehpour M, Alkass K, Bernard S, Sjostrom SL, Szewczykowska M, Jackowska T, Dos Remedios C, Malm T, Andra M, Jashari R, Nyengaard JR, Possnert G, Jovinge S, Druid H, Frisen J (2015) Dynamics of Cell Generation and Turnover in the Human Heart. Cell 161, 1566-1575. 
Boehm U, Klamp T, Groot M, Howard JC (1997) Cellular responses to interferongamma. Annu Rev Immunol 15, 749-795.

Boheler KR, Czyz J, Tweedie D, Yang HT, Anisimov SV, Wobus AM (2002) Differentiation of pluripotent embryonic stem cells into cardiomyocytes. Circ Res 91, 189-201.

Bonde S, Zavazava N (2006) Immunogenicity and engraftment of mouse embryonic stem cells in allogeneic recipients. Stem Cells 24, 2192-2201.

Boyd AS, Higashi Y, Wood KJ (2005) Transplanting stem cells: potential targets for immune attack. Modulating the immune response against embryonic stem cell transplantation. Adv Drug Deliv Rev 57, 1944-1969.

Boyd AS, Wood KJ (2009) Variation in MHC expression between undifferentiated mouse ES cells and ES cell-derived insulin-producing cell clusters. Transplantation 87, 1300-1304.

Bradley JA, Bolton EM, Pedersen RA (2002) Stem cell medicine encounters the immune system. Nat Rev Immunol 2, 859-871.

Brower RC, England R, Takeshita T, Kozlowski S, Margulies DH, Berzofsky JA, Delisi C (1994) Minimal requirements for peptide mediated activation of CD8+ CTL. Mol Immunol 31, 1285-1293.

Brunlid G, Pruszak J, Holmes B, Isacson O, Sonntag KC (2007) Immature and neurally differentiated mouse embryonic stem cells do not express a functional Fas/Fas ligand system. Stem Cells 25, 2551-2558.

Buckingham M, Meilhac S, Zaffran S (2005) Building the mammalian heart from two sources of myocardial cells. Nat Rev Genet 6, 826-835.

Burridge PW, Holmstrom A, Wu JC (2015) Chemically Defined Culture and Cardiomyocyte Differentiation of Human Pluripotent Stem Cells. Curr Protoc Hum Genet $87,212321-15$.

Cao J, Li X, Lu X, Zhang C, Yu H, Zhao T (2013) Cells derived from iPSC can be immunogenic - Yes or No? Protein Cell.

Carnaud C, Lee D, Donnars O, Park SH, Beavis A, Koezuka Y, Bendelac A (1999) Cutting edge: Cross-talk between cells of the innate immune system: NKT cells rapidly activate NK cells. J Immunol 163, 4647-4650.

Carpenedo RL, Sargent CY, McDevitt TC (2007) Rotary suspension culture enhances the efficiency, yield, and homogeneity of embryoid body differentiation. Stem Cells 25, 2224-2234. 
Cibelli JB, Grant KA, Chapman KB, Cunniff K, Worst T, Green HL, Walker SJ, Gutin PH, Vilner L, Tabar V, Dominko T, Kane J, Wettstein PJ, Lanza RP, Studer L, Vrana KE, West MD (2002) Parthenogenetic stem cells in nonhuman primates. Science 295, 819.

Daar AS, Fuggle SV, Fabre JW, Ting A, Morris PJ (1984) The detailed distribution of MHC Class II antigens in normal human organs. Transplantation 38, 293-298.

Dargemont C, Dunon D, Salamero J, Deugnier MA, Davoust J, Thiery JP (1991) Overproduction and secretion of beta 2-microglobulin by a rat thymic epithelial cell line that expresses MHC class I heavy chain. J Cell Sci 98 ( Pt 4), 559-565.

Daughtry B, Mitalipov S (2014) Concise review: parthenote stem cells for regenerative medicine: genetic, epigenetic, and developmental features. Stem Cells Transl Med 3, 290-298.

de Almeida PE, Ransohoff JD, Nahid A, Wu JC (2013) Immunogenicity of pluripotent stem cells and their derivatives. Circ Res 112, 549-561.

de Fried EP, Ross P, Zang G, Divita A, Cunniff K, Denaday F, Salamone D, Kiessling A, Cibelli J (2008) Human parthenogenetic blastocysts derived from noninseminated cryopreserved human oocytes. Fertil Steril 89, 943-947.

Delcarpio JB, Claycomb WC (1995) Cardiomyocyte transfer into the mammalian heart. Cell-to-cell interactions in vivo and in vitro. Ann N Y Acad Sci 752, 267-285.

DeWard AD, Komori J, Lagasse E (2014) Ectopic transplantation sites for cell-based therapy. Curr Opin Organ Transplant 19, 169-174.

Didie M, Christalla P, Rubart M, Muppala V, Doker S, Unsold B, El-Armouche A, Rau T, Eschenhagen T, Schwoerer AP, Ehmke H, Schumacher U, Fuchs S, Lange C, Becker A, Tao W, Scherschel JA, Soonpaa MH, Yang T, Lin Q, Zenke M, Han DW, Scholer HR, Rudolph C, Steinemann D, Schlegelberger B, Kattman S, Witty A, Keller G, Field LJ, Zimmermann WH (2013) Parthenogenetic stem cells for tissue-engineered heart repair. J Clin Invest 123, 1285-1298.

Doppler SA, Deutsch MA, Lange R, Krane M (2013) Cardiac regeneration: current therapies-future concepts. J Thorac Dis 5, 683-697.

Doulatov S, Daley GQ (2013) Development. A stem cell perspective on cellular engineering. Science 342, 700-702.

Dressel R, Guan K, Nolte J, Elsner L, Monecke S, Nayernia K, Hasenfuss G, Engel W (2009) Multipotent adult germ-line stem cells, like other pluripotent stem cells, can be killed by cytotoxic $\mathrm{T}$ lymphocytes despite low expression of major histocompatibility complex class I molecules. Biol Direct 4, 31. 
Dressel R, Nolte J, Elsner L, Novota P, Guan K, Streckfuss-Bomeke K, Hasenfuss G, Jaenisch R, Engel W (2010) Pluripotent stem cells are highly susceptible targets for syngeneic, allogeneic, and xenogeneic natural killer cells. FASEB J 24, 2164-2177.

Dressel R, Schindehutte J, Kuhlmann T, Elsner L, Novota P, Baier PC, Schillert A, Bickeboller H, Herrmann T, Trenkwalder C, Paulus W, Mansouri A (2008) The tumorigenicity of mouse embryonic stem cells and in vitro differentiated neuronal cells is controlled by the recipients' immune response. PLoS One 3, e2622.

Dronavalli VB, Rogers CA, Banner NR (2015) Primary Cardiac Allograft DysfunctionValidation of a Clinical Definition. Transplantation 99, 1919-1925.

Drukker M (2004) Immunogenicity of human embryonic stem cells: can we achieve tolerance? Springer Semin Immunopathol 26, 201-213.

Drukker M, Benvenisty N (2004) The immunogenicity of human embryonic stem-derived cells. Trends Biotechnol 22, 136-141.

Drukker M, Katchman H, Katz G, Even-Tov Friedman S, Shezen E, Hornstein E, Mandelboim O, Reisner Y, Benvenisty N (2006) Human embryonic stem cells and their differentiated derivatives are less susceptible to immune rejection than adult cells. Stem Cells 24, 221-229.

Drukker M, Katz G, Urbach A, Schuldiner M, Markel G, Itskovitz-Eldor J, Reubinoff B, Mandelboim O, Benvenisty N (2002) Characterization of the expression of MHC proteins in human embryonic stem cells. Proc Natl Acad Sci U S A 99, 9864-9869.

E LL, Zhao YS, Guo XM, Wang CY, Jiang H, Li J, Duan CM, Song Y (2006) Enrichment of cardiomyocytes derived from mouse embryonic stem cells. J Heart Lung Transplant 25, 664-674.

Eschenhagen T, Fink C, Remmers U, Scholz H, Wattchow J, Weil J, Zimmermann W, Dohmen HH, Schafer H, Bishopric N, Wakatsuki T, Elson EL (1997) Three-dimensional reconstitution of embryonic cardiomyocytes in a collagen matrix: a new heart muscle model system. FASEB J 11, 683-694.

Espejel S, Eckardt S, Harbell J, Roll GR, McLaughlin KJ, Willenbring H (2014) Brief report: Parthenogenetic embryonic stem cells are an effective cell source for therapeutic liver repopulation. Stem Cells 32, 1983-1988.

Evans MJ, Kaufman MH (1981) Establishment in culture of pluripotential cells from mouse embryos. Nature 292, 154-156.

Fallarino F, Grohmann U, Vacca C, Bianchi R, Orabona C, Spreca A, Fioretti MC, Puccetti P (2002) T cell apoptosis by tryptophan catabolism. Cell Death Differ 9, 10691077. 
Fandrich F, Lin X, Chai GX, Schulze M, Ganten D, Bader M, Holle J, Huang DS, Parwaresch R, Zavazava N, Binas B (2002) Preimplantation-stage stem cells induce long-term allogeneic graft acceptance without supplementary host conditioning. Nat Med 8, 171-178.

Ferguson TA, Griffith TS (1997) A vision of cell death: insights into immune privilege. Immunol Rev 156, 167-184.

Fok EY, Zandstra PW (2005) Shear-controlled single-step mouse embryonic stem cell expansion and embryoid body-based differentiation. Stem Cells 23, 1333-1342.

Francisco LM, Sage PT, Sharpe AH (2010) The PD-1 pathway in tolerance and autoimmunity. Immunol Rev 236, 219-242.

Frenzel LP, Abdullah Z, Kriegeskorte AK, Dieterich R, Lange N, Busch DH, Kronke M, Utermohlen O, Hescheler J, Saric T (2009) Role of natural-killer group 2 member D ligands and intercellular adhesion molecule 1 in natural killer cell-mediated lysis of murine embryonic stem cells and embryonic stem cell-derived cardiomyocytes. Stem Cells 27, 307-316.

Frucht DM, Fukao T, Bogdan C, Schindler H, O'Shea JJ, Koyasu S (2001) IFN-gamma production by antigen-presenting cells: mechanisms emerge. Trends Immunol 22, 556560.

Godier-Furnemont AF, Tiburcy M, Wagner E, Dewenter M, Lammle S, El-Armouche A, Lehnart SE, Vunjak-Novakovic G, Zimmermann WH (2015) Physiologic force-frequency response in engineered heart muscle by electromechanical stimulation. Biomaterials 60 , 82-91.

Goulmy E (1997) Human minor histocompatibility antigens: new concepts for marrow transplantation and adoptive immunotherapy. Immunol Rev 157, 125-140.

Griffith TS, Ferguson TA (1997) The role of FasL-induced apoptosis in immune privilege. Immunol Today 18, 240-244.

Grinnemo KH, Kumagai-Braesch M, Mansson-Broberg A, Skottman H, Hao X, Siddiqui A, Andersson A, Stromberg AM, Lahesmaa R, Hovatta O, Sylven C, Corbascio M, Dellgren G (2006) Human embryonic stem cells are immunogenic in allogeneic and xenogeneic settings. Reprod Biomed Online 13, 712-724.

Guan K, Nayernia K, Maier LS, Wagner S, Dressel R, Lee JH, Nolte J, Wolf F, Li M, Engel W, Hasenfuss G (2006) Pluripotency of spermatogonial stem cells from adult mouse testis. Nature 440, 1199-1203. 
Guha P, Morgan JW, Mostoslavsky G, Rodrigues NP, Boyd AS (2013) Lack of immune response to differentiated cells derived from syngeneic induced pluripotent stem cells. Cell Stem Cell 12, 407-412.

Gulick J, Subramaniam A, Neumann J, Robbins J (1991) Isolation and characterization of the mouse cardiac myosin heavy chain genes. J Biol Chem 266, 9180-9185.

Guthrie M, Lodge PA, Huber SA (1984) Cardiac injury in myocarditis induced by Coxsackievirus group B, type 3 in Balb/c mice is mediated by Lyt 2 + cytolytic lymphocytes. Cell Immunol 88, 558-567.

Hannes T, Wolff M, Doss MX, Pfannkuche K, Haustein M, Muller-Ehmsen J, Sachinidis A, Hescheler J, Khalil M, Halbach M (2015) Electrophysiological characteristics of embryonic stem cell-derived cardiomyocytes are cell line-dependent. Cell Physiol Biochem 35, 305-314.

Hao J, Zhu W, Sheng C, Yu Y, Zhou Q (2009) Human parthenogenetic embryonic stem cells: one potential resource for cell therapy. Sci China C Life Sci 52, 599-602.

Hentze H, Soong PL, Wang ST, Phillips BW, Putti TC, Dunn NR (2009) Teratoma formation by human embryonic stem cells: evaluation of essential parameters for future safety studies. Stem Cell Res 2, 198-210.

Hidaka K, Lee JK, Kim HS, Ihm CH, lio A, Ogawa M, Nishikawa S, Kodama I, Morisaki $\mathrm{T}$ (2003) Chamber-specific differentiation of Nkx2.5-positive cardiac precursor cells from murine embryonic stem cells. FASEB J 17, 740-742.

Hipp J, Atala A (2004) Tissue engineering, stem cells, cloning, and parthenogenesis: new paradigms for therapy. J Exp Clin Assist Reprod 1, 3.

Huber S, Sartini D, Exley M (2003) Role of CD1d in coxsackievirus B3-induced myocarditis. J Immunol 170, 3147-3153.

Huber SA (2000) T cells expressing the gamma delta T cell receptor induce apoptosis in cardiac myocytes. Cardiovasc Res 45, 579-587.

Huber SA (2005) Increased susceptibility of male BALB/c mice to coxsackievirus B3induced myocarditis: role for CD1d. Med Microbiol Immunol 194, 121-127.

Huber SA, Lodge PA (1984) Coxsackievirus B-3 myocarditis in Balb/c mice. Evidence for autoimmunity to myocyte antigens. Am J Pathol 116, 21-29.

Hufnagel G, Maisch B (1991) Expression of MHC class I and II antigens and the II-2 receptor in rejection, myocarditis and dilated cardiomyopathy. Eur Heart $\mathrm{J} 12$ Suppl $D$, 137-140. 
Isobe M, Narula J, Southern JF, Strauss HW, Khaw BA, Haber E (1992) Imaging the rejecting heart. In vivo detection of major histocompatibility complex class II antigen induction. Circulation 85, 738-746.

Jones ND, Turvey SE, Van Maurik A, Hara M, Kingsley Cl, Smith CH, Mellor AL, Morris PJ, Wood KJ (2001) Differential susceptibility of heart, skin, and islet allografts to T cellmediated rejection. J Immunol 166, 2824-2830.

Kadereit S, Trounson A (2011) In vitro immunogenicity of undifferentiated pluripotent stem cells (PSC) and derived lineages. Semin Immunopathol 33, 551-562.

Kanno S, Kim PK, Sallam K, Lei J, Billiar TR, Shears LL, 2nd (2004) Nitric oxide facilitates cardiomyogenesis in mouse embryonic stem cells. Proc Natl Acad Sci U S A $101,12277-12281$.

Karabekian Z, Posnack NG, Sarvazyan N (2011) Immunological barriers to stem-cell based cardiac repair. Stem Cell Rev 7, 315-325.

Karikkineth BC, Zimmermann WH (2013) Myocardial tissue engineering and heart muscle repair. Curr Pharm Biotechnol 14, 4-11.

Kattman SJ, Witty AD, Gagliardi M, Dubois NC, Niapour M, Hotta A, Ellis J, Keller G (2011) Stage-specific optimization of activin/nodal and BMP signaling promotes cardiac differentiation of mouse and human pluripotent stem cell lines. Cell Stem Cell 8, 228240.

Katz AM (2008) The "modern" view of heart failure: how did we get here? Circ Heart Fail 1, 63-71.

Kaufman MH, Barton SC, Surani MA (1977) Normal postimplantation development of mouse parthenogenetic embryos to the forelimb bud stage. Nature 265, 53-55.

Kaul AM, Goparaju S, Dvorina N, lida S, Keslar KS, de la Motte CA, Valujskikh A, Fairchild RL, Baldwin WM, 3rd (2015) Acute and chronic rejection: compartmentalization and kinetics of counterbalancing signals in cardiac transplants. Am J Transplant 15, 333-345.

Kawamura T, Miyagawa S, Fukushima S, Maeda A, Kashiyama N, Kawamura A, Miki K, Okita K, Yoshida Y, Shiina T, Ogasawara K, Miyagawa S, Toda K, Okuyama H, Sawa Y (2016) Cardiomyocytes Derived from MHC-Homozygous Induced Pluripotent Stem Cells Exhibit Reduced Allogeneic Immunogenicity in MHC-Matched Non-human Primates. Stem Cell Reports 6, 312-320.

Kempf H, Olmer R, Kropp C, Ruckert M, Jara-Avaca M, Robles-Diaz D, Franke A, Elliott DA, Wojciechowski D, Fischer M, Roa Lara A, Kensah G, Gruh I, Haverich A, Martin U, 
Zweigerdt R (2014) Controlling expansion and cardiomyogenic differentiation of human pluripotent stem cells in scalable suspension culture. Stem Cell Reports 3, 1132-1146.

Khademhosseini A, Ferreira L, Blumling J, 3rd, Yeh J, Karp JM, Fukuda J, Langer R (2006) Co-culture of human embryonic stem cells with murine embryonic fibroblasts on microwell-patterned substrates. Biomaterials 27, 5968-5977.

Kim C, Lee IH, Lee K, Ryu SS, Lee SH, Lee KJ, Lee J, Kang JY, Kim TS (2007) Multiwell chip for forming a uniform embryoid body in a tiny droplet with mouse embryonic stem cells. Biosci Biotechnol Biochem 71, 2985-2991.

King JA, Miller WM (2007) Bioreactor development for stem cell expansion and controlled differentiation. Curr Opin Chem Biol 11, 394-398.

Klug MG, Soonpaa MH, Koh GY, Field LJ (1996) Genetically selected cardiomyocytes from differentiating embronic stem cells form stable intracardiac grafts. J Clin Invest 98, 216-224.

Koch CA, Geraldes P, Platt JL (2008) Immunosuppression by embryonic stem cells. Stem Cells 26, 89-98.

Kofidis T, deBruin JL, Tanaka M, Zwierzchoniewska M, Weissman I, Fedoseyeva E, Haverich A, Robbins RC (2005) They are not stealthy in the heart: embryonic stem cells trigger cell infiltration, humoral and T-lymphocyte-based host immune response. Eur $\mathrm{J}$ Cardiothorac Surg 28, 461-466.

Koh GY, Soonpaa MH, Klug MG, Field LJ (1993) Long-term survival of AT-1 cardiomyocyte grafts in syngeneic myocardium. Am J Physiol 264, H1727-1733.

Koh GY, Soonpaa MH, Klug MG, Pride HP, Cooper BJ, Zipes DP, Field LJ (1995) Stable fetal cardiomyocyte grafts in the hearts of dystrophic mice and dogs. J Clin Invest 96, 2034-2042.

Kohlhuber F, Rogers NC, Watling D, Feng J, Guschin D, Briscoe J, Witthuhn BA, Kotenko SV, Pestka S, Stark GR, Ihle JN, Kerr IM (1997) A JAK1/JAK2 chimera can sustain alpha and gamma interferon responses. Mol Cell Biol 17, 695-706.

Kolodney MS, Elson EL (1993) Correlation of myosin light chain phosphorylation with isometric contraction of fibroblasts. J Biol Chem 268, 23850-23855.

Kono T, Obata Y, Wu Q, Niwa K, Ono Y, Yamamoto Y, Park ES, Seo JS, Ogawa H (2004) Birth of parthenogenetic mice that can develop to adulthood. Nature 428, 860864.

Korngold R, Sprent J (1983) Lethal GVHD across minor histocompatibility barriers: nature of the effector cells and role of the H-2 complex. Immunol Rev 71, 5-29. 
Kruse V, Hamann C, Monecke S, Cyganek L, Elsner L, Hubscher D, Walter L, Streckfuss-Bomeke K, Guan K, Dressel R (2015) Human Induced Pluripotent Stem Cells Are Targets for Allogeneic and Autologous Natural Killer (NK) Cells and Killing Is Partly Mediated by the Activating NK Receptor DNAM-1. PLoS One 10, e0125544.

Kurosawa H (2007) Methods for inducing embryoid body formation: in vitro differentiation system of embryonic stem cells. J Biosci Bioeng 103, 389-398.

Laflamme MA, Chen KY, Naumova AV, Muskheli V, Fugate JA, Dupras SK, Reinecke H, Xu C, Hassanipour M, Police S, O'Sullivan C, Collins L, Chen Y, Minami E, Gill EA, Ueno S, Yuan C, Gold J, Murry CE (2007) Cardiomyocytes derived from human embryonic stem cells in pro-survival factors enhance function of infarcted rat hearts. Nat Biotechnol 25, 1015-1024.

Lampton PW, Crooker RJ, Newmark JA, Warner CM (2008) Expression of major histocompatibility complex class I proteins and their antigen processing chaperones in mouse embryonic stem cells from fertilized and parthenogenetic embryos. Tissue Antigens 72, 448-457.

Lee AS, Tang C, Cao F, Xie X, van der Bogt K, Hwang A, Connolly AJ, Robbins RC, Wu JC (2009) Effects of cell number on teratoma formation by human embryonic stem cells. Cell Cycle 8, 2608-2612.

Levick SP, Goldspink PH (2014) Could interferon-gamma be a therapeutic target for treating heart failure? Heart Fail Rev 19, 227-236.

Li L, Baroja ML, Majumdar A, Chadwick K, Rouleau A, Gallacher L, Ferber I, Lebkowski J, Martin T, Madrenas J, Bhatia M (2004) Human embryonic stem cells possess immune-privileged properties. Stem Cells 22, 448-456.

Lian X, Zhang J, Azarin SM, Zhu K, Hazeltine LB, Bao X, Hsiao C, Kamp TJ, Palecek SP (2013) Directed cardiomyocyte differentiation from human pluripotent stem cells by modulating Wnt/beta-catenin signaling under fully defined conditions. Nat Protoc $8,162-$ 175.

Lin H, Lei J, Wininger D, Nguyen MT, Khanna R, Hartmann C, Yan WL, Huang SC (2003) Multilineage potential of homozygous stem cells derived from metaphase II oocytes. Stem Cells 21, 152-161.

Lin Q, Fu Q, Zhang Y, Wang H, Liu Z, Zhou J, Duan C, Wang Y, Wu K, Wang C (2010) Tumourigenesis in the infarcted rat heart is eliminated through differentiation and enrichment of the transplanted embryonic stem cells. Eur J Heart Fail 12, 1179-1185.

Lipscomb MF, Masten BJ (2002) Dendritic cells: immune regulators in health and disease. Physiol Rev 82, 97-130. 
Liu W, Huber SA (2011) Cross-talk between cd1d-restricted nkt cells and gammadelta cells in t regulatory cell response. Virol $\mathrm{J} 8,32$.

Liu Y, Ye X, Mao L, Cheng Z, Yao X, Jia X, Mao D, Ou L, Li Z, Che Y, Liu N, Steinhoff G, Liu L, Kong D (2013a) Transplantation of parthenogenetic embryonic stem cells ameliorates cardiac dysfunction and remodelling after myocardial infarction. Cardiovasc Res 97, 208-218.

Liu Z, Wen X, Wang H, Zhou J, Zhao M, Lin Q, Wang Y, Li J, Li D, Du Z, Yao A, Cao F, Wang $C(2013 b)$ Molecular imaging of induced pluripotent stem cell immunogenicity with in vivo development in ischemic myocardium. PLoS One 8, e66369.

Lutz MB, Schuler G (2002) Immature, semi-mature and fully mature dendritic cells: which signals induce tolerance or immunity? Trends Immunol 23, 445-449.

Lutz MB, Suri RM, Niimi M, Ogilvie AL, Kukutsch NA, Rossner S, Schuler G, Austyn JM (2000) Immature dendritic cells generated with low doses of GM-CSF in the absence of IL-4 are maturation resistant and prolong allograft survival in vivo. Eur $\mathrm{J}$ Immunol 30, 1813-1822.

Ma M, Ding S, Lundqvist A, San H, Fang F, Konoplyannikov M, Berry C, Beltran LE, Chen G, Kovacic JC, Boehm M (2010) Major histocompatibility complex-I expression on embryonic stem cell-derived vascular progenitor cells is critical for syngeneic transplant survival. Stem Cells 28, 1465-1475.

Magliocca JF, Held IK, Odorico JS (2006) Undifferentiated murine embryonic stem cells cannot induce portal tolerance but may possess immune privilege secondary to reduced major histocompatibility complex antigen expression. Stem Cells Dev 15, 707-717.

Mai Q, Yu Y, Li T, Wang L, Chen MJ, Huang SZ, Zhou C, Zhou Q (2007) Derivation of human embryonic stem cell lines from parthenogenetic blastocysts. Cell Res 17, 10081019.

Malliaras K, Li TS, Luthringer D, Terrovitis J, Cheng K, Chakravarty T, Galang G, Zhang Y, Schoenhoff F, Van Eyk J, Marban L, Marban E (2012) Safety and efficacy of allogeneic cell therapy in infarcted rats transplanted with mismatched cardiospherederived cells. Circulation 125, 100-112.

Marshall VS, Wilton LJ, Moore HD (1998) Parthenogenetic activation of marmoset (Callithrix jacchus) oocytes and the development of marmoset parthenogenones in vitro and in vivo. Biol Reprod 59, 1491-1497.

Medema JP, Schuurhuis DH, Rea D, van Tongeren J, de Jong J, Bres SA, Laban S, Toes RE, Toebes M, Schumacher TN, Bladergroen BA, Ossendorp F, Kummer JA, Melief CJ, Offringa R (2001) Expression of the serpin serine protease inhibitor 6 
protects dendritic cells from cytotoxic $T$ lymphocyte-induced apoptosis: differential modulation by T helper type 1 and type 2 cells. J Exp Med 194, 657-667.

Menendez P, Bueno C, Wang L, Bhatia M (2005) Human embryonic stem cells: potential tool for achieving immunotolerance? Stem Cell Rev 1, 151-158.

Mohr JC, de Pablo JJ, Palecek SP (2006) 3-D microwell culture of human embryonic stem cells. Biomaterials 27, 6032-6042.

Moussa P, Marton J, Vidal SM, Fodil-Cornu N (2012) Genetic dissection of NK cell responses. Front Immunol 3, 425.

Muller-Ehmsen J, Peterson KL, Kedes L, Whittaker P, Dow JS, Long TI, Laird PW, Kloner RA (2002) Rebuilding a damaged heart: long-term survival of transplanted neonatal rat cardiomyocytes after myocardial infarction and effect on cardiac function. Circulation 105, 1720-1726.

Munn DH, Mellor AL (2007) Indoleamine 2,3-dioxygenase and tumor-induced tolerance. $\mathrm{J}$ Clin Invest 117, 1147-1154.

Munn DH, Shafizadeh E, Attwood JT, Bondarev I, Pashine A, Mellor AL (1999) Inhibition of $\mathrm{T}$ cell proliferation by macrophage tryptophan catabolism. J Exp Med 189, 1363-1372.

Murry CE, Keller G (2008) Differentiation of embryonic stem cells to clinically relevant populations: lessons from embryonic development. Cell 132, 661-680.

Nagata S (1996) Fas-mediated apoptosis. Adv Exp Med Biol 406, 119-124.

Nagy A, Sass M, Markkula M (1989) Systematic non-uniform distribution of parthenogenetic cells in adult mouse chimaeras. Development 106, 321-324.

Naito AT, Shiojima I, Akazawa H, Hidaka K, Morisaki T, Kikuchi A, Komuro I (2006a) Developmental stage-specific biphasic roles of Wnt/beta-catenin signaling in cardiomyogenesis and hematopoiesis. Proc Natl Acad Sci U S A 103, 19812-19817.

Naito H, Melnychenko I, Didie M, Schneiderbanger K, Schubert P, Rosenkranz S, Eschenhagen T, Zimmermann WH (2006b) Optimizing engineered heart tissue for therapeutic applications as surrogate heart muscle. Circulation 114, 172-78.

Naito H, Nishizaki K, Yoshikawa M, Yamada T, Satoh H, Nagasaka S, Kiji T, Taniguchi S (2004) Xenogeneic embryonic stem cell-derived cardiomyocyte transplantation. Transplant Proc 36, 2507-2508. 
Nakagawa K, Yamano S, Nakasaka H, Hinokio K, Yoshizawa M, Aono T (2001) A combination of calcium ionophore and puromycin effectively produces human parthenogenones with one haploid pronucleus. Zygote 9, 83-88.

Nakajima F, Tokunaga K, Nakatsuji N (2007) Human leukocyte antigen matching estimations in a hypothetical bank of human embryonic stem cell lines in the Japanese population for use in cell transplantation therapy. Stem Cells 25, 983-985.

Nakatsuji N, Nakajima F, Tokunaga K (2008) HLA-haplotype banking and iPS cells. Nat Biotechnol 26, 739-740.

Ng ES, Davis RP, Azzola L, Stanley EG, Elefanty AG (2005) Forced aggregation of defined numbers of human embryonic stem cells into embryoid bodies fosters robust, reproducible hematopoietic differentiation. Blood 106, 1601-1603.

Nussbaum J, Minami E, Laflamme MA, Virag JA, Ware CB, Masino A, Muskheli V, Pabon L, Reinecke H, Murry CE (2007) Transplantation of undifferentiated murine embryonic stem cells in the heart: teratoma formation and immune response. FASEB $\mathrm{J}$ $21,1345-1357$.

Oliveira FG, Dozortsev D, Diamond MP, Fracasso A, Abdelmassih S, Abdelmassih V, Goncalves SP, Abdelmassih R, Nagy ZP (2004) Evidence of parthenogenetic origin of ovarian teratoma: case report. Hum Reprod 19, 1867-1870.

Olivetti G, Melissari M, Capasso JM, Anversa P (1991) Cardiomyopathy of the aging human heart. Myocyte loss and reactive cellular hypertrophy. Circ Res 68, 1560-1568.

Ozil JP (1990) The parthenogenetic development of rabbit oocytes after repetitive pulsatile electrical stimulation. Development 109, 117-127.

Paulis LE, Klein AM, Ghanem A, Geelen T, Coolen BF, Breitbach M, Zimmermann K, Nicolay K, Fleischmann BK, Roell W, Strijkers GJ (2013) Embryonic cardiomyocyte, but not autologous stem cell transplantation, restricts infarct expansion, enhances ventricular function, and improves long-term survival. PLoS One 8, e61510.

Picascia A, Grimaldi V, Casamassimi A, De Pascale MR, Schiano C, Napoli C (2014) Human leukocyte antigens and alloimmunization in heart transplantation: an open debate. J Cardiovasc Transl Res 7, 664-675.

Pinto AR, llinykh A, Ivey MJ, Kuwabara JT, D'Antoni ML, Debuque R, Chandran A, Wang L, Arora K, Rosenthal NA, Tallquist MD (2016) Revisiting Cardiac Cellular Composition. Circ Res 118, 400-409.

Quah BJ, Parish CR (2012) New and improved methods for measuring lymphocyte proliferation in vitro and in vivo using CFSE-like fluorescent dyes. J Immunol Methods $379,1-14$. 
Quah BJ, Warren HS, Parish CR (2007) Monitoring lymphocyte proliferation in vitro and in vivo with the intracellular fluorescent dye carboxyfluorescein diacetate succinimidyl ester. Nat Protoc 2, 2049-2056.

Revazova ES, Turovets NA, Kochetkova OD, Agapova LS, Sebastian JL, Pryzhkova MV, Smolnikova VI, Kuzmichev LN, Janus JD (2008) HLA homozygous stem cell lines derived from human parthenogenetic blastocysts. Cloning Stem Cells 10, 11-24.

Revazova ES, Turovets NA, Kochetkova OD, Kindarova LB, Kuzmichev LN, Janus JD, Pryzhkova MV (2007) Patient-specific stem cell lines derived from human parthenogenetic blastocysts. Cloning Stem Cells 9, 432-449.

Riegler J, Tiburcy M, Ebert A, Tzatzalos E, Raaz U, Abilez OJ, Shen Q, Kooreman NG, Neofytou E, Chen VC, Wang M, Meyer T, Tsao PS, Connolly AJ, Couture LA, Gold JD, Zimmermann WH, Wu JC (2015) Human Engineered Heart Muscles Engraft and Survive Long Term in a Rodent Myocardial Infarction Model. Circ Res 117, 720-730.

Riella LV, Paterson AM, Sharpe AH, Chandraker A (2012) Role of the PD-1 pathway in the immune response. Am J Transplant 12, 2575-2587.

Robertson NJ, Brook FA, Gardner RL, Cobbold SP, Waldmann H, Fairchild PJ (2007) Embryonic stem cell-derived tissues are immunogenic but their inherent immune privilege promotes the induction of tolerance. Proc Natl Acad Sci U S A 104, 20920 20925.

Roell W, Lewalter T, Sasse P, Tallini YN, Choi BR, Breitbach M, Doran R, Becher UM, Hwang SM, Bostani T, von Maltzahn J, Hofmann A, Reining S, Eiberger B, Gabris B, Pfeifer A, Welz A, Willecke K, Salama G, Schrickel JW, Kotlikoff MI, Fleischmann BK (2007) Engraftment of connexin 43-expressing cells prevents post-infarct arrhythmia. Nature 450, 819-824.

Rosa FM, Fellous M (1988) Regulation of HLA-DR gene by IFN-gamma. Transcriptional and post-transcriptional control. J Immunol 140, 1660-1664.

Rose ML, Coles MI, Griffin RJ, Pomerance A, Yacoub MH (1986) Expression of class I and class II major histocompatibility antigens in normal and transplanted human heart. Transplantation 41, 776-780.

Rose ML, Coles MI, Griffin RJ, Yacoub MH (1985) Induction of class I and class II antigens during rejection of allografted human hearts. Adv Exp Med Biol 186, 555-563.

Rubart M, Pasumarthi KB, Nakajima H, Soonpaa MH, Nakajima HO, Field LJ (2003) Physiological coupling of donor and host cardiomyocytes after cellular transplantation. Circ Res 92, 1217-1224. 
Sanchez PL, San Roman JA, Villa A, Fernandez ME, Fernandez-Aviles F (2006) Contemplating the bright future of stem cell therapy for cardiovascular disease. Nat Clin Pract Cardiovasc Med 3 Suppl 1, S138-151.

Sarvella P (1973) Adult parthenogenetic chickens. Nature 243, 171.

Sasaki D, Shimizu T, Masuda S, Kobayashi J, Itoga K, Tsuda Y, Yamashita JK, Yamato M, Okano T (2009) Mass preparation of size-controlled mouse embryonic stem cell aggregates and induction of cardiac differentiation by cell patterning method. Biomaterials 30, 4384-4389.

Sasaki H, Jones PA, Chaillet JR, Ferguson-Smith AC, Barton SC, Reik W, Surani MA (1992) Parental imprinting: potentially active chromatin of the repressed maternal allele of the mouse insulin-like growth factor II (Igf2) gene. Genes Dev 6, 1843-1856.

Schroder K, Hertzog PJ, Ravasi T, Hume DA (2004) Interferon-gamma: an overview of signals, mechanisms and functions. J Leukoc Biol 75, 163-189.

Schroeder M, Niebruegge S, Werner A, Willbold E, Burg M, Ruediger M, Field LJ, Lehmann J, Zweigerdt R (2005) Differentiation and lineage selection of mouse embryonic stem cells in a stirred bench scale bioreactor with automated process control. Biotechnol Bioeng 92, 920-933.

Seko Y, Tsuchimochi H, Nakamura T, Okumura K, Naito S, Imataka K, Fujii J, Takaku F, Yazaki Y (1990) Expression of major histocompatibility complex class I antigen in murine ventricular myocytes infected with Coxsackievirus B3. Circ Res 67, 360-367.

Sen GC (2001) Viruses and interferons. Annu Rev Microbiol 55, 255-281.

Sepac A, Si-Tayeb K, Sedlic F, Barrett S, Canfield S, Duncan SA, Bosnjak ZJ, Lough JW (2012) Comparison of cardiomyogenic potential among human ESC and iPSC lines. Cell Transplant 21, 2523-2530.

Serra M, Brito C, Costa EM, Sousa MF, Alves PM (2009) Integrating human stem cell expansion and neuronal differentiation in bioreactors. BMC Biotechnol 9, 82.

Severs NJ (2000) The cardiac muscle cell. Bioessays 22, 188-199.

Shimizu T, Yamato M, Isoi Y, Akutsu T, Setomaru T, Abe K, Kikuchi A, Umezu M, Okano T (2002) Fabrication of pulsatile cardiac tissue grafts using a novel 3dimensional cell sheet manipulation technique and temperature-responsive cell culture surfaces. Circ Res 90, e40.

Simpson E, Scott D, James E, Lombardi G, Cwynarski K, Dazzi F, Millrain M, Dyson PJ (2002) Minor H antigens: genes and peptides. Transpl Immunol 10, 115-123. 
Sjogren J, Ljungdahl-Waller F, Senneby E, Ekmehag B, Koul B, Nilsson J (2010) Heart transplantation with $\mathrm{ABO}$-identical versus $\mathrm{ABO}$-compatible cardiac grafts: influence on long-term survival. Scand Cardiovasc J 44, 373-379.

Soler-Botija C, Bago JR, Bayes-Genis A (2012) A bird's-eye view of cell therapy and tissue engineering for cardiac regeneration. Ann N Y Acad Sci 1254, 57-65.

Soong PL, Tiburcy M, Zimmermann WH (2012) Cardiac differentiation of human embryonic stem cells and their assembly into engineered heart muscle. Curr Protoc Cell Biol Chapter 23, Unit23 28.

Spindle A, Sturm KS, Flannery M, Meneses JJ, Wu K, Pedersen RA (1996) Defective chorioallantoic fusion in mid-gestation lethality of parthenogenone<-->tetraploid chimeras. Dev Biol 173, 447-458.

Sturm KS, Flannery ML, Pedersen RA (1994) Abnormal development of embryonic and extraembryonic cell lineages in parthenogenetic mouse embryos. Dev Dyn 201, 11-28.

Suarez-Alvarez B, Rodriguez RM, Calvanese V, Blanco-Gelaz MA, Suhr ST, Ortega F, Otero J, Cibelli JB, Moore H, Fraga MF, Lopez-Larrea C (2010) Epigenetic mechanisms regulate $\mathrm{MHC}$ and antigen processing molecules in human embryonic and induced pluripotent stem cells. PLoS One 5, e10192.

Sun J, McCaughan GW, Gallagher ND, Sheil AG, Bishop GA (1995) Deletion of spontaneous rat liver allograft acceptance by donor irradiation. Transplantation 60, 233236.

Surani MA, Barton SC (1983) Development of gynogenetic eggs in the mouse: implications for parthenogenetic embryos. Science 222, 1034-1036.

Surani MA, Barton SC, Norris ML (1984) Development of reconstituted mouse eggs suggests imprinting of the genome during gametogenesis. Nature $308,548-550$.

Surani MA, Kothary R, Allen ND, Singh PB, Fundele R, Ferguson-Smith AC, Barton SC (1990) Genome imprinting and development in the mouse. Dev Suppl, 89-98.

Swijnenburg RJ, Tanaka M, Vogel H, Baker J, Kofidis T, Gunawan F, Lebl DR, Caffarelli $A D$, de Bruin JL, Fedoseyeva EV, Robbins RC (2005) Embryonic stem cell immunogenicity increases upon differentiation after transplantation into ischemic myocardium. Circulation 112, I166-172.

Takahashi K, Yamanaka S (2006) Induction of pluripotent stem cells from mouse embryonic and adult fibroblast cultures by defined factors. Cell 126, 663-676. 
Takahashi T, Lord B, Schulze PC, Fryer RM, Sarang SS, Gullans SR, Lee RT (2003) Ascorbic acid enhances differentiation of embryonic stem cells into cardiac myocytes. Circulation 107, 1912-1916.

Tarrio ML, Grabie N, Bu DX, Sharpe AH, Lichtman AH (2012) PD-1 protects against inflammation and myocyte damage in $\mathrm{T}$ cell-mediated myocarditis. J Immunol 188, 4876-4884.

Taylor CJ, Bolton EM, Bradley JA (2011) Immunological considerations for embryonic and induced pluripotent stem cell banking. Philos Trans R Soc Lond B Biol Sci 366, 2312-2322.

Taylor CJ, Bolton EM, Pocock S, Sharples LD, Pedersen RA, Bradley JA (2005) Banking on human embryonic stem cells: estimating the number of donor cell lines needed for HLA matching. Lancet 366, 2019-2025.

Thomson JA, Itskovitz-Eldor J, Shapiro SS, Waknitz MA, Swiergiel JJ, Marshall VS, Jones JM (1998) Embryonic stem cell lines derived from human blastocysts. Science $282,1145-1147$.

Tian L, Catt JW, O'Neill C, King NJ (1997) Expression of immunoglobulin superfamily cell adhesion molecules on murine embryonic stem cells. Biol Reprod 57, 561-568.

Tiburcy M, Didie M, Boy O, Christalla P, Doker S, Naito H, Karikkineth BC, El-Armouche A, Grimm M, Nose M, Eschenhagen T, Zieseniss A, Katschinksi DM, Hamdani N, Linke WA, Yin X, Mayr M, Zimmermann WH (2011) Terminal differentiation, advanced organotypic maturation, and modeling of hypertrophic growth in engineered heart tissue. Circ Res 109, 1105-1114.

Tiburcy M, Meyer T, Soong PL, Zimmermann WH (2014) Collagen-based engineered heart muscle. Methods Mol Biol 1181, 167-176.

Todorova D, Kim J, Hamzeinejad S, He J, Xu Y (2015) Brief Report: Immune Microenvironment Determines the Immunogenicity of Induced Pluripotent Stem Cell Derivatives. Stem Cells.

Tohyama S, Hattori F, Sano M, Hishiki T, Nagahata Y, Matsuura T, Hashimoto H, Suzuki T, Yamashita H, Satoh Y, Egashira T, Seki T, Muraoka N, Yamakawa H, Ohgino Y, Tanaka T, Yoichi M, Yuasa S, Murata M, Suematsu M, Fukuda K (2013) Distinct metabolic flow enables large-scale purification of mouse and human pluripotent stem cell-derived cardiomyocytes. Cell Stem Cell 12, 127-137.

Trowsdale J, Betz AG (2006) Mother's little helpers: mechanisms of maternal-fetal tolerance. Nat Immunol 7, 241-246. 
van Laake LW, Hassink R, Doevendans PA, Mummery C (2006) Heart repair and stem cells. J Physiol 577, 467-478.

van Laake LW, Passier R, Monshouwer-Kloots J, Verkleij AJ, Lips DJ, Freund C, den Ouden K, Ward-van Oostwaard D, Korving J, Tertoolen LG, van Echteld CJ, Doevendans PA, Mummery CL (2007) Human embryonic stem cell-derived cardiomyocytes survive and mature in the mouse heart and transiently improve function after myocardial infarction. Stem Cell Res 1, 9-24.

Varda-Bloom N, Leor J, Ohad DG, Hasin Y, Amar M, Fixler R, Battler A, Eldar M, Hasin D (2000) Cytotoxic $T$ lymphocytes are activated following myocardial infarction and can recognize and kill healthy myocytes in vitro. J Mol Cell Cardiol 32, 2141-2149.

Vrana KE, Hipp JD, Goss AM, McCool BA, Riddle DR, Walker SJ, Wettstein PJ, Studer LP, Tabar V, Cunniff K, Chapman K, Vilner L, West MD, Grant KA, Cibelli JB (2003) Nonhuman primate parthenogenetic stem cells. Proc Natl Acad Sci U S A 100 Suppl 1, 11911-11916.

Vunjak-Novakovic G, Tandon N, Godier A, Maidhof R, Marsano A, Martens TP, Radisic M (2010) Challenges in cardiac tissue engineering. Tissue Eng Part B Rev 16, 169-187.

Wang D, Quan Y, Yan Q, Morales JE, Wetsel RA (2015) Targeted Disruption of the beta2-Microglobulin Gene Minimizes the Immunogenicity of Human Embryonic Stem Cells. Stem Cells Transl Med 4, 1234-1245.

Wininger JD (2004). Parthenogenetic stem cells. In Hand book of stem cells, R.P. Lanza, ed. (Elsevier academic press).

Wobus AM, Boheler KR (2005) Embryonic stem cells: prospects for developmental biology and cell therapy. Physiol Rev 85, 635-678.

Wobus AM, Kaomei G, Shan J, Wellner MC, Rohwedel J, Ji G, Fleischmann B, Katus HA, Hescheler J, Franz WM (1997) Retinoic acid accelerates embryonic stem cellderived cardiac differentiation and enhances development of ventricular cardiomyocytes. J Mol Cell Cardiol 29, 1525-1539.

Wobus AM, Wallukat G, Hescheler J (1991) Pluripotent mouse embryonic stem cells are able to differentiate into cardiomyocytes expressing chronotropic responses to adrenergic and cholinergic agents and $\mathrm{Ca} 2+$ channel blockers. Differentiation 48, 173182.

Wright PT, Nikolaev VO, O'Hara T, Diakonov I, Bhargava A, Tokar S, Schobesberger S, Shevchuk Al, Sikkel MB, Wilkinson R, Trayanova NA, Lyon AR, Harding SE, Gorelik J (2014) Caveolin-3 regulates compartmentation of cardiomyocyte beta2-adrenergic receptor-mediated cAMP signaling. J Mol Cell Cardiol 67, 38-48. 
Wu AJ, Chen ZJ, Kan EC, Baum BJ (1997) Interferon-gamma-induced JAK2 and STAT1 signalling in a human salivary gland cell line. J Cell Physiol 173, 110-114.

Wu DC, Boyd AS, Wood KJ (2008) Embryonic stem cells and their differentiated derivatives have a fragile immune privilege but still represent novel targets of immune attack. Stem Cells 26, 1939-1950.

Yang XF (2007) Immunology of stem cells and cancer stem cells. Cell Mol Immunol 4, 161-171.

Ye L, Zimmermann WH, Garry DJ, Zhang J (2013) Patching the heart: cardiac repair from within and outside. Circ Res 113, 922-932.

Young HA (1996) Regulation of interferon-gamma gene expression. J Interferon Cytokine Res 16, 563-568.

Yuasa S, Itabashi Y, Koshimizu U, Tanaka T, Sugimura K, Kinoshita M, Hattori F, Fukami S, Shimazaki T, Ogawa S, Okano H, Fukuda K (2005) Transient inhibition of BMP signaling by Noggin induces cardiomyocyte differentiation of mouse embryonic stem cells. Nat Biotechnol 23, 607-611.

Zandstra PW, Bauwens C, Yin T, Liu Q, Schiller H, Zweigerdt R, Pasumarthi KB, Field LJ (2003) Scalable production of embryonic stem cell-derived cardiomyocytes. Tissue Eng 9, 767-778.

Zhao T, Zhang ZN, Rong Z, Xu Y (2011) Immunogenicity of induced pluripotent stem cells. Nature 474, 212-215.

Zhu WZ, Van Biber B, Laflamme MA (2011) Methods for the derivation and use of cardiomyocytes from human pluripotent stem cells. Methods Mol Biol 767, 419-431.

Zimmermann WH, Didie M, Wasmeier GH, Nixdorff U, Hess A, Melnychenko I, Boy O, Neuhuber WL, Weyand M, Eschenhagen T (2002) Cardiac grafting of engineered heart tissue in syngenic rats. Circulation 106, I151-157.

Zimmermann WH, Fink C, Kralisch D, Remmers U, Weil J, Eschenhagen T (2000) Three-dimensional engineered heart tissue from neonatal rat cardiac myocytes. Biotechnol Bioeng 68, 106-114.

Zimmermann WH, Melnychenko I, Wasmeier G, Didie M, Naito H, Nixdorff U, Hess A, Budinsky L, Brune K, Michaelis B, Dhein S, Schwoerer A, Ehmke H, Eschenhagen T (2006) Engineered heart tissue grafts improve systolic and diastolic function in infarcted rat hearts. Nat Med 12, 452-458. 
Zinkernagel RM, Doherty PC (1979) MHC-restricted cytotoxic T cells: studies on the biological role of polymorphic major transplantation antigens determining T-cell restriction-specificity, function, and responsiveness. Adv Immunol 27, 51-177. 


\section{Appendix}

\subsection{Appendix 1 (Supporting Information)}
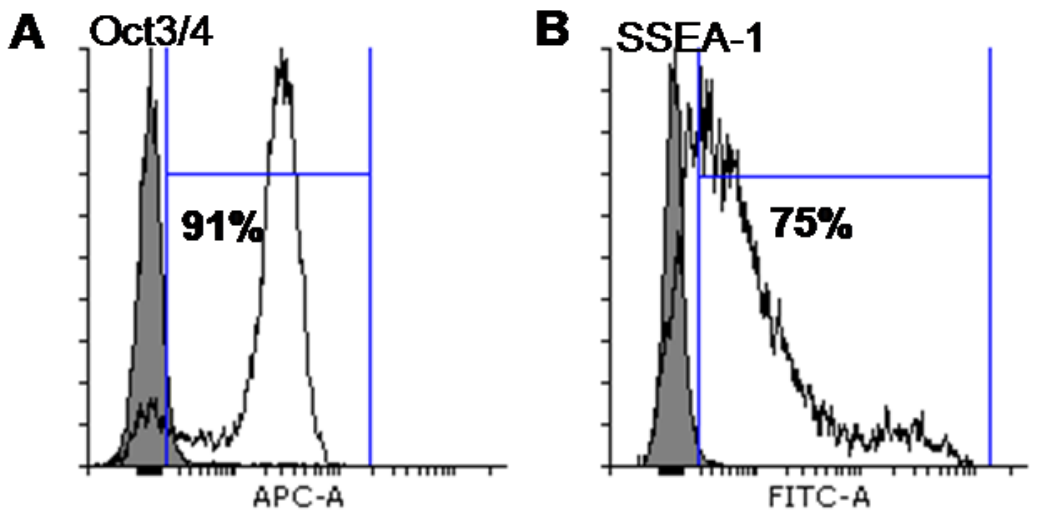

A1.1: Pluripotency markers expression on PSC by flow cytometry. A. Histogramoverlay showing the expression of Oct3/4 on PSC at passage p21. B. Histogramoverlay showing the expression of SSEA-1on PSC. Grey filled histogram represents isotype control (IgG).
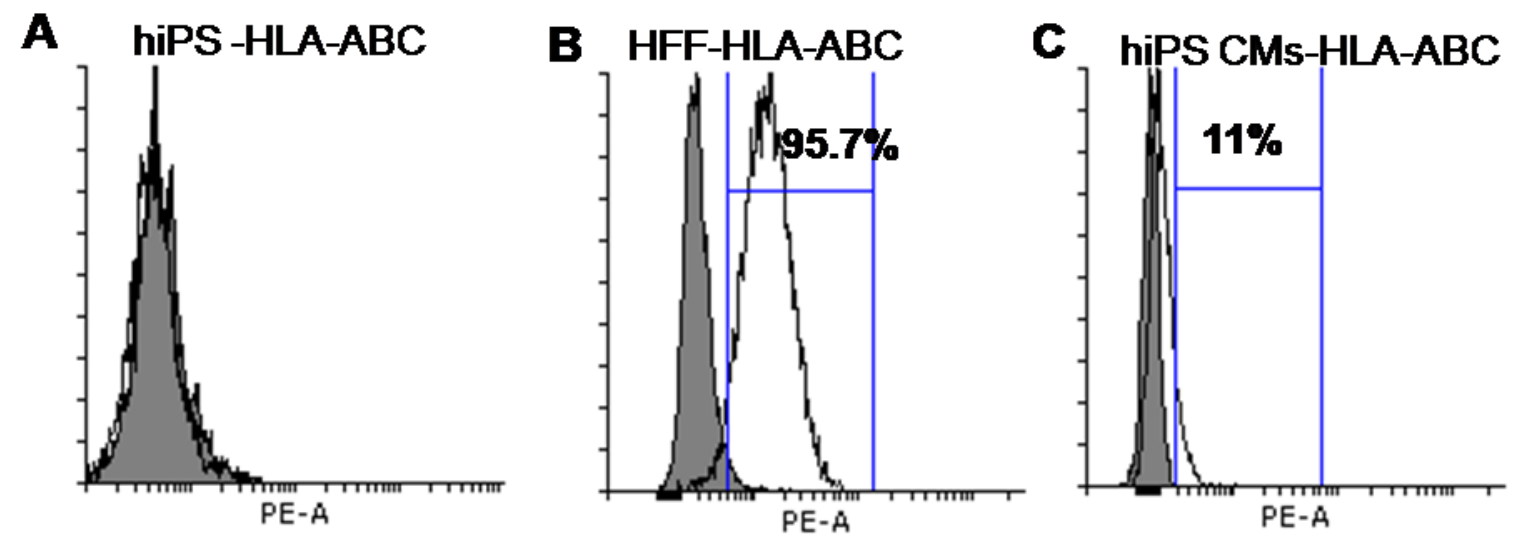

A1.2: Expression of HLA-ABC molecules on human iPSC. Histogram-overlay of hiPSC (A) HFF (B) and hiPSC-CMs (C) were shown. Grey filled histogram represents isotype control. 


\subsection{Appendix 2 (Reagents)}

\section{For cloning}

$\underline{\text { 1X TAE-buffer } \quad \mathrm{mM}}$

Tris-Acetate $\quad 40$

Sodium-Acetate 20

EDTA, $\mathrm{pH} 7.5$

$\underline{\text { LB-agarose plate (with ampicillin) }}$

$\begin{array}{ll}\text { Agar } & 7.5 \mathrm{~g}\end{array}$

LB-medium $\quad 500 \mathrm{ml}$

Ampicillin stock $(100 \mathrm{mg} / \mathrm{ml}) \quad 500 \mu \mathrm{l}$

The LB-agar was autoclaved. After cooled down to around $60^{\circ} \mathrm{C}$, LB-agar was poured into $10-\mathrm{cm}$ petri dishes. Plates were stored at $4^{\circ} \mathrm{C}$ after the agar has hardened.

\section{$\underline{\text { LB-medium }}$}

Bacto-Tryptone

$10 \mathrm{~g}$

Bacto Yeast Extract

$5 \mathrm{~g}$

$\mathrm{NaCl}$

$10 \mathrm{~g}$

Chemicals were dissolved with $950 \mathrm{ml}$ of $\mathrm{ddH}_{2} \mathrm{O}$ and $\mathrm{pH}$ was adjusted to 7.4 with $0.1 \mathrm{~N}$ $\mathrm{NaOH}$. Final volume was brought up to 1 liter and medium was autoclaved. Medium can be kept at $4^{\circ} \mathrm{C}$ for 3 weeks.

Ampicillin stock $(100 \mathrm{mg} / \mathrm{ml})$

$500 \mathrm{mg}$ of Ampicillin was dissolved in $5 \mathrm{ml}$ of $\mathrm{dd}_{2} \mathrm{O}$. The stock solution was stored at $20^{\circ} \mathrm{C}$ in $500 \mu$ l aliquots. 


\section{$\underline{\text { Reagents and solutions for isometric force measurement }}$}

For making Tyrode's working solution, the following stock solutions should be prepared:

$\underline{\mathrm{CaCl}_{2}} \underline{\text { stock }(2.25 \mathrm{M})}$

$\mathrm{CaCl}_{2} \times 2 \mathrm{H}_{2} \mathrm{O}(\mathrm{Mw}=147.02)$

$165.57 \mathrm{~g}$

$\mathrm{ddH}_{2} \mathrm{O}$

$500 \mathrm{ml}$

$\underline{\mathrm{MgCl}_{2}} \underline{\text { stock }(1.05 \mathrm{M})}$

$\mathrm{MgCl}_{2} \times 6 \mathrm{H}_{2} \mathrm{O}(\mathrm{Mw}=203.01)$

$106.83 \mathrm{~g}$

$\mathrm{ddH}_{2} \mathrm{O}$

$500 \mathrm{ml}$

Stock I: $\mathrm{Ca}^{2+}$ concentration in stock I can be adjusted accordingly.

$\left[\mathrm{Ca}^{2+]}(\mathrm{mM})\right.$

$\mathrm{NaCl}(\mathrm{Mw}=58.44)$

$\mathrm{KCl}(\mathrm{Mw}=74.58)$

$\mathrm{CaCl}_{2}$ stock

$\mathrm{MgCl}_{2}$ stock

Make up with dd $\mathrm{H}_{2} \mathrm{O}$ to

Stock II

$\mathrm{NaHCO}_{3}(\mathrm{Mw}=84.01)$

$\mathrm{ddH}_{2} \mathrm{O}$

Stock III

$\mathrm{NaH}_{2} \mathrm{PO}_{4}(\mathrm{Mw}=137.99)$

$\mathrm{ddH}_{2} \mathrm{O}$ $\begin{array}{lll}1.8 & 0.4 & 0.2\end{array}$

$175 \mathrm{~g} \quad 175 \mathrm{~g} \quad 175 \mathrm{~g}$

$10 \mathrm{~g} \quad 10 \mathrm{~g} \quad 10 \mathrm{~g}$

$20 \mathrm{ml} \quad 4.44 \mathrm{ml} \quad 2.22 \mathrm{ml}$

$25 \mathrm{ml} \quad 25 \mathrm{ml} \quad 25 \mathrm{ml}$

$1000 \mathrm{ml} 1000 \mathrm{ml} \quad 1000 \mathrm{ml}$

All stock solutions should be stored at $4^{\circ} \mathrm{C}$ till required. 


\section{Tyrode's working solution (for 8 EHMs)}

Stock I $\quad 80 \mathrm{ml}$

Stock II $\quad 76 \mathrm{ml}$

Stock III $\quad 20 \mathrm{ml}$

Glucose $\quad 2 \mathrm{~g}$

Ascorbic acid $\quad 100 \mathrm{mg}$

$\mathrm{H}_{2} \mathrm{O}$ to 2 liters

\section{Reagents for the isolation of Adult mouse cardiomyocytes by Langendorff method}

1.Perfusion buffer in mmol/L: $113 \mathrm{NaCl}, 4.7 \mathrm{KCl}, 0.6 \mathrm{KH} 2 \mathrm{PO} 4,0.6 \mathrm{Na} 2 \mathrm{HPO} 4 \times 2 \mathrm{H} 2 \mathrm{O}$, $1.2 \mathrm{MgSO} 4 \times 7 \mathrm{H} 2 \mathrm{O}, 12 \mathrm{NaHCO}, 10 \mathrm{KHCO}$, 10 HEPES, 30 taurine, 10 2,3butanedione-monoxime, 5.5 glucose, 0.03 phenol red, $\mathrm{pH} 7.4$ in $\mathrm{H} 2 \mathrm{O}$.

2. Liberase $\mathrm{DH}$ solution $(4.2 \mathrm{mg} / \mathrm{ml}): 50 \mathrm{mg}$ of Liberase $\mathrm{DH}$ were dissolved in $12 \mathrm{ml}$ of sterile water, reconstituted on ice for 20 minutes and stored in $150 \mu \mathrm{l}$ aliquots at $-20^{\circ} \mathrm{C}$.

3. Digestion buffer: $30 \mathrm{ml}$ of the perfusion buffer were supplemented with $12.5 \mu \mathrm{mol} / \mathrm{l}$ $\mathrm{CaCl} 2,150-450 \mu \mathrm{l}$ of Liberase solution, and $300 \mu \mathrm{l}$ of $2.5 \%$ trypsin solution. Enzymes were added straight before use.

4. Stopping buffer 1: $2.5 \mathrm{ml}$ perfusion buffer supplemented with $50 \mu \mathrm{mol} / / \mathrm{CaCl} 2$ and 1 $\%$ bovine serum albumin (BSA).

5. Stopping buffer 2: $10 \mathrm{ml}$ perfusion buffer supplemented with $37.5 \mu \mathrm{mol} / / \mathrm{CaCl} 2$ and $0.5 \%$ bovine serum albumin (BSA).

6. Culture medium: Minimum essential medium (MEM) supplemented with $0.1 \%$ BSA, $2 \mathrm{mM}$ L-glutamine, $10 \mathrm{mM}$ BDM, antibiotics $(100 \mathrm{U} / \mathrm{ml}$ Penicillin, $100 \mu \mathrm{g} / \mathrm{ml}$ Streptomycin) and insulin-transferrin-selenium supplement. 


\section{Cell culture Medium:}

MEF Medium: DMEM (Gibco \# 61965), 10\% FCS, 2 mmol/L L-glutamine,1\% non essential aminoacids (NEAA), $100 \mathrm{U} / \mathrm{ml}$ Penicillin und $100 \mu \mathrm{g} / \mathrm{ml}$ Streptomycin.

Freezing medium: $80 \%$ FBS,20\% DMSO.

SC medium: DMEM (Gibco \#42430), 15\% FCS, $1.000 \mathrm{U} / \mathrm{ml}$ LIF,2 mmol/L L-Glutamine, $1 \times$ NEAA, $50 \mathrm{U} / \mathrm{ml}$ Penicillin, $50 \mu \mathrm{g} / \mathrm{ml}$ Streptomycin, $1 \mathrm{mmol} / \mathrm{L} \mathrm{Na}^{+}$-Pyruvate, $1 \mathrm{X}$ Nucleoside mix ( in $\mu \mathrm{mol} / \mathrm{L}$ : 30 adenosine, 30 guanosine, 30 cytidine, 30 uridine, 10 thymidine) and $100 \mu \mathrm{mol} / \mathrm{L} 2$-mercaptoethanol.

Differentiation medium: Iscove Medium (Biochrom \#F0465), 20\% FCS, 2 mmol/L Lglutamine, 1\% NEAA, $100 \mathrm{U} / \mathrm{ml}$ Penicillin(P), $100 \mu \mathrm{g} / \mathrm{ml}$ Streptomycin(S), $100 \mu \mathrm{mol} / \mathrm{L} 2-$ mercaptoethanol, $0.02 \mathrm{mmol} / \mathrm{L}$ L-ascorbic acid 2-phosphate sesquimagnesium salt hydrate (sigma).

RPMI medium: RPMI with Glutamax(Gibco), 10\% heat inactivated FCS, $100 \mathrm{U} / \mathrm{ml}$ penicillin, $100 \mu \mathrm{g} / \mathrm{ml}$ streptomycin, $100 \mu \mathrm{mol} / \mathrm{L}$ 2-mercaptoethanol,

eFluor® 670 stock solution: 5 mmol/L eFluor® 670 dissolved in DMSO 


\section{A2.1 List of primers}

\begin{tabular}{|c|c|c|c|}
\hline Gene & Sequence & $\begin{array}{l}\mathrm{Tm} \\
\left({ }^{\circ} \mathrm{C}\right)\end{array}$ & $\begin{array}{l}\text { Product } \\
\text { size(bp) }\end{array}$ \\
\hline \multirow{2}{*}{ D17Mit178 } & For: 5'-ACACAATTTCTTTTAGTGGGTTCC -3' & \multirow[t]{2}{*}{56} & \multirow{2}{*}{$\begin{array}{l}144(\mathrm{~b} / \mathrm{b}) / \\
162(\mathrm{~d} / \mathrm{d}) \\
\end{array}$} \\
\hline & Rev: 5'-TGTGGAAGACACTCAATATCAACC-3' & & \\
\hline \multirow[t]{2}{*}{$\begin{array}{l}\text { Neomycin } \\
\text { resistance }\end{array}$} & $\begin{array}{l}\text { For: 5'-TCCTGCCGAGAAAGTATCCATCATGGCTGA- } \\
3 \text { - }\end{array}$ & \multirow[t]{2}{*}{63} & \multirow[t]{2}{*}{383} \\
\hline & $\begin{array}{c}\text { Rev: 5'-ATTCGCCGCCAAGCTCTTCAGCAATATCAC- } \\
\text { 3' }\end{array}$ & & \\
\hline
\end{tabular}

\begin{tabular}{|c|c|c|c|}
\hline Gene & Sequence & $\begin{array}{c}\mathrm{Tm} \\
\left({ }^{\circ} \mathrm{C}\right)\end{array}$ & $\begin{array}{c}\text { Produc } \\
t \\
\text { size(bp } \\
\text { ) }\end{array}$ \\
\hline \multirow[t]{2}{*}{ Oct3/4 } & For: 5'-GCCCCAATGCCGTGAAG- 3' & \multirow[t]{2}{*}{59} & \multirow[t]{2}{*}{101} \\
\hline & Rev: 5'-CAGCAGCTTGGCAAACTGTTC- 3' & & \\
\hline \multirow{2}{*}{ Nanog } & For: 5'-TGCTACTGAGATGCTCTGCACA- 3' & \multirow[t]{2}{*}{59} & \multirow[t]{2}{*}{71} \\
\hline & Rev: 5'-TGCCTTGAAGAGGCAGGTCT- 3' & & \\
\hline \multirow[t]{2}{*}{ Sox2 } & $\begin{array}{l}\text { For: 5'-GGCAGCTACAGCATGATGCAGGAGC- } \\
3 \text { ' }\end{array}$ & \multirow[t]{2}{*}{60} & \multirow[t]{2}{*}{131} \\
\hline & Rev: 5'-CCTGCAGTACAACTCCATGACCAG- 3' & & \\
\hline \multirow[t]{2}{*}{ Rex-1 } & For: 5'-GGCCAGTCCAGAATACCAGA- 3' & \multirow[t]{2}{*}{59} & \multirow[t]{2}{*}{232} \\
\hline & Rev: 5'- GAACTCGCTTCCAGAACCTG - 3' & & \\
\hline \multirow{2}{*}{ GAPDH } & For: 5'-ATGTTCCAGTATGACTCCACTCACG- 3' & \multirow[t]{2}{*}{60} & \multirow[t]{2}{*}{171} \\
\hline & $\begin{array}{c}\text { Rev: 5'- TGTCGTGGAGTCTACTGGTGTCTTC - } \\
3 \text {, }\end{array}$ & & \\
\hline
\end{tabular}

\section{A2.2 List of primary antibodies}

\begin{tabular}{|c|c|c|c|}
\hline Antibody & Dilution & Company & clone \\
\hline PE anti mouse CD1d & $1: 100$ & Biolegend & $1 \mathrm{~B} 1$ \\
\hline PE anti mouse H-2Kd & $1: 100$ & Biolegend & SF1-1.1 \\
\hline PE anti mouse H-2Kb & $1: 100$ & Biolegend & AF6.88.5 \\
\hline $\begin{array}{c}\text { Alexa Fluor 594 anti } \\
\text { mouse CD3 }\end{array}$ & $1: 100$ & Biolegend & $17 \mathrm{~A} 2$ \\
\hline $\begin{array}{c}\text { Alexa Fluor 488 anti } \\
\text { mouse CD3 }\end{array}$ & $1: 100$ & Biolegend & $17 \mathrm{~A} 2$ \\
\hline $\begin{array}{c}\text { FITC Hamster anti mouse } \\
\text { CD40 }\end{array}$ & $1: 100$ & Biolegend & $3 / 23$ \\
\hline PE anti mouse CD86 & $1: 100$ & Biolegend & GL-1 \\
\hline FITC anti mouse CD 80 & $1: 100$ & Biolegend & $16-10 \mathrm{~A} 1$ \\
\hline Alexa Fluor 488 rat anti & $1: 100$ & BD Pharmingen & M5/114.15.2 \\
\hline
\end{tabular}




\begin{tabular}{|c|c|c|c|}
\hline mouse I-A/I-E & & & \\
\hline $\begin{array}{c}\text { PE anti mouse CD274(B7- } \\
\text { H1,PD-L1) }\end{array}$ & $1: 100$ & Biolegend & $10 \mathrm{~F} .9 \mathrm{G} 2$ \\
\hline $\begin{array}{c}\text { FITC anti mouse } \\
\text { CD279(PD-1) }\end{array}$ & $1: 100$ & Biolegend & $29 \mathrm{~F} .1 \mathrm{~A} 12$ \\
\hline $\begin{array}{c}\text { Monoclonal anti - } \alpha- \\
\text { Actinin }\end{array}$ & $\begin{array}{c}1: 4000(\mathrm{FC}) \\
1: 1000(\mathrm{IF})\end{array}$ & sigma & EA-53 \\
\hline $\begin{array}{c}\text { Anti cardiac Troponin I } \\
\beta-2-M i c r o g l o b u l i n\end{array}$ & $1: 500$ & abcam & ab47003 \\
\hline Myosin heavy chain & $1: 250$ & abcam & EP2978Y \\
\hline Connexin 43 & $1: 500$ & DSHB & MF20 \\
\hline
\end{tabular}

\section{A2.3 List of isotype controls}

\begin{tabular}{|c|c|c|c|}
\hline Isotype Controls & Dilution & company & clone \\
\hline PE Rat IgG2b, $\mathrm{k}$ & $1: 100$ & Biolegend & RTK4530 \\
\hline PE mouse IgG2a, $\mathrm{k}$ & $1: 100$ & Biolegend & MOPC-173 \\
\hline PE Mouse IgG2b, $\mathrm{k}$ & $1: 100$ & Biolegend & MPC-11 \\
\hline $\begin{array}{c}\text { Alexa Fluor 488 Rat } \\
\text { IgG2b, } \mathrm{k}\end{array}$ & $1: 100$ & Biolegend & RTK4530 \\
\hline FITC Rat IgG2a, $\mathrm{k}$ & $1: 100$ & Biolegend & RTK2758 \\
\hline PE Rat IgG2a, $\mathrm{B}$ & $1: 100$ & Biolegend & RTK2758 \\
\hline $\begin{array}{c}\text { FITC Armenian } \\
\text { Hamster IgG }\end{array}$ & $1: 100$ & Biolegend & HTK888 \\
\hline Mouse IgG1 & $1: 250$ & R\&D systems & MAB002 \\
\hline Rabbit IgG & $1: 2000$ & sigma & I5006 \\
\hline
\end{tabular}

\section{A2.4 List of secondary antibodies}

\begin{tabular}{|c|c|c|c|}
\hline $\begin{array}{c}\text { Secondary } \\
\text { Antibody }\end{array}$ & Dilution & Species & Company \\
\hline $\begin{array}{c}\text { Anti-mouse IgG } \\
\text { Alexa 488 }\end{array}$ & $1: 1000$ & Goat & Invitrogen \\
\hline $\begin{array}{c}\text { Anti-mouse IgG } \\
\text { Alexa 546 }\end{array}$ & $1: 1000$ & Goat & Invitrogen \\
\hline $\begin{array}{c}\text { Anti-mouse IgG } \\
\text { Alexa 633 }\end{array}$ & $1: 1000$ & Goat & Invitrogen \\
\hline $\begin{array}{c}\text { Anti-rabbit IgG } \\
\text { Alexa 488 }\end{array}$ & $1: 1000$ & Goat & Invitrogen \\
\hline $\begin{array}{c}\text { Anti-rabbit IgG } \\
\text { Alexa 546 }\end{array}$ & $1: 1000$ & Goat & Invitrogen \\
\hline $\begin{array}{c}\text { Anti-rabbit IgG } \\
\text { Alexa 633 }\end{array}$ & $1: 1000$ & & \\
\hline
\end{tabular}




\section{A2.5 List of fluorescent labels}

\begin{tabular}{|c|c|c|c|}
\hline Label & Concentration & Target & Company \\
\hline DAPI & $0.1 \mu \mathrm{g} / \mathrm{ml}$ & DNA & sigma \\
\hline Hoechst & $1 \mu \mathrm{ml}$ & DNA & BD biosciences \\
\hline Phalloidin 488 & 300 units & f-actin & Invitrogen \\
\hline Phalloidin 546 & 300 units & f-actin & Invitrogen \\
\hline Phalloidin 633 & 300 units & f-actin & Invitrogen \\
\hline
\end{tabular}




\section{Curriculum Vitae}

\section{SATISH GALLA}

Hermann Rein Strasse-11, 37075,

Göttingen,Germany.

E-mail: satish.galla@med.uni-goettingen.de

Phone No: +4917630526509 .

Current position: (Since May 2011)

Graduate student at Department of Pharmacology and Toxicology, University Medical Center Göttingen, Georg-August-University, Göttingen, Germany.Working on the project titled "Immunological properties of parthenogenetic stem cell derived cardiomyocytes and their application in cardiac tissue engineering". Supervisor: Prof. WolframHubertus Zimmermann.

\section{Research Experience}

Frontier lifeline Pvt.LTD (K.M.Cherian Heart foundation)

Scientist, Dept of Tissue engineering and stem cell biology
Chennai June 2007- March 2011

- Investigation on scaffold generation for heart tissue repair.

- Research focus on "Electrospun Polymeric Nanofiber Reinforced Processed Porcine Pulmonary Xenograft as a Versatile Conduit in Cardiovascular Surgery".

- Worked on "Characterization and optimization of homografts and xenografts for heart tissue repair".

Indian Institute of Technology Madras (IIT M)

Under the supervision of Prof. Dr. Mukesh Doble
Chennai

May 2006- June 2007

- Master Thesis entitled "Physicochemical and biocompatible characterization of curdlan biolpolymer". 


\section{Academic Qualifications}

Master of

Medical biotechnolgy

IIT Madras, Chennai

2005-07

Technology

Masters of Science Biochemistry

Bhavans Vivekananda

college, Hyderabad

2003-05

Bachelor of Science Microbiology,

P.B Siddhartha College of arts 2000-03

Biochemistry, Chemistry and Science, Vijaywada.

\section{Academic Distinctions}

Was among the top 3\% in the all India entrance exam, GATE 2005.

\section{Publications}

- Crosslinked acellular saphenous vein for small-diameter vascular graft. Ramesh B, Mathapati S, Galla S, Cherian KM, Guhathakurta S. Asian Cardiovascular and Thoracic Annals 2013 21: 293.

- Nanofiber-reinforced biological conduit in cardiac surgery: preliminary report. Guhathakurta S, Galla S, Ramesh B, Venugopal JR, Ramakrishna S, Cherian KM. Asian Cardiovascular and Thoracic Annals 2011 19: 207.

- Analytical Study to Evaluate the Extracellular Matrix in Processed Acellular Xenografts. Galla S, Santosh Mathapati, Vijaya Nayak, K.M. Cherian, Soma Guhathakurta. Indian J Thorac Cardiovasc Surg (2010) 26:132-138.

- Qualitative and Quantitative Detection of Sodium Deoxycholic Acid in Decellurized Tissue. Santosh Mathapati, Galla S, Kavitha Sankaranarayanan, Rama Shanker Verma, Kotturathu Mammen Cherian, Soma Guhathakurta. Indian J Thorac Cardiovasc Surg (2010) 26:129-131.

\section{Conferences/Symposiums/Workshops Attended (International and National)}

- Satish Galla, Michael Didie, Vijayakumar Muppala, Ralf Dressel, W-H.Zimmermann. Immunological properties of parthenogenetic stem cell-derived cardiomyocytes. Symposium on cardiovascular regenerative medicine by $\mathrm{NIH}-\mathrm{NHLBI}$ at Bathesda, U.S.A. September 29-30, 2015. 
- Satish Galla, Michael Didie, Vijayakumar Muppala, Ralf Dressel, W-H.Zimmermann. Parthenogenetic Stem Cell-derived Cardiomyocytes Express Major Histocompatibility Complex-I only after Inflammatory Stimulation. Basic Cardiovascular sciences meeting by AHA at Las Vegas, U.S.A. July 14th-17th 2014.

- Satish Galla, R.Bala Sundari, Sheerinbegam Naser, K.M.Cherian, Soma Guhathakurtha. Electrospun polymeric nanofiber reinforced porcine pulmonary xenograft as a versatile conduit in cardiovascular surgery. $20^{\text {th }}$ World Congress, World society of Cardio-thoracic surgeons Oct 20-23, 2010, Chennai,India.

- Participated in "International conference on cardiovascular genetics" held on Dec $3^{\text {rd }}$ 2008 organized by Frontier lifeline hospital, Chennai.

- Participated in "Workshop on Nanoscience \& Technology for Health Care: Medical Diagnosis, Imaging and Drug Delivery" organized by IGCAR, Chennai on Feb $26^{\text {th }}$, 2008.

- Participated in "Recent Trends in Collagen" an international conference held from 24-25 January 2008 at CLRI, Chennai.

- Radha C; Ananthakrishnan B; Veerappan S; Satish Galla; K M Cherian; S Guhathakurta, Surface characterization of processed natural biological tissue, International conference on stem cell, Tissue engineering and regenerative medicine, 2007, Frontier Lifeline, Chennai.

- Radha C; Ananthakrishnan B; Veerappan S; Satish Galla; K M Cherian; S Guhathakurta, Validation of Tissue engineered products: The Frontier Lifeline experience, International conference on stem cell, Tissue engineering and regenerative medicine, 2007, Frontier Lifeline, Chennai.

- Participated in DBT sponsored workshop on "Industrial Biotechnology-Taking Ideas from Lab to Market" organized by IIT MADRAS in 2006.

\section{Technical Skills}

\section{Animal surgeries:}

- Implantation of cardiomyocytes under the kidney capsule of mice.

- Teratoma assays in mice.

- Isolation of cardiomyocytes from neonatal mice hearts.

- Langendorff heart perfusion in mice.

- Isolation of splenocytes and T lymphocytes from mice.

\section{Animal Handling:}

- IP injections in mice and rats

- Blood sampling techniques from mice and rats

- Tail vein injections in mice and rats

- Organs collection for histology 


\section{Cell Culture:}

- Parthenogenetic and embryonic murine stem cell culture, generation of stable cell lines.

- Differentiation of stem cell into cardiomyocytes.

- Immune cell proliferation assays and cytotoxicity assays.

- T lymphocyte culture.

- Preparation of engineered heart muscle.

Microscopic techniques:

- Fluorescent microscopy

- Confocal microscopy

- 2 photon imaging techniques

\section{Other Techniques:}

- Flow cytometry (FACS Diva)

- Electrospinning of nanofibers

- Immunohistochemistry / Immunofluorescence

- Universal tensile testing machine

- Organ bath setup to study the contractile properties of engineered heart muscle,

- PCR, qPCR

- Western blotting.

\section{Teaching Experience}

- Was involved in the teaching of the course "P.G Diploma in stem cell technology and tissue engineering" from Madras University, Chennai.

- Supervised 2 Bachelors and one medicine student for their thesis at Institute of pharmacology, UMG, Goettingen.

\section{Certifications}

- FELASA B certification for Animal experiments.

\section{Language skills}

- English, Basic German language (A2 level). 